Pacific Northwest

National Laboratory

Operated by Battelle for the

U.S. Department of Energy

\section{Evaluation of an Alternative Statistical Method for Analysis of RCRA Groundwater Monitoring Data at the Hanford Site}

\author{
C. J. Chou
}

June 2004 


\title{
DISCLAIMER
}

This report was prepared as an account of work sponsored by an agency of the United States Government. Reference herein to any specific commercial product, process, or service by trade name, trademark, manufacturer, or otherwise does not necessarily constitute or imply its endorsement, recommendation, or favoring by the United States Government or any agency thereof, or Battelle Memorial Institute.

\author{
PACIFIC NORTHWEST NATIONAL LABORATORY \\ operated by \\ BATTELLE \\ for the \\ UNITED STATES DEPARTMENT OF ENERGY \\ under Contract DE-AC06-76RL01830
}

\author{
Printed in the United States of America \\ Available to DOE and DOE contractors from the \\ Office of Scientific and Technical Information, P.O. Box 62, Oak Ridge, TN 37831; \\ prices available from (615) 576-8401. \\ Available to the public from the National Technical Information Service, \\ U.S. Department of Commerce, 5285 Port Royal Rd., Springfield, VA 22161
}

This document was printed on recycled paper. 


\title{
Evaluation of an Alternative Statistical Method for Analysis of RCRA Groundwater Monitoring Data at the Hanford Site
}

\author{
C. J. Chou
}

June 2004

Prepared for

the U.S. Department of Energy

under Contract DE-AC06-76RL01830

Pacific Northwest National Laboratory

Richland, Washington 99352 


\section{Summary}

Statistical methods are required in groundwater monitoring programs to determine if a Resource Conservation and Recovery Act (RCRA)-regulated unit affects groundwater quality beneath a site. Statistical analyses are used to compare the chemical groundwater quality downgradient of a waste management unit with either: 1) the concentrations obtained from an upgradient well screened in the same hydrostratigraphic zone and unaffected by facility operations (inter-well comparisons); 2) historical concentrations from the same well (intra-well comparisons); or 3) a permit-established standard. The inter- or intra-well comparisons, the main focus of this report, are designed for a waste management unit that is in a detection monitoring program status. Comparisons with permit-established standards are conducted for sites with known groundwater contamination in compliance monitoring programs.

For sites regulated under interim status detection regulations, the statistical determination is based on the averaged replicate (AR) t-test method. This involves comparison of the mean concentrations of four indicator parameters (i.e., specific conductance, $\mathrm{pH}$, total organic carbon, and total organic halides) between the upgradient and downgradient wells using four replicate measurements during each sampling event (inter-well comparisons). However, because of problems associated with the interim status requirements, other sampling and statistical evaluation methods warrant consideration.

The 216-B-3 pond system (B Pond), an interim status site in the 200 East Area of the Hanford Site, is one example where an alternative was needed because this unit has unique hydrologic conditions that preclude use of standard upgradient-downgradient comparisons. One method, allowable under final status regulations, is the use of a combined Shewhart-CUSUM control chart (an intra-well comparison) approach.

After numerous discussions and negotiations with Washington State Department of Ecology, the U.S. Department of Energy requested 1) a variance from applying interim status regulations at B Pond and 2) a trial period for applying the combined Shewhart-CUSUM control method at the 300 Area process trenches. Ecology granted the request for a trial period of 2 years or four sampling events and an alternative statistical approach was developed to address the special case when standard upgradientdowngradient comparisons are not valid. However, before applying this method to the sites, and potentially other RCRA sites at Hanford, analysis of groundwater data collected over a 2-year trial period starting January 2002 was required by Ecology.

This report presents the results of the statistical analysis of groundwater monitoring data acquired at B Pond and the 300 Area process trenches during the 2-year trial or test period. The results indicate that, for a detection status site (e.g., the B Pond case), the Shewhart-CUSUM control chart approach is superior (more powerful) than the AR t-test method to detect a change in mean concentration above baseline while keeping the overall network-wide false positive rate at acceptably low levels ( $\sim 5 \%)$. These levels are consistent with guidance from the U.S. Department of Ecology and the American Society for Testing and Materials. For the 300 Area process trenches (compliance status site), the primary concern was that a bimodal contaminant distribution (due to flow reversal and river water dilution effects) could invalidate application of the Shewhart-CUSUM control chart method. Results of statistical goodness-of-fit test on both dilution-corrected and non-corrected data indicate the data were either normal or log-normal for the 
dilution corrected or uncorrected data set. It was concluded that the combined Shewhart-CUSUM method is a viable alternative for application at the 300 Area process trenches as well as at other regulated sites that may be subject to river water dilution effects. 


\section{Contents}

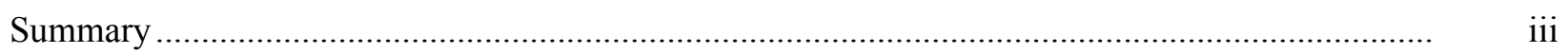

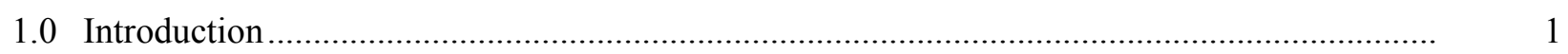

1.1 Background …………………………………………………………………...

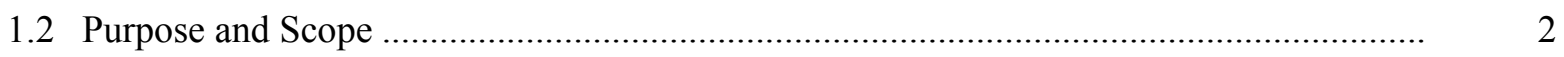

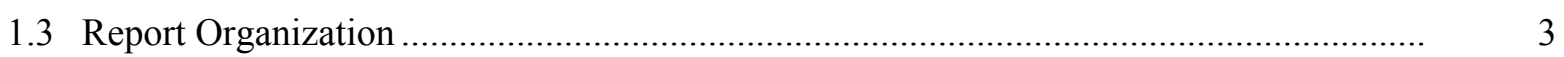

2.0 Statistical Assumptions and Test Procedures............................................................................ 5

2.1 Minimum Time Interval to Obtain Independent Samples .................................................. 5

2.2 Check Assumption on Normally Distributed Data Set...................................................... 6

2.3 Combined Shewhart-CUSUM Testing Procedures ………………………………………..... 7

3.0 Statistical Evaluations of B Pond Data .................................................................................... 9

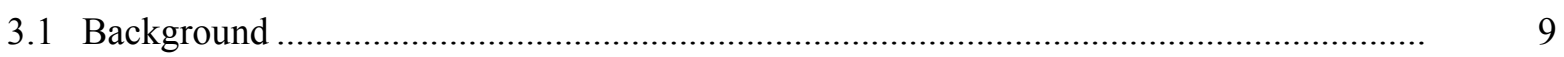

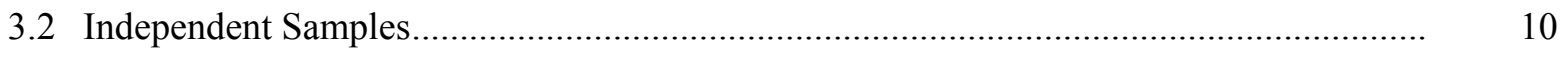

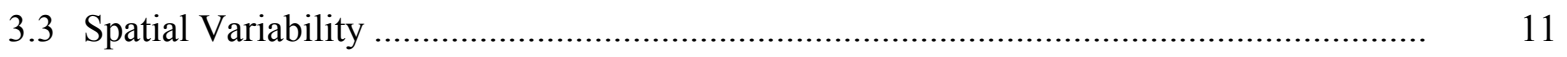

3.4 Rationale for Selecting the Combined Shewhart-CUSUM Control Chart Method............ 12

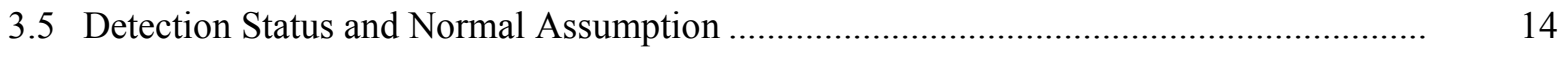

3.6 Baseline Summary Statistics and Control Limits ............................................................ 15

3.7 Data Comparisons ........................................................................................... 15

4.0 Statistical Evaluations of 300 Area Process Trench Data ...................................................... 21

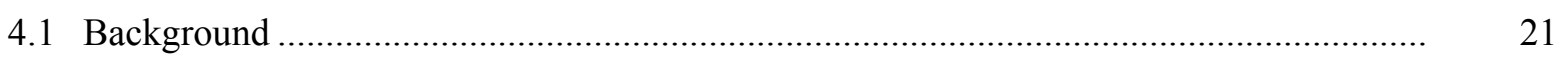

4.2 Independent Samples..................................................................................................... 23

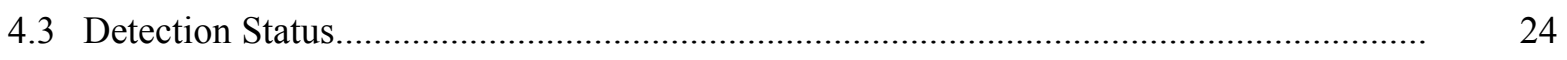

4.4 Influence of River Water on Contaminant Concentrations ............................................... 25

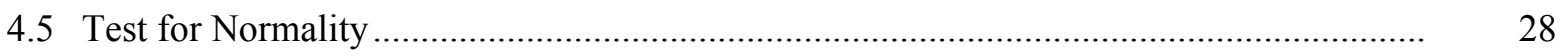




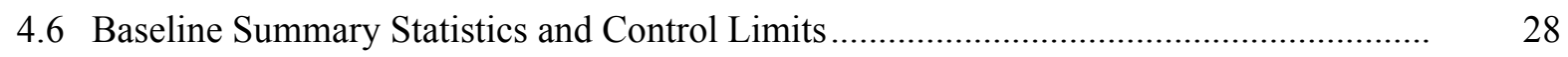

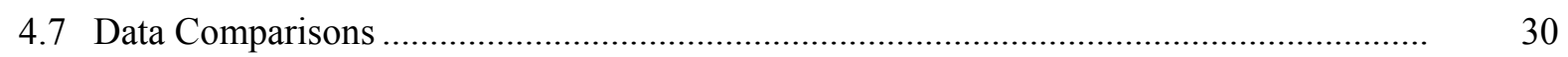

5.0 Special Conditions Encountered .............................................................................. 37

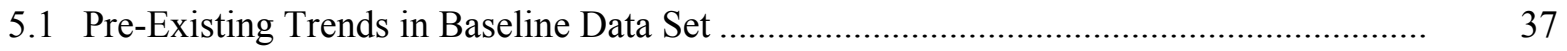

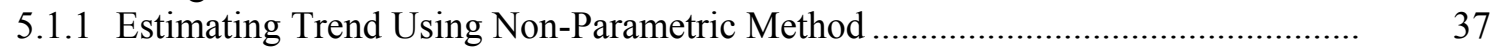

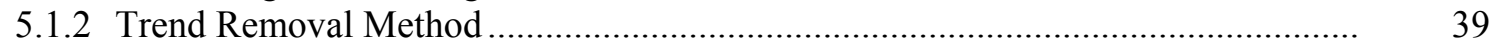

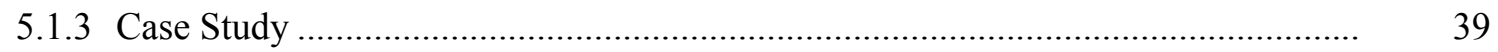

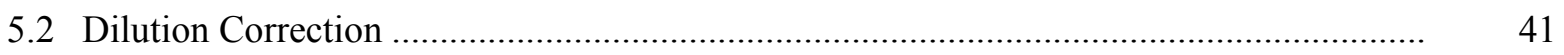

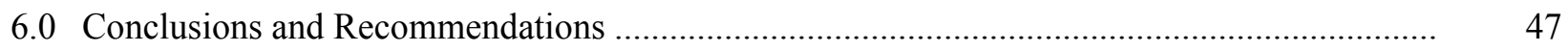

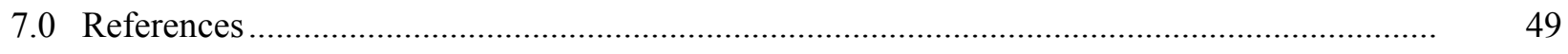

Appendix A - Communications with Ecology …................................................................. A.1

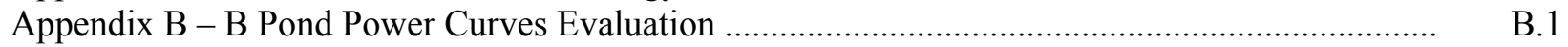

Appendix C - Normal Probability Plots for B Pond System ................................................... C. 1

\section{Figures}

1 RCRA Groundwater Monitoring Timeline for the 216-B-3 Pond System .............................. 9

2 Historical and Revised Monitoring Network for the B Pond System .................................. 10

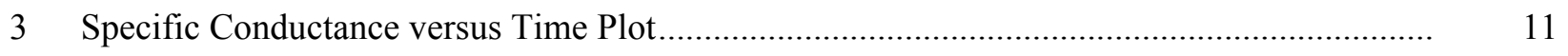

4 Examples of Spatial Variability Exhibited by B Pond Network Wells using Specific Conductance Data Obtained from January 2000 through July 2003....................................... 12

5 Observed Specific Conductance Measurements from Well 699-43-45 Compared with the Combined Shewhart-CUSUM Control Limits from Table 2 .............................................. 18

6 Observed Gross Alpha Measurements from Well 699-43-45 Compared with the Combined

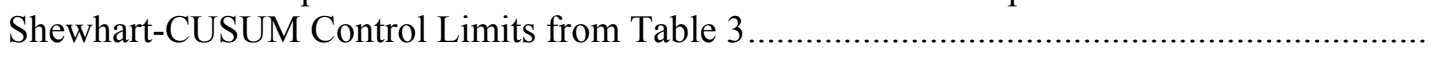

7 Observed Gross Beta Measurements from Well 699-43-45 Compared with the Combined Shewhart-CUSUM Control Limits from Table 4 ............................................................. 19

8 Locations of Groundwater Monitoring Wells at the 300 Area Process Trenches.................... 22

9 Conceptual Models Depicting Potential Dilution Effect on Contaminant Concentration for the 300 Area process trenches Due to Mixing of Columbia River Water with Groundwater.... 
10 Normalized and Original Uranium Concentrations versus Time for Well 399-1-10A ............. 27

11 Normalized and Original Uranium Concentrations versus Time for Well 399-1-17A ............. 27

12 Original and De-Trended Specific Conductance Data from Well 699-43-45 ........................ 41

13 Specific Conductance and Head versus Time for Well 399-1-17A ...................................... 44

14 Specific Conductance and Head versus Time for Well 399-1-17B ....................................... 44

\section{Tables}

1 Detection Status and Results of Shapiro-Wilk Test for the B Pond System Monitoring Wells Using Site-Specific Constituents of Concern

2 Specific Conductance Baseline Periods, Summary Statistics, Various Control Limits, and 2-Year Trial Evaluation Data for the B Pond System Wells...

3 Gross Alpha Baseline Periods, Summary Statistics, Various Control Limits and 2-Year Trial Evaluation Data for the B Pond System Wells.

4 Gross Beta Baseline Periods, Summary Statistics, and Various Control Limits for the B Pond System Wells.

5 Detection Status of Constituents of Concern Analyzed for the 300 Area Process Trenches .....

6 Comparisons of Mean Concentrations for the Original and Normalized Data

7 Results of Shapiro-Wilk's Test for the 300 Area Process Trenches Using the Original and Adjusted Data

8 Baseline Summary Statistics for Detected Constituents of Concern Analyzed for the 300 Area Process Trenches

9 Summary of Various Control Limits at the 300 Area Process Trenches

10 Uranium Control Limits and 2-Year Trial Evaluation Data for the 300 Area Process Trenches.....

11 cis1,2-Dichloroethene Control Limits and 2-Year Trial Evaluation Data for the 300 Area Process Trenches

12 Trichloroethene Control Limits and 2-Year Trial Evaluation Data for the 300 Area Process Trenches.....

13 Baseline and De-Trended Specific Conductance Data in Well 699-43-45 


\subsection{Introduction}

\subsection{Background}

Statistical methods are required in groundwater monitoring programs to determine if a Resource Conservation and Recovery Act (RCRA)-regulated unit affects groundwater quality beneath a site. Statistical analyses are used to compare the chemical groundwater quality downgradient of a waste management unit with either: (1) the concentrations obtained from an upgradient well screened in the same hydrostratigraphic zone and unaffected by facility operations (inter-well comparisons); (2) historical concentrations from the same well (intra-well comparisons); or (3) a permit-established standard. The inter- or intra-well comparisons, the main focus of this report, are designed for a waste management unit that is in a detection monitoring program status. Comparisons with permit-established standards are conducted for sites with known groundwater contamination in compliance monitoring programs.

For sites regulated under interim status detection regulations (40 CFR 265 Subpart F and by reference of WAC 173-303-400), the statistical determination is based on the averaged replicate (AR) t-test method. This involves comparison of the mean concentrations of four indicator parameters (i.e., specific conductance, $\mathrm{pH}$, total organic carbon, and total organic halides) between the upgradient and downgradient wells using four replicate measurements during each sampling event (inter-well comparisons). However, these interim status sampling and statistical analysis methods are flawed for the following reasons (see Davis and McNichols 1994 and Cameron 1996):

- Replicate measurements made on the same sample only measure analytical variability. The required pooling of background data is not valid when spatial, temporal, and sampling variability constitute a significant portion of the total variability.

- A static background is assumed because one initial set of background samples is collected and statistically compared to downgradient data collected during later monitoring.

- The background data pool does not incorporate any component of spatial variability if only one upgradient well is used.

- The four indicator parameters selected do not serve well as early warning indicators of groundwater contamination by leachate from the facility.

Because of the problems associated with the interim status requirements, other sampling and statistical evaluation methods warrant consideration. The 216-B-3 pond system (B Pond), an interim status site in the 200 East Area of the Hanford Site, is one example where an alternative is needed because, in addition to the above noted shortcomings, this unit has unique hydrologic conditions that preclude use of standard upgradient-downgradient comparisons.

RCRA allows application of alternative statistical methods for analysis of groundwater monitoring data at permitted (i.e., final status) facilities where the standard protocol is inappropriate. One method, allowable under final status regulations WAC 173-303-645(8), is the use of a combined 
Shewhart-CUSUM control chart (an intra-well comparison) approach. The method was first referenced by Westgard et al. (1977) and further developed by Lucas (1982). For groundwater applications, testing procedures are discussed in U.S. Environmental Protection Agency (EPA) guidance (EPA 1989, 1992), Starks (1989), Gibbons (1994), ASTM (1998, formerly known as ASTM 1996), and Chou et al (2001).

After numerous discussions and negotiations with Washington State Department of Ecology (Ecology), the U.S. Department of Energy (DOE) requested 1) a variance from applying interim status regulations at B Pond and 2) a trial period for applying the combined Shewhart-CUSUM control method at the 300 Area process trenches. Ecology granted the request for a trial period of 2 years or four sampling events (Appendix A.1, May 7, 2001 letter from Dib Goswami to Marv Furman). An alternative statistical approach was developed to address the special case when standard upgradient-downgradient comparisons are not valid (Chou et al. 2001). However, before applying this method to the sites, and potentially other RCRA sites at Hanford, analysis of groundwater data collected over a 2-year trial period starting January 2002 was required by Ecology. Sampling conducted during July 2003 and September 2003 constitutes the last sampling event for B Pond and 300 Area process trenches, respectively. The results of this trial application will assist Ecology in deciding whether to continue, modify, or abandon the proposed approach at these facilities and/or to apply the approach to other RCRA facilities.

\subsection{Purpose and Scope}

The purpose of this report is to present the results of the statistical analysis of groundwater monitoring data acquired at B Pond and the 300 Area process trenches during the 2-year trial or test period and to make recommendations concerning application of the statistical methods evaluated. Overall, a more efficient and technically sound statistical method for analysis of groundwater monitoring data at the Hanford Site is the desired outcome of this effort.

The scope for this report is limited to the following:

- Constituents of concern (COCs) and monitoring networks that were negotiated and agreed upon by Ecology. For the B Pond case, specific conductance, gross alpha, ${ }^{1}$ and gross beta ${ }^{1}$ are the COCs that are subject to statistical evaluation; and monitoring network wells include one upgradient well 69944-39B and four downgradient wells, 699-42-42B, 699-43-44, 699-43-45 and 699-43-43 (Appendix A.2, November 20, 2001, Letter from John Morse, DOE to Jane Hedges, Ecology). Well 699-43-43 was added to the network at Ecology's request and later it went dry.

\footnotetext{
${ }^{1}$ Special nuclear and by-product materials, as defined in the Atomic Energy Act of 1954, are regulated at DOE facilities exclusively by DOE and are not subject to regulation by the state of Washington. However, gross alpha and gross beta activity were included in the B Pond monitoring program by special agreement between DOE and Washington State Department of Ecology.
} 
- For the 300 Area process trenches case, uranium, ${ }^{2}$ cis1,2-dichloroethene (cis-DCE), and trichloroethene (TCE) are the COCs; and network wells under evaluation include 399-1-16A, 399-1-16B, 399-1-17A, 399-1-17B (Appendix A.1, May 7, 2001 letter from Dib Goswami to Marv Furman), and 399-1-10A and B (for completeness).

- For the B Pond case, data acquired prior to January 1995 are not used in statistical evaluations because the change in discharge practices rendered previously collected data unrepresentative of current site conditions. For example, in April 1994, discharges to the main pond ceased, and all effluents were rerouted to the $3 \mathrm{C}$ expansion pond via a pipeline. Also, during 1994, the main pond and the 216-B-3-3 ditch (B-3-3 ditch) were filled with clean soil, and all vegetation was removed from the perimeter and included with the filled soil as part of interim stabilization activities. Termination of discharges to the B Pond system caused groundwater flow direction changes.

- For the 300 Area process trenches case, data acquired prior to January 1995 are not used in the statistical evaluations because the trenches were administratively isolated and all discharges were terminated in December 1994. The Shewhart-CUSUM control limits agreed upon by Ecology as indicated in Appendix A.1 (May 7, 2001 letter from Dib Goswami to Marv Furman) did not address public comments concerning: 1) the possible dilution effect of mixing Columbia River water with contaminated groundwater; and 2) the assumption of normality may be compromised due to the bimodal nature of groundwater flow direction (i.e., high river stage reverses the groundwater flow direction for wells near the river, resulting in mixing and dilution of groundwater with river water). To address these comments, the baseline data and control limits were updated, corrected for dilution effect, if necessary, and normality tests performed.

- The statistical method is focused on the use of the combined Shewhart-CUSUM control chart approach in evaluating groundwater quality data. The statistical power of this testing method will be compared to other methods as appropriate.

\subsection{Report Organization}

Chapter 2 provides a brief description of the basic assumptions and the step-by-step procedures associated with the control chart method. Chapters 3 and 4 provide results of statistical evaluation and findings for the B Pond system and the 300 Area process trenches, respectively. Chapter 5 addresses special conditions encountered for each site. Chapter 6 presents conclusions and recommendations regarding the applicability of the methodology to other facilities on the Hanford Site. Letters of communications with Ecology that document agreed upon conditions are presented in Appendix A. Power curve evaluations for the proposed combined Shewhart-CUSUM method and interim status required AR t-test method are presented in Appendix B. Normal probability plots are presented in Appendix C.

\footnotetext{
${ }^{2}$ Special nuclear and by-product materials, as defined in the Atomic Energy Act of 1954, are regulated at DOE facilities exclusively by DOE and are not subject to regulation by the state of Washington. Uranium currently is included for the 300 Area process trenches because it remains in the monitoring plan cited in the Hanford Facility RCRA Permit and by special agreement between DOE and Washington State Department of Ecology.
} 


\subsection{Statistical Assumptions and Test Procedures}

Before choosing a statistical method, an evaluation must be made of whether the available sitespecific data meet underlying basic assumptions required for statistical testing. For example, typical methods (referred to as inter-well comparisons) involve difference testing of contamination indicator parameters or contaminant concentrations between upgradient and downgradient wells. In these cases, independent and identically distributed populations of upgradient and downgradient concentrations are assumed. The difference between upgradient and downgradient water quality is attributed to the site. However, in practice, this condition may not be met due to either a flat water table or spatial variability among network wells, and other methods are needed.

The statistical method discussed here can be used when the above assumptions are not valid, and an alternative is required to detect changes in groundwater quality attributable to the regulated unit. The method used is a sequential quality control scheme called a combined Shewhart-CUSUM control chart approach (Westgard et al. 1977; Lucas 1982; Starks 1989; EPA 1989, 1992; Gibbons 1994; ASTM 1998). This method can be implemented for each well in the monitoring network separately after a baseline period of eight or more independent observations is acquired. This procedure assumes that groundwater data obtained in a well during the baseline period and a future timeframe are independent and normally distributed with a fixed mean $\mu$ and variance $\sigma^{2}$. The most important assumption is that the data are independent. The assumption of normality can generally be satisfied by data transformation. Even in situations where the normality assumption is violated to a slight or moderate degree, the control chart methods will still work reasonably well (Montgomery 1991, page 342). The control charts will not work well if monitoring data collected from a well are auto-correlated over time. To ensure groundwater quality data are independent, wells should not be sampled too frequently. Gibbons (1994, pages 163 and 185) recommends groundwater not be sampled more than quarterly to reduce the likelihood of obtaining dependent data. Useful techniques to check the validity of these assumptions are provided below followed by a description of the Shewhart-CUSUM methodology that can be used once the assumptions of independence and normality are satisfied.

\subsection{Minimum Time Interval to Obtain Independent Samples}

To ensure statistical independence between sampling events, adequate time should elapse to allow the aquifer near the well to return to an unperturbed state. Generally, the recovery time needed depends on the groundwater flow rate and the size of the disturbed zone created during a typical well purging and sampling event. The EPA (1989, pages 3-1-10) suggested using the following steps to determine the minimum time needed to acquire independent samples by reference to the uppermost aquifer's effective porosity $\left(n_{e}\right)$; horizontal hydraulic conductivity $\left(K_{h}\right)$; and hydraulic gradient $(i)$.

1. Calculate the horizontal component of the average linear velocity of groundwater $\left(\bar{v}_{h}\right)$ using Darcy's equation Freeze and Cherry (1979, page 71)

$$
\bar{v}_{h}=\frac{\left(K_{h} * i\right)}{n_{e}}
$$


where the dimension of $\bar{v}_{h}$ is the same as $K_{h}$ (or distance divided by time, L/T).

2. The minimum time interval between independent sampling events is obtained by:

$$
\text { Minimum Time Interval }=\frac{W_{d}}{\bar{v}_{h}}
$$

where $\bar{v}_{h}$ is determined in Step 1, and $W_{d}$ is the diameter of the monitoring well. This approximation is most applicable to zero or low purge sampling conditions.

The Darcy equation is not valid in turbulent and nonlinear laminar flow regimes. In those cases where Darcy flow cannot be assumed (e.g., in karst or pseudo-karst aquifers; EPA 1989, page 3-11), the groundwater velocity must be determined by more direct methods such as tracer travel time between two wells or with a flow meter.

In those cases where Darcy flow conditions apply, well purging might create a much larger effective disturbed zone diameter than just the diameter of the well screen. This can occur if large volumes of purge water are withdrawn prior to sampling. Therefore, to account for this effect, an estimated disturbed zone diameter (2 times $r$ where $r$ is the radius of the affected area) can be substituted for $W_{d}$ in Equation 2.2 to calculate a more conservative estimate of the time interval required to obtain independent samples. An approximation for the disturbed zone radius $r$ is as follows in Equation 2.3:

$$
r=\sqrt{\frac{3 V_{w}}{\pi * h^{*} n_{e}}}
$$

where $V_{w}$ is the volume of water purged prior to sample collection (typically three bore volumes); $\mathrm{h}$ is the length of the wetted well screen; and $n_{e}$ is the effective porosity.

The EPA (1989, Table 3.1) provides default values for effective porosity for use in time of travel analyses.

\subsection{Check Assumption on Normally Distributed Data Set}

A normal probability plot of each COC could be constructed first to examine whether a normal distribution could be used to describe the groundwater data. If a straight line can approximate these data points, a normal distribution is assumed to be a reasonable representation of the monitoring data. Also, goodness-of-fit tests such as the Shapiro and Wilk's W test and the Lilliefors test for normality of data as described in Conover (1980, pages 357-367) are effective methods for testing the null hypothesis that these data were drawn from an underlying normal distribution. Because environmental data are highly skewed, the assumption of normality can generally be satisfied by log-transforming the data or by other techniques such as the Box-Cox transformations. Draper and Smith (1980, pages 226-232) provide a detailed discussion on this useful family of transformations. 


\subsection{Combined Shewhart-CUSUM Testing Procedures}

This method is a sequential testing procedure to test for an upward shift in the mean concentration of a COC. It combines the advantages of a Shewhart control chart with that of a CUSUM control chart. It allows monitoring data from a well to be viewed graphically over time so changes over baseline conditions can be detected. The Shewhart portion of the test checks for any sudden upward shift in groundwater quality parameters based on a single observation. The CUSUM checks for a gradually increasing trend in the groundwater quality parameters. The procedure can be implemented as follows: Let $\mathrm{x}_{\mathrm{i}}^{\prime}$ be a series of independent baseline observations $i=1,2 \ldots, n(n=8)$. Let $x_{i}$ be a series of future monitoring measurements $i=1,2,3 \ldots \ldots$. Then, using the baseline data, the following steps are applied:

1. Using methods discussed in Sections 2.1 and 2.2, determine if the $\mathrm{x}_{\mathrm{i}}^{\prime}$ can be assumed to be independent and follow a normal distribution with mean $\mu$ and standard deviation $\sigma$. If not, transform the $\mathrm{x}_{\mathrm{i}}$ using the appropriate Box-Cox transformation, and work with the transformed data.

2. Next, use the baseline data to compute the estimates

$$
\bar{x}_{b}^{\prime}=\sum_{i=1}^{n} x_{i}^{\prime} / \mathrm{n} \text { for } \mu \text { and } s_{b}{ }^{\prime}=\sqrt{\sum_{i=1}^{n}\left(x_{i}^{\prime}-\bar{x}_{b}^{\prime}\right)^{2} /(n-1)} \text { for } \sigma \text {. }
$$

3. Determine the upper Shewhart control limit (SCL) for the procedure by calculating $S C L=\bar{x}_{b}{ }^{\prime}+z_{s} s_{b}{ }^{\prime}$ where $z_{s}$ is a percentile of the standard normal distribution used to set the false negative and false positive values of the Shewhart control limit. The value of $z_{s}$ most often suggested for groundwater use, is 4.5 (Starks 1989 and EPA 1989). Other values may also be used, depending on the sampling scheme used and whether verification sampling is used to modify the false positive and false negative error rates. If the Shewhart control scheme test were used alone, without the CUSUM portion of the test, then the false positive values of this portion of the test alone would be given by $1-\Phi\left(z_{s}\right)^{\mathrm{m}}$, which is the probability of at least one of the m comparisons (number of wells in the network times the number of water quality parameters) exceeding their respective SCL's, where $\Phi(z)$ is the cumulative distribution function of the standard normal distribution.

For illustrative purposes, let us assume a waste disposal site has four wells and three water quality parameters. Using the above-suggested value of 4.5 for $z_{s}$, this would translate to a false positive rate of 0.00004 . For values of $z_{s}$ being 2,3 , and 4 , the respective false positive rates would be 0.24 , 0.02 , and 0.00038 . Thus, higher values of $z_{s}$ ensure that the probability of falsely declaring the site has affected groundwater quality in any one sampling period, when in fact it has not, is small. The false negative rate for the network, for various shifts from the baseline means, needs to be computed by simulation and is computed in conjunction with the CUSUM test. 
4. Determine the upper CUSUM control limit (CCL), with $C C L=\bar{x}_{b}{ }^{\prime}+z_{c} s_{b}{ }^{\prime}$. The value of $z_{c}$ suggested by Lucas (1982), Starks (1989), and EPA (1989) is $z_{c}=5$. This value can also be adjusted to reach desired false negative and false positive error rates.

5. Determine the amount of increased shift in the mean of the water quality parameter of interest to detect an upward trend. This value is referred to as $\mathrm{k}$ and is usually measured in $\sigma$ units of the water quality parameter. Lucas (1982), Starks (1989), and EPA (1989) suggest a value of $k=1$ if there are fewer than 12 baseline observations and a value of $\mathrm{k}=0.75$ if there are 12 or more baseline observations.

After the baseline measurements are established, use the subsequent monitoring data to:

6. Compute the CUSUM statistic as $S_{i}=\max \left\{0,\left(x_{i}-k s_{b}^{\prime}\right)+S_{i-1} s_{b}^{\prime}\right\}$ as each new monitoring measurement, $x_{i}$ becomes available, where $\mathrm{i}=1,2,3, \ldots \ldots$ and $S_{0}=0$.

7. As each new monitoring measurement becomes available, compute the Shewhart and CUSUM tests; a verification sampling will be conducted if either $x_{i} \geq \mathrm{SCL}$ or $S_{i} \geq \mathrm{CCL}$. A well is declared to be out of compliance only if the verification result also exceeds the SCL or the CCL. If both $x_{i}<\mathrm{SCL}$ and $\mathrm{S}_{\mathrm{i}}<\mathrm{CCL}$, then continue monitoring.

If resampling is implemented during monitoring, the new analytical result is substituted into the above formulas for the original value obtained, and the CUSUM statistic is updated. Note in the above combined test that the Shewhart portion of the test quickly detects extremely large deviations from the baseline period. The CUSUM portion of the combined test is sequential; thus, a small positive shift in the mean concentration over the baseline period will slowly aggregate in the CUSUM statistic and eventually cause the test to exceed the CUSUM control limit CCL. 


\subsection{Statistical Evaluations of B Pond Data}

This section presents results of statistical evaluations at B Pond including evaluating data independence and normality assumptions, detection status, and presenting the Shewhart-CUSUM input parameter values (i.e., control limits, see Appendix B). Only measurements obtained subsequent to January 1995 were used for data evaluation purposes.

\subsection{Background}

The B Pond system consisted of the original or main pond and three expansion ponds A, B, and C. Wastewater discharges to the main pond began in 1945 . Three expansion ponds $(-3 \mathrm{~A},-3 \mathrm{~B}$, and $-3 \mathrm{C})$ were built in 1983, 1984, and 1985 respectively. Discharges to the main pond ceased in 1994, and use of the 3C-expansion pond was terminated in 1997. During its operating lifetime, the B Pond system received more than 1.0 E+12 L of wastewater (Barnett et al. 2000). Most of the water discharged to B Pond in the recent past was cooling water (Columbia River water), which has lower dissolved solids and ionic strength than ambient groundwater.

The B Pond system has been monitored as a RCRA interim status facility since 1988 as illustrated in Figure 1. Locations of current and historical monitoring wells are shown in Figure 2. From 1988 until 2001, sampling procedures and statistical evaluation method were based on 40 CFR 265 Subpart F (and by reference of WAC 173-303-400). During the 2-year trial evaluation period from 2001 through 2003, sampling was conducted in accordance with variance agreement (Appendix A.1 and A.2). In January 2004, sampling will revert to interim status requirements pending an Ecology decision whether to allow the alternative method.

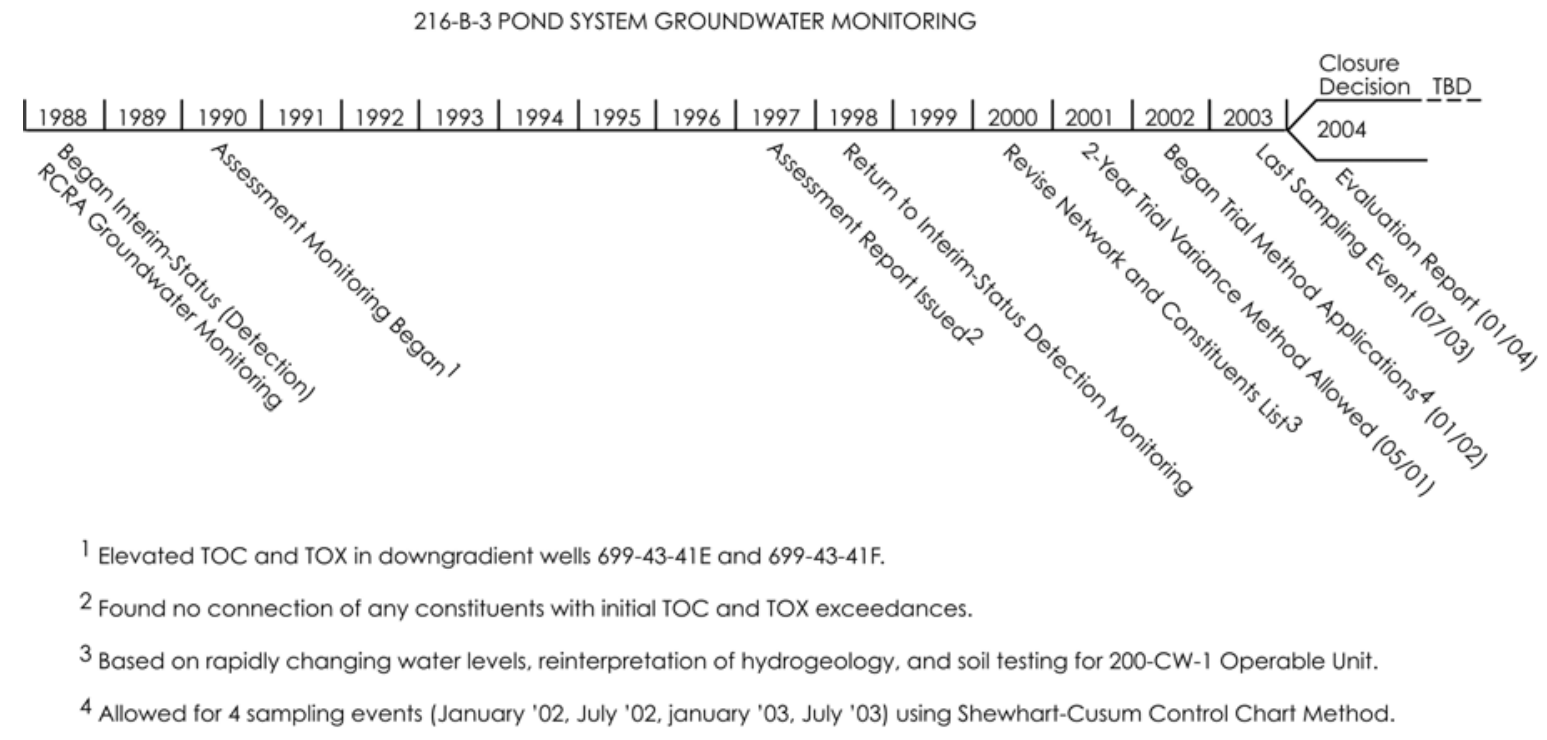

2003/DCL/216-B-3/002 (11/18)

Figure 1. RCRA Groundwater Monitoring Timeline for the 216-B-3 Pond System 


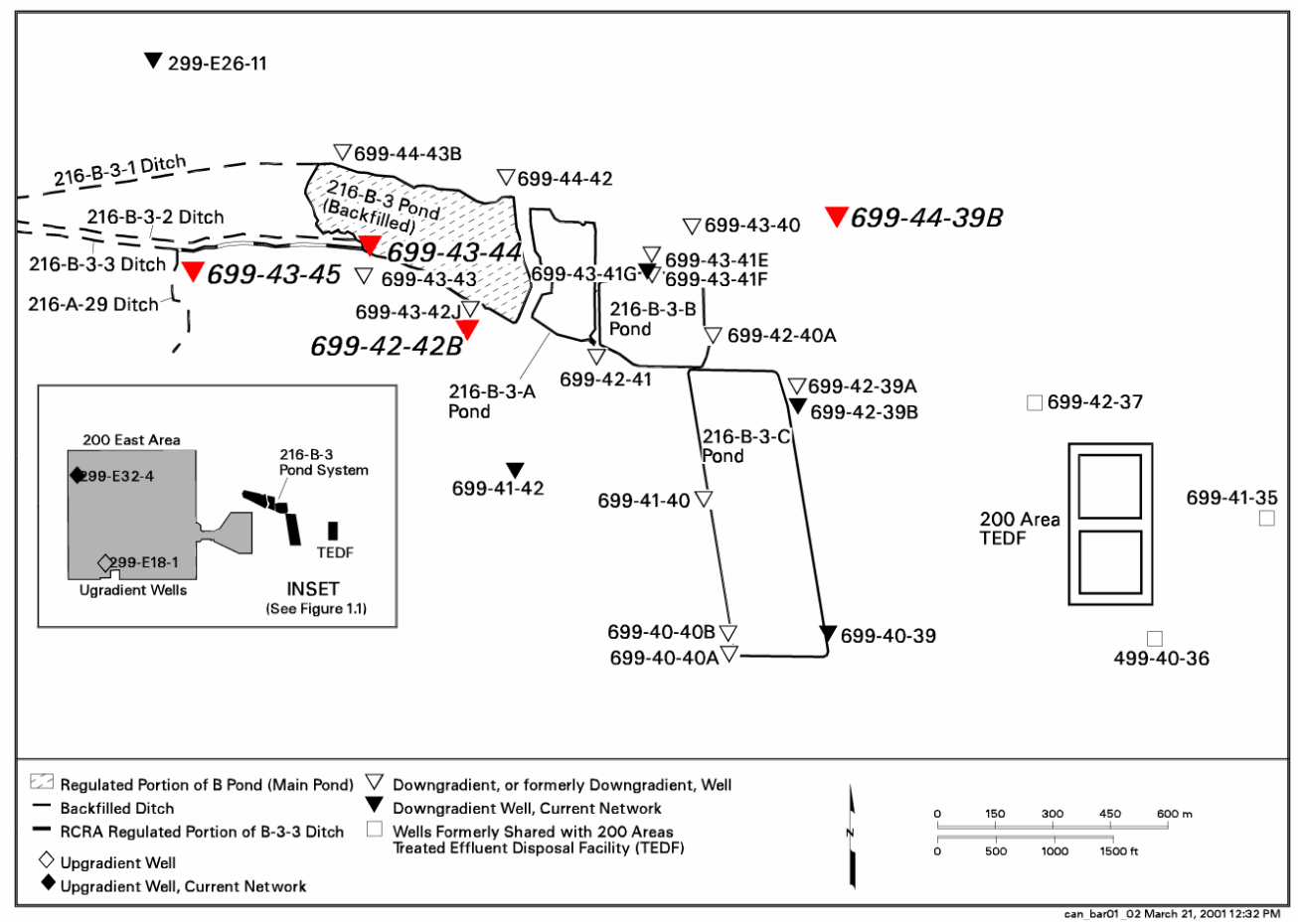

Figure 2. Historical and Revised Monitoring Network for the B Pond System. Revised network wells are shown in red, except for well 699-43-43 which was added to the revised network (but became dry in October 2001).

\subsection{Independent Samples}

Using a monitoring well diameter of $0.1016 \mathrm{~m}$ and a B Pond groundwater flow rate of $0.008 \mathrm{~m} / \mathrm{d}$ (Hartman et al. 2003, Table A.2), Equation 2.2 yields a minimum time of 13 days between sampling events to ensure independence. However, this estimate is not realistic because the effective diameter of the disturbed zone is much greater than the well diameter. To account for this effect, an approximation for the disturbed zone radius $r$ was calculated to be $0.1822 \mathrm{~m}$ using Equation 2.3. Thus, a more conservative estimate of the time interval required to obtain independent samples is about 46 days $(2 * 0.1822 \mathrm{~m} / 0.008 \mathrm{~m} / \mathrm{d}=45.6$ or 46 days). Under this scenario, a time interval of $\sim 184$ days would be needed to obtain four independent samples for use in the default analysis of variance (ANOVA) method [WAC 173-303-645 (9)(d)].

Because of the slow moving groundwater, the regulatory requirement to collect four independent samples during each semi-annual period for the ANOVA method cannot be satisfied at B Pond. Furthermore, the power of the ANOVA procedure depends greatly on having at least 3 to 4 samples per well available for testing (EPA 1992, page 67). Because the samples must be statistically independent, collection of four samples at a given well for verification purposes will necessitate a 6-month ( $\sqcup 4 \times 46$ days) waiting period at B Pond monitoring wells due to the very low groundwater velocity (i.e., $0.008 \mathrm{~m} / \mathrm{d}$ or $\sim 2.9 \mathrm{~m} / \mathrm{yr}$ ). It would not be environmentally responsible to wait 6 months to verify an initial statistical 
exceedance. An alternative method that relies on collection of one sample from each well during each semi-annual period is more appropriate under this condition.

\subsection{Spatial Variability}

The existence of high spatial variability among the B Pond historical wells was documented in Chou et al. (2001, Figure 4). Spatial variability affects the mean concentrations of naturally occurring constituents among network wells but not typically the variance within each well, whereas contamination can affect both mean concentrations and variance. Specific conductance data obtained from the current network wells during January 1995 through July 2003 are presented in Figure 3. Within well variability of more recent data is less than that of earlier data. Thus, the more recent data (2000 and after) are used to demonstrate the spatial variability for the B Pond wells. The mean specific conductance values vary from $\sim 220$ to $270 \mu \mathrm{S} / \mathrm{cm}$, while observations over time from wells fluctuate little from their respective mean values.

Another simple method to evaluate spatial variability is the box-and-whisker plot where the distributions of specific conductance among the network wells are displayed as shown in Figure 4. For each well, the top and bottom of a box represent the upper $\left(\mathrm{Q}_{3}\right)$ and lower $\left(\mathrm{Q}_{1}\right)$ quartiles of the specific conductance values, and a line segment within the box indicates the median $\left(\mathrm{Q}_{2}\right)$. The box covers the middle $50 \%$ of the data values. The whiskers extend out to the extremes (minimum and maximum observations). When extremely large or small values occur, they are plotted as individual points. The whiskers extend only to

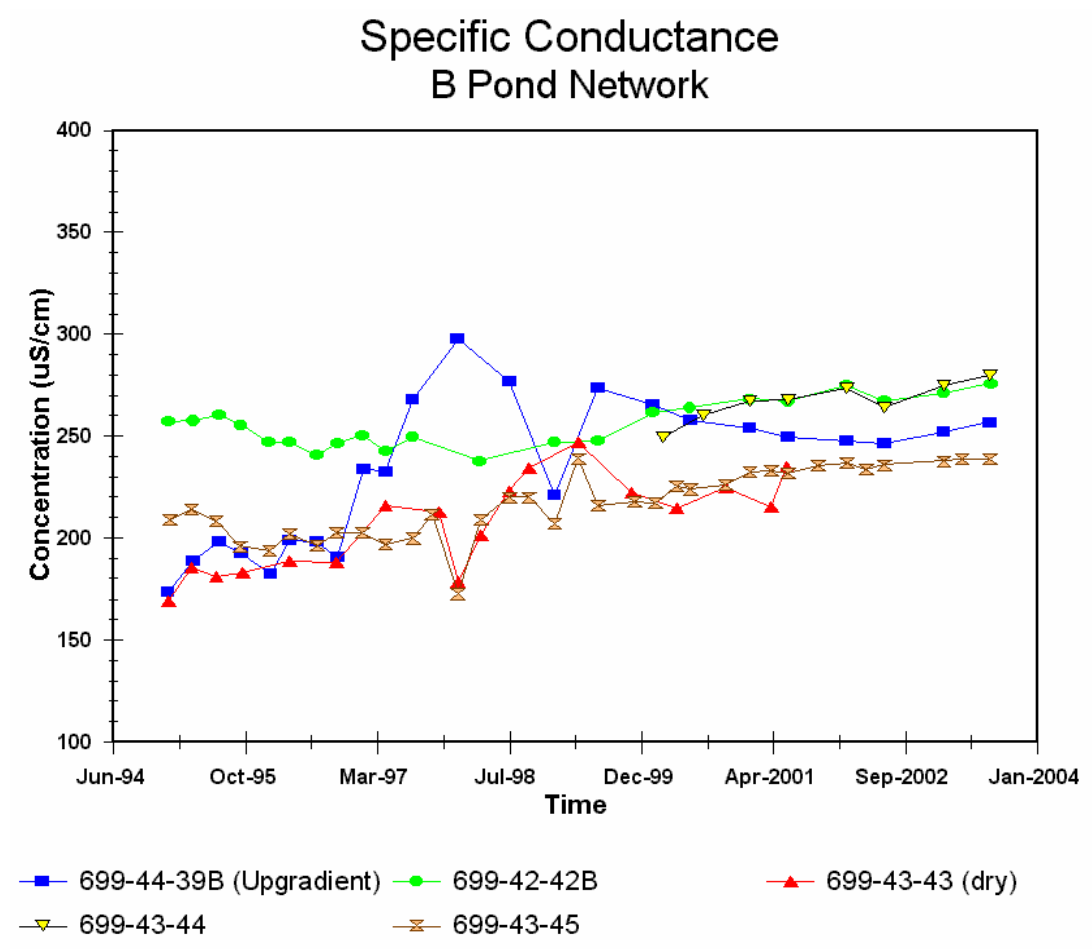

Figure 3. Specific Conductance versus Time Plot 


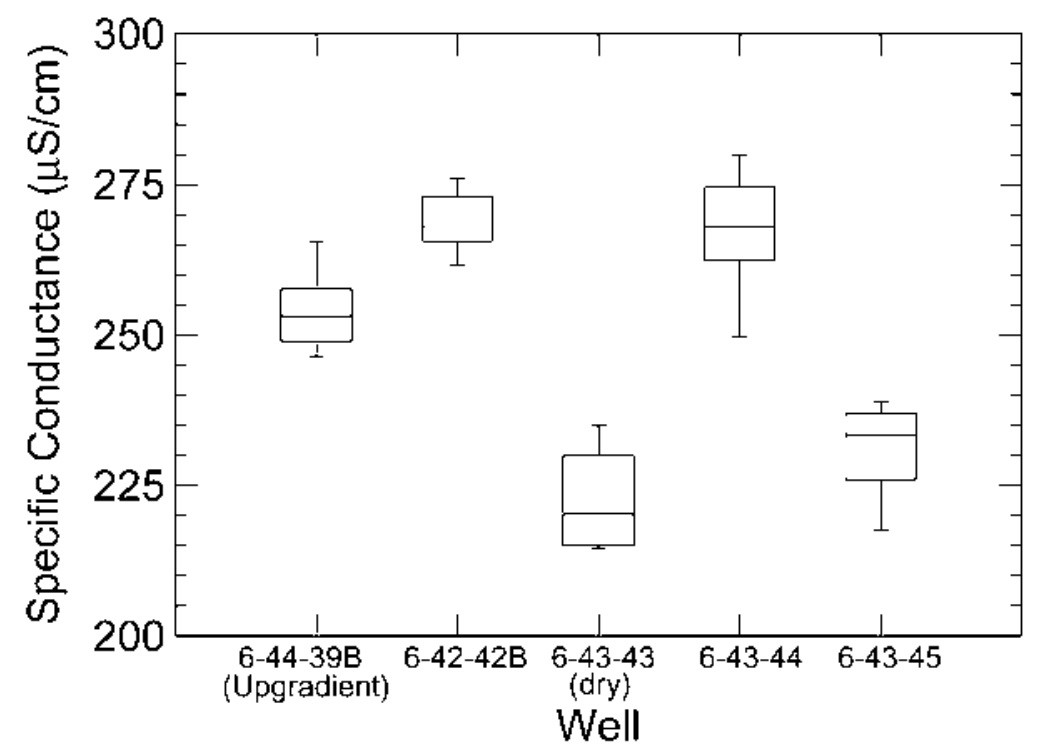

Figure 4. Examples of Spatial Variability Exhibited by B Pond Network Wells using Specific Conductance Data Obtained from January 2000 through July 2003

those points within 1.5 times the interquartile range $\left(\mathrm{Q}_{3}-\mathrm{Q}_{1}\right)$. Any data point that falls outside the whisker could be classified as a suspected outlier (Ostle and Malone 1988, pages 65-67).

The presence of spatial variability among B Pond network wells is again demonstrated in Figure 4. Figure 4 shows that the specific conductance distributions from each well (as represented by each box) are relatively symmetric and without extremely large values. These are characteristics of wells that do not intersect groundwater contamination, yet most of the median values (which range from $\sim 220 \mu \mathrm{S} / \mathrm{cm}$ to $\sim 270 \mu \mathrm{S} / \mathrm{cm}$ ) do not overlap indicating differences among network wells. In this case, the spatial variability invalidates the inter-well comparison method because that method assumes the only impact between the upgradient well and down gradient wells is from the facility.

\subsection{Rationale for Selecting the Combined Shewhart-CUSUM Control Chart Method}

The goal of a RCRA final status detection-monitoring program [WAC 173-303-645(9)] is to determine whether the regulated unit has adversely affected the groundwater quality in the uppermost aquifer beneath the site. This is accomplished by testing for statistically significant changes in concentrations of constituents of interest in a downgradient well relative to baseline values. In the B Pond case, the objectives of the proposed statistical evaluation method are:

1. To keep the site-wide false-positive rate (across all constituents and wells being tested) at an acceptably low level.

2. To have adequate statistical power to detect real contamination when it occurs. 
To achieve the goal of lowering the site-wide false-positive rate, the number of tested constituents is limited to the most useful indicators (EPA 1992, page 62; Gibbons 1994, page 16); therefore, only the three site-specific parameters (specific conductance, gross alpha, and gross beta) were be subject to statistical evaluation for the B Pond system under this trial. Another strategy to lower the overall falsepositive rate is to perform verification sampling to determine whether the statistically significant changes between baseline and compliance-point data is an artifact caused by an error in sampling, analysis, or statistical evaluation.

Another goal of the statistical method applied here is to maintain adequate statistical power for detecting real contamination. The power of a test depends on several factors that include the baseline sample size, the type of statistical test proposed, and the number of comparisons (i.e., the false-positive rate). Evaluation of power curves, for the B Pond case, is presented in Appendix B. Based on power curves evaluations (see Appendix B) as well as other reasons as discussed below, it is judged that the statistical goals will be best achieved by the combined Shewhart-CUSUM control chart method.

In accordance with WAC 173-303-645(8)(h), acceptable statistical methodology includes analysis of variance (ANOVA), tolerance intervals, prediction intervals, control charts, test of proportions, or other statistical methods approved by Ecology. The type of monitoring, the nature of the data, the proportions of non-detects, and spatial and temporal variations are some of the important factors to be considered in the selection of appropriate statistical methods. As described in Sections 3.1.1 and 3.1.2, the existence of spatial variability and the low groundwater velocity at the B Pond facility limit the use of inter-well comparison procedures such as the ANOVA. As previously noted, one of the alternative statistical tests, allowable under final status regulations WAC 173-303-645(8)(h), is the use of a combined ShewhartCUSUM control chart approach, first referenced by Westgard et al. (1977) and further developed by Lucas (1982). This method is also discussed in a groundwater context by Starks (1989), Gibbons (1994), and ASTM (1998) and was first adopted into EPA guidance in 1989 (EPA 1989, 1992). There are several advantages in applying the control chart procedure:

- This method can be implemented with a single observation at any monitoring event (i.e., this method is efficient).

- This method could be applied to monitoring each well individually and yet maintain desired sitewide false positive and false-negative error rates. That is, this method is effective. The spatial variations that adversely affect the ANOVA procedure do not play a role under the control chart procedure. [Note: Due to the elimination of spatial variability, the uncertainty in measured concentrations is decreased making intra-well comparisons more sensitive to a real release (that is, false negatives) and false positive results (ASTM 1998)].

- The power of the control chart method could be enhanced by the combined Shewhart and CUSUM procedures. It is well known that the Shewhart procedure is sensitive to sudden shifts and the CUSUM procedure is sensitive to gradual changes in the mean concentrations. A combined Shewhart and CUSUM procedure, therefore, is well designed to detect both types of changes. 
Statisticians of Washington State University (WSU) evaluated the efficacy of this method for monitoring groundwater quality on behalf of Ecology (WSU 1999) in 1999 using B Pond monitoring data from historical monitoring wells. In their report, WSU also endorsed the control chart method of monitoring groundwater quality.

\subsection{Detection Status and Normal Assumption}

In order to arrive at appropriate control limits, the detection history for each COC at each well must first be evaluated (ASTM 1998). Detection status and results of Shapiro-Wilk test for the site-specific COCs is presented in Table 1 using data obtained from January 1995 through June 2001. Detection frequencies for the three COCs are greater than 25\%; therefore, the use of a nonparametric prediction limit, which equals the maximum quantified value as the intra-well limit, is not necessary (see ASTM 1998, Section 5.1.2.4, page 8). Additionally, the analytical laboratory provided actual concentrations even when gross alpha and gross beta values were below background signals (i.e., non-detect). For statistical evaluation purposes, methods to account for non-detects (e.g., Cohen's method) are not needed and actual concentrations provided by the laboratory were used.

Table 1. Detection Status and Results of Shapiro-Wilk Test for the B Pond System Monitoring Wells Using Site-Specific Constituents of Concern

\begin{tabular}{|c|c|c|c|c|c|}
\hline Network & $699-42-42 B$ & $699-43-43^{(a)}$ & $699-43-44$ & $699-43-45$ & 699-44-39B \\
\hline \multicolumn{6}{|c|}{ Specific Conductance } \\
\hline $\begin{array}{l}\text { Time Period } \\
\mathrm{n}^{(\mathrm{b})} \\
\text { Detected } \\
\text { Non-Detect } \\
\text { W-test Statistic } \\
\text { Critical Value } \\
\text { Distribution }\end{array}$ & $\begin{array}{c}1 / 95-6 / 01 \\
18 \\
18 \\
0 \\
0.9525 \\
0.897 \\
\text { Normal } \\
\end{array}$ & $\begin{array}{c}1 / 95-6 / 01 \\
18 \\
18 \\
0 \\
0.9475 \\
0.897 \\
\text { Normal } \\
\end{array}$ & $\begin{array}{c}9 / 99-7 / 03 \\
8^{(\mathrm{c})} \\
8^{(\mathrm{c})} \\
0 \\
0.9634 \\
0.818 \\
\text { Normal } \\
\end{array}$ & $\begin{array}{c}1 / 95-6 / 01 \\
27 \\
27 \\
0 \\
0.9752 \\
0.923 \\
\text { Normal } \\
\end{array}$ & $\begin{array}{c}1 / 95-6 / 01 \\
19 \\
19 \\
0 \\
0.9261 \\
0.901 \\
\text { Normal } \\
\end{array}$ \\
\hline \multicolumn{6}{|c|}{ Gross Alpha } \\
\hline $\begin{array}{l}\text { Time Period } \\
\mathrm{n}^{(\mathrm{b})} \\
\text { Detected } \\
\text { Non-Detect } \\
\text { W-test Statistic } \\
\text { Critical Value } \\
\text { Distribution }\end{array}$ & $\begin{array}{c}1 / 95-6 / 01 \\
18 \\
15 \\
3 \\
0.9547 \\
0.897 \\
\text { Normal } \\
\end{array}$ & $\begin{array}{c}1 / 95-7 / 95 \\
3 \\
0 \\
3 \\
\mathrm{NC} \\
\mathrm{NC} \\
\mathrm{NC} \\
\end{array}$ & $\begin{array}{c}9 / 99-6 / 02 \\
8 \\
6 \\
2 \\
0.9395 \\
0.818 \\
\text { Normal } \\
\end{array}$ & $\begin{array}{c}1 / 95-1 / 01 \\
16 \\
6 \\
10 \\
0.9204 \\
0.887 \\
\text { Normal } \\
\end{array}$ & $\begin{array}{c}1 / 95-6 / 01 \\
17 \\
12 \\
5 \\
0.9385 \\
0.892 \\
\text { Normal } \\
\end{array}$ \\
\hline \multicolumn{6}{|c|}{ Gross Beta } \\
\hline $\begin{array}{l}\text { Time Period } \\
\mathrm{n}^{(\mathrm{b})} \\
\text { Detected } \\
\text { Non-Detect } \\
\text { W-test Statistic } \\
\text { Critical Value } \\
\text { Distribution }\end{array}$ & $\begin{array}{c}1 / 95-6 / 01 \\
18 \\
17 \\
1 \\
0.9293^{(\mathrm{d})} \\
0.897 \\
\text { Log-Normal }\end{array}$ & $\begin{array}{c}1 / 95-7 / 95 \\
3 \\
3 \\
0 \\
\mathrm{NC} \\
\mathrm{NC} \\
\mathrm{NC} \\
\end{array}$ & $\begin{array}{c}9 / 99-6 / 02 \\
8 \\
7 \\
1 \\
0.9417 \\
0.818 \\
\text { Normal } \\
\end{array}$ & $\begin{array}{c}1 / 95-1 / 01 \\
16 \\
16 \\
0 \\
0.9423 \\
0.887 \\
\text { Normal } \\
\end{array}$ & $\begin{array}{c}1 / 95-6 / 01 \\
17 \\
15 \\
2 \\
0.9043 \\
0.892 \\
\text { Normal } \\
\end{array}$ \\
\hline \multicolumn{6}{|c|}{$\begin{array}{l}\text { (a) Well 699-43-43 was added to the network as long as it remained serviceable in accordance with Ecology's request } \\
\text { (Appendix A.2). Well went dry in October } 2001 \text {. } \\
\text { (b) } \mathrm{n} \text { is the number of samples obtained in the time period under evaluation. } \\
\text { (c) Excluding unrepresentative samples collected during drilling on September } 22 \text { and } 28,1999 . \\
\text { (d) The W-test statistic is calculated using log-transformed (natural) data because the data are log-normally distributed. } \\
\text { NC = Not calculated due to insufficient sample size. }\end{array}$} \\
\hline
\end{tabular}


One of the assumptions for the combined Shewhart-CUSUM control chart approach is that the data are normally distributed. One simple and easy way to evaluate whether a sample can reasonably be regarded as having come from a normal distribution is through the use of a normal probability plot. The plot is constructed so that if data points fall on a straight line, then these data can be assumed to be from a population with a normal distribution. Following Ecology guidance (Appendix A.1), normal probability plots were generated for each of the site-specific parameters in each B Pond system well. The plots are presented in Appendix C.

Additionally, statistical testing to evaluate whether or not the data follow a specified distribution (called the goodness-of-fit tests) is also used. A recommended test is the Shapiro-Wilk test for normality of the data (Shapiro and Wilk 1965). It is considered to be one of the very best tests of normality available (Miller 1986; Mandansky 1988). The Shapiro-Wilk test statistic (W) will tend to be large when a probability plot of the data indicates a nearly straight line (i.e., normal distribution). Only when the plotted data show significant departure from normality the test statistic will be small. Hence if the computed value of $\mathrm{W}$ is less than the critical value $\mathrm{W}_{\alpha}$ for a prechosen value of $\alpha$ (e.g., $\alpha=5 \%$ ) shown in statistical tables, the hypothesis of normality is rejected. The Shapiro-Wilk test of normality can be used for sample sizes up to 50. Procedures are provided in EPA (1992, pages 9-12), Shapiro (1980, pages 2024), and Conover (1980, pages 363-366). The Shapiro-Wilk test results for each B Pond system network well and for each site-specific COC are also presented in Table 1. The normal distribution is a reasonable assumption except for gross beta in 699-42-42B, which is better represented by a log-normal distribution (Table 1).

\subsection{Baseline Summary Statistics and Control Limits}

Following Ecology guidance (Appendix A.1), it is judged that the most recent eight sampling events prior to January 2002 would provide the most appropriate (e.g., data are less variable and more representtative) baseline period for deriving the combined Shewhart-CUSUM control limits with which subsequent sampling data (obtained during the 2-year trial evaluation period from January 2002 through July 2003) are compared. Tables 2 to 4 provide respective baseline periods, the summary statistics, selected control limits, and data obtained during the 2-year trial evaluation period for the three site-specific parameters for each of the B Pond system network wells except for well 699-43-43, which went dry in October 2001. Unrepresentative specific conductance values collected during drilling (September 22 and September 28, 1999) for well 699-43-44 were not included in the statistical calculations.

\subsection{Data Comparisons}

Specific conductance, gross alpha, and gross beta data obtained during the four sampling periods (January 2002, July 2002, January 2003, and July 2003) were compared to the various control limits as 
Table 2. Specific Conductance Baseline Periods, Summary Statistics, Various Control Limits, and 2-Year Trial Evaluation Data for the B Pond System Wells

\begin{tabular}{|c|c|c|c|c|}
\hline & $\begin{array}{c}\text { 699-42-42B } \\
(\mu / \mathrm{cm})\end{array}$ & $\begin{array}{c}699-43-44 \\
(\mu / \mathrm{cm}) \\
\end{array}$ & $\begin{array}{c}699-43-45 \\
(\mu / \mathrm{cm})\end{array}$ & $\begin{array}{c}699-44-39 B \\
(\mu / \mathrm{cm}) \\
\end{array}$ \\
\hline \multicolumn{5}{|l|}{ Baseline Statistics } \\
\hline $\begin{array}{l}\text { Baseline Period: } \\
\text { Number of Samples } \\
\text { Mean }(\bar{x}) \\
\text { Standard Deviation (s) } \\
\text { CV }^{(\mathrm{a})}(\%) \\
\text { Fitted Distribution }^{(\mathrm{b})} \\
\end{array}$ & $\begin{array}{c}7 / 27 / 97-6 / 12 / 01 \\
8 \\
255.50 \\
11.23 \\
4.4 \\
\text { Normal } \\
\end{array}$ & $\begin{array}{c}2 / 25 / 00-7 / 17 / 03 \\
8 \\
267.41 \\
9.50 \\
3.6 \\
\text { Normal } \\
\end{array}$ & \begin{tabular}{|c|}
$11 / 10 / 99-6 / 13 / 01$ \\
8 \\
226.03 \\
6.23 \\
2.8 \\
Normal \\
\end{tabular} & $\begin{array}{c}1 / 9 / 98-6 / 12 / 01 \\
8 \\
262.22 \\
22.55 \\
8.6 \\
\text { Normal } \\
\end{array}$ \\
\hline \multicolumn{5}{|c|}{ Shewhart-CUSUM Control Limits } \\
\hline \begin{tabular}{|l} 
Control Limit $(\bar{x}+2 \mathrm{~s})$ \\
Control Limit $(\bar{x}+3 \mathrm{~s})$ \\
Control Limit $(\bar{x}+3.5 \mathrm{~s})$ \\
Control Limit $(\bar{x}+4 \mathrm{~s})$ \\
Control Limit $(\bar{x}+4.5 \mathrm{~s})$ \\
\end{tabular} & $\begin{array}{l}278 \\
289 \\
295 \\
300 \\
306 \\
\end{array}$ & $\begin{array}{l}286 \\
296 \\
301 \\
305 \\
310 \\
\end{array}$ & $\begin{array}{l}238 \\
245 \\
248 \\
251 \\
254 \\
\end{array}$ & $\begin{array}{l}307 \\
330 \\
341 \\
352 \\
364 \\
\end{array}$ \\
\hline \multicolumn{5}{|c|}{ 2-Year Trial Evaluation Data Subsequent to Baseline Period } \\
\hline $\begin{array}{l}\text { First Sampling }(1 / 02) \\
\text { Second Sampling }(7 / 02) \\
\text { Third Sampling }(1 / 03) \\
\text { Fourth Sampling }(7 / 03) \\
\end{array}$ & $\begin{array}{l}262 \\
268 \\
271 \\
276 \\
\end{array}$ & $\begin{array}{l}-- \\
--- \\
---\end{array}$ & $\begin{array}{l}233 \\
236 \\
\text { 238 }^{(\mathrm{c})} \\
\mathbf{2 3 9}^{(\mathrm{c})}\end{array}$ & $\begin{array}{l}246 \\
246 \\
252 \\
257\end{array}$ \\
\hline \multicolumn{5}{|c|}{$\begin{array}{l}\text { (a) Coefficient of variation }=(\mathrm{s} / \overline{\mathrm{x}}) * 100 \\
\text { (b) Based on goodness-of-fit test results shown in Table } 1 . \\
\text { (c) Bold indicates number is at or exceeding the lowest control limit }(\bar{x}+2 s) \text {. }\end{array}$} \\
\hline
\end{tabular}

Table 3. Gross Alpha Baseline Periods, Summary Statistics, Various Control Limits and 2-Year Trial Evaluation Data for the B Pond System Wells

\begin{tabular}{|c|c|c|c|c|}
\hline & $\begin{array}{c}699-42-42 B \\
(\mathrm{pCi} / \mathrm{L})\end{array}$ & $\begin{array}{c}699-43-44 \\
(\mathrm{pCi} / \mathrm{L})\end{array}$ & $\begin{array}{c}699-43-45 \\
(\mathrm{pCi} / \mathrm{L})\end{array}$ & $\begin{array}{c}699-44-39 B \\
(\mathrm{pCi} / \mathrm{L})\end{array}$ \\
\hline \multicolumn{5}{|l|}{ Baseline Statistics } \\
\hline Baseline Period & $7 / 7 / 22 / 97-6 / 12 / 01$ & 9/22/99-6/13/02 & 1/13/97-1/18/01 & /4/10/97-6/12/01 \\
\hline Number of Samples & 8 & 8 & 8 & 8 \\
\hline $\operatorname{Mean}(\bar{x})$ & 1.76 & 1.99 & 1.03 & 1.65 \\
\hline Standard Deviation (s) & 0.64 & 0.84 & 0.52 & 0.52 \\
\hline $\mathrm{CV}^{(\mathrm{a})}(\%)$ & 36.5 & 42.3 & 50.6 & 31.3 \\
\hline Fitted Distribution $^{(b)}$ & Normal & Normal & Normal & Normal \\
\hline \multicolumn{5}{|c|}{ Shewhart-CUSUM Control Limits } \\
\hline Control Limit $(\bar{x}+2 s)$ & 3.04 & 3.67 & 2.07 & 2.68 \\
\hline Control Limit $(\bar{x}+3 s)$ & 3.68 & 4.52 & 2.59 & 3.20 \\
\hline Control Limit $(\bar{x}+3.5 \mathrm{~s})$ & 4.00 & 4.93 & 2.85 & 3.46 \\
\hline Control Limit $(\bar{x}+4 s)$ & 4.32 & 5.36 & 3.11 & 3.72 \\
\hline Control Limit $(\bar{x}+4.5 \mathrm{~s})$ & 4.65 & 5.78 & 3.37 & 3.97 \\
\hline \multicolumn{5}{|c|}{ 2-Year Trial Evaluation Data Subsequent to Baseline Period } \\
\hline First Sampling (1/02) & 2.50 & "--- & 2.05 & 1.74 \\
\hline Second Sampling $(7 / 02)$ & 2.60 & --- & 1.92 & 2.14 \\
\hline Third Sampling (1/03) & 2.96 & 2.59 & $1.10 \mathrm{U}$ & 2.55 \\
\hline Fourth Sampling $(7 / 03)$ & 2.09 & 2.46 & 1.38 & 1.84 \\
\hline \multicolumn{5}{|c|}{ (a) Coefficient of variation $=(\mathrm{s} / \overline{\mathrm{x}}) * 100$} \\
\hline
\end{tabular}


Table 4. Gross Beta Baseline Periods, Summary Statistics, and Various Control Limits for the B Pond System Wells

\begin{tabular}{|c|c|c|c|c|}
\hline Wells & $\begin{array}{c}\text { 699-42-42B } \\
(\mathrm{pCi} / \mathrm{L}) \\
\end{array}$ & $\begin{array}{c}\text { 699-43-44 } \\
(\mathrm{pCi} / \mathrm{L}) \\
\end{array}$ & $\begin{array}{c}\text { 699-43-45 } \\
(\mathrm{pCi} / \mathrm{L}) \\
\end{array}$ & $\begin{array}{c}\text { 699-44-39B } \\
(\mathrm{pCi} / \mathrm{L}) \\
\end{array}$ \\
\hline \multicolumn{5}{|l|}{ Baseline Statistics } \\
\hline $\begin{array}{l}\text { Baseline Period } \\
\text { Number of Samples } \\
\text { Mean }(\bar{x}) \\
\text { Standard Deviation (s) } \\
\mathrm{CV}^{(\mathrm{a})}(\%) \\
\text { Fitted Distribution }^{(\mathrm{b})} \\
\end{array}$ & $\begin{array}{c}7 / 22 / 97-6 / 12 / 01 \\
8 \\
6.51 \\
1.11 \\
18.9 \\
\text { Log-Normal } \\
\end{array}$ & $\begin{array}{c}9 / 22 / 99-6 / 13 / 02 \\
8 \\
6.06 \\
1.04 \\
17.1 \\
\text { Normal } \\
\end{array}$ & $\begin{array}{c}1 / 13 / 97-1 / 18 / 01 \\
8 \\
5.91 \\
1.09 \\
18.4 \\
\text { Normal } \\
\end{array}$ & $\begin{array}{c}4 / 10 / 97-6 / 12 / 01 \\
8 \\
5.88 \\
2.35 \\
40.0 \\
\text { Normal } \\
\end{array}$ \\
\hline \multicolumn{5}{|c|}{ Shewhart-CUSUM Control Limits } \\
\hline $\begin{array}{l}\text { Control Limit }(\bar{x}+2 \mathrm{~s}) \\
\text { Control Limit }(\bar{x}+3 \mathrm{~s}) \\
\text { Control Limit }(\bar{x}+3.5 \mathrm{~s}) \\
\text { Control Limit }(\bar{x}+4 \mathrm{~s}) \\
\text { Control Limit }(\bar{x}+4.5 \mathrm{~s}) \\
\end{array}$ & $\begin{array}{r}9.00 \\
10.66 \\
11.60 \\
12.62 \\
13.73 \\
\end{array}$ & $\begin{array}{r}8.13 \\
9.17 \\
9.70 \\
10.21 \\
10.73 \\
\end{array}$ & $\begin{array}{r}8.08 \\
9.17 \\
9.72 \\
10.26 \\
10.80 \\
\end{array}$ & $\begin{array}{l}10.58 \\
12.93 \\
14.10 \\
15.28 \\
16.45 \\
\end{array}$ \\
\hline \multicolumn{5}{|c|}{ 2-Year Trial Evaluation Data Subsequent to Baseline Period } \\
\hline $\begin{array}{l}\text { First Sampling }(1 / 02) \\
\text { Second Sampling }(7 / 02) \\
\text { Third Sampling }(1 / 03) \\
\text { Fourth Sampling }(7 / 03) \\
\end{array}$ & $\begin{array}{l}.00 \\
7.99 \\
5.12 \\
4.99 \\
\end{array}$ & $\begin{array}{l}-- \\
--- \\
5.51 \\
6.48 \\
\end{array}$ & $\begin{array}{l}8.61^{(\mathrm{c})} \\
7.72 \\
5.94 \\
5.33 \\
\end{array}$ & $\begin{array}{l}5.80 \\
5.10 \\
5.36 \\
5.33 \\
\end{array}$ \\
\hline \multicolumn{5}{|c|}{$\begin{array}{l}\text { (a) Coefficient of variation }=(\mathrm{s} / \overline{\mathrm{x}}) * 100 \\
\text { (b) Based on goodness-of-fit test results shown in Table } 1 . \\
\text { (c) Bold indicates number is at or exceeding the lowest control limit }(\bar{x}+2 s) \text {. }\end{array}$} \\
\hline
\end{tabular}

shown in Tables 2 through 4. Results of comparisons have been reported to Ecology via RCRA quarterly reports and important observations are summarized below:

- The lowest control limit ( $\bar{x}+2 \mathrm{~s})$ of $238 \mu \mathrm{S} / \mathrm{cm}$ was either met or exceeded for specific conductance in well 699-43-45 during the sampling events that occurred in January and July 03 (see Table 2 and Figure 5). Exceedances of the lowest CUSUM control limits for specific conductance is due to small but gradual increases as shown in Figure 5 (see discussion in Section 5.1).

- There is no exceedance of any control limit values in any of the B Pond system wells for gross alpha during the 2-year trial evaluation period (see Figure 6).

- The lowest control limit $(\bar{x}+2 \mathrm{~s})$ of $8.08 \mathrm{pCi} / \mathrm{L}$ was exceeded once for gross beta in well 699-43-45 during the first sampling event that occurred in January 2002 (sample value $=8.61 \mathrm{pCi} / \mathrm{L}$ ). This exceedance was not confirmed by results of subsequent sampling events from this well (see Figure 7).

- Gross alpha, gross beta, and specific conductance, all have a natural background resulting from water rock reactions that occur during evolution of the ambient groundwater. This natural background forms a permanent baseline above which changes due to addition from the regulated unit must be detected. Gross alpha, gross beta, and specific conductance are about three to four times lower in Columbia River water (the main source of B Pond water) than in natural background groundwater composition. Thus, the existing concentrations of all three of these constituents will tend to increase 


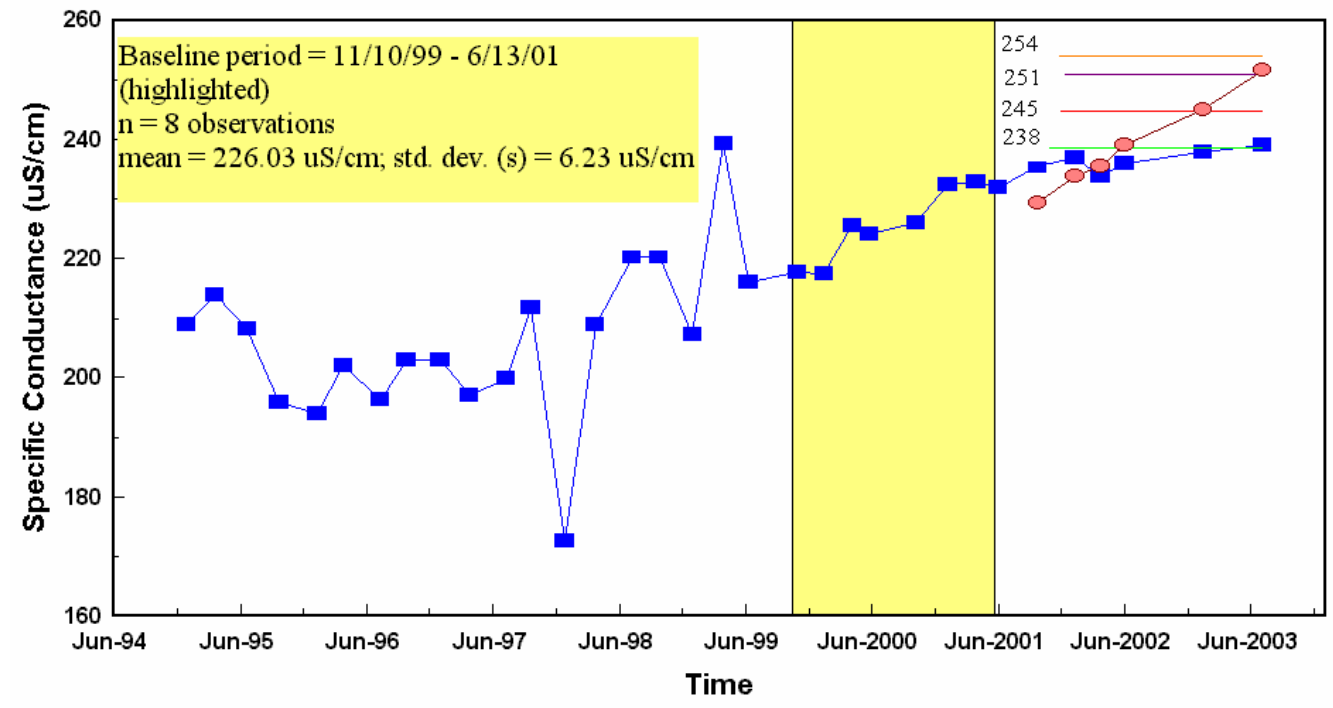

$\begin{array}{lll}- \text { Specific Conductance } & - \text { mean }+2 \mathrm{~s}(238) & - \text { mean }+3 \mathrm{~s}(245) \\ - \text { mean }+4 \mathrm{~s}(251) & \text { mean }+4.5 \mathrm{~s}(254) & -\circ \text { CUSUM (uS/cm) }\end{array}$

Figure 5. Observed Specific Conductance Measurements from Well 699-43-45 Compared with the Combined Shewhart-CUSUM Control Limits from Table 2

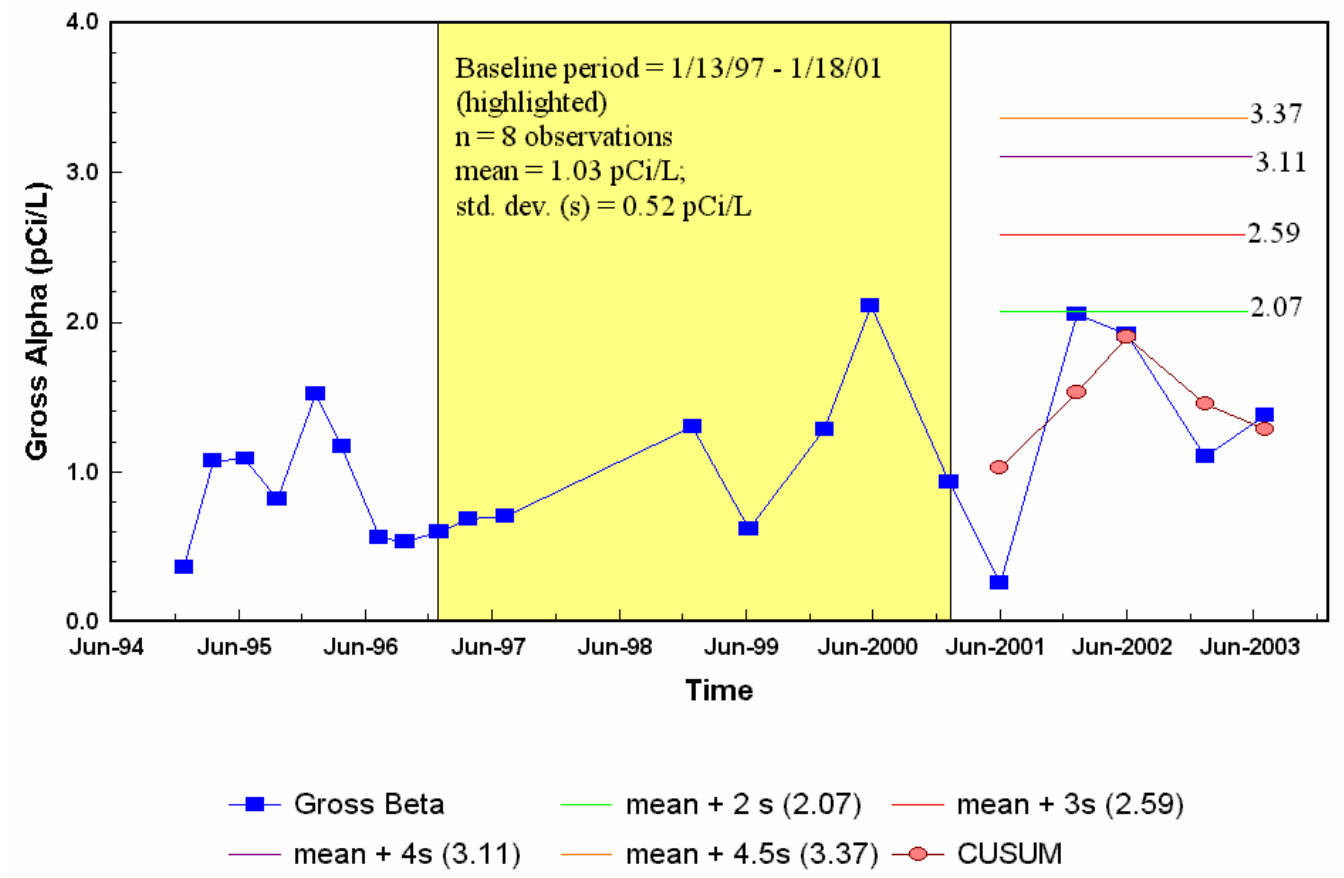

Figure 6. Observed Gross Alpha Measurements from Well 699-43-45 Compared with the Combined Shewhart-CUSUM Control Limits from Table 3 


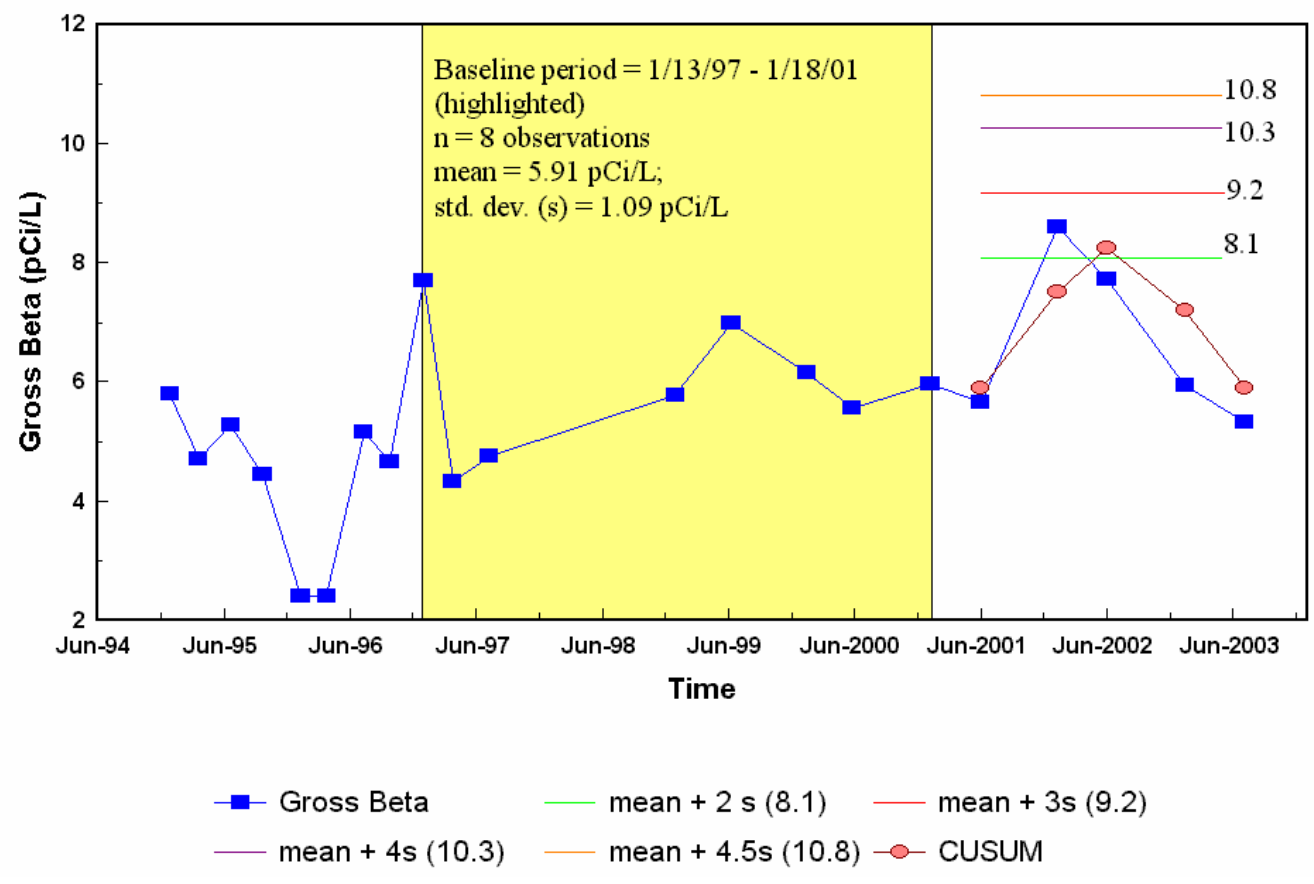

Figure 7. Observed Gross Beta Measurements from Well 699-43-45 Compared with the Combined Shewhart-CUSUM Control Limits from Table 4

in time as natural groundwater conditions resume, and the influence of the relatively dilute pond water subsides. Therefore, baseline concentrations based on the past few years will tend to be lower than in the future as the amount of pond water diluting ambient groundwater diminishes. Accordingly, the baseline should be re-established approximately every 2 years to adjust for this changing condition.

The control chart method may be insensitive to detect real changes if a pre-existing trend is observed in the background data set. A method describing how a trend observed in a background data set could be removed using a transformation suggested by Gibbons (1994, page 165) is presented in Section 5.1. 


\subsection{Statistical Evaluations of 300 Area Process Trench Data}

This section presents results of statistical evaluations at the 300 Area process trenches including evaluating data independence, detection status, normality, and the potential dilution effect of mixing Columbia River water with groundwater. The Shewhart-CUSUM limits provided in Ecology's guidance letter (Appendix A.1) was derived using older monitoring data obtained during 1995 to 1997, which were not adjusted for any possible dilution effect. Ecology's guidance was followed in deriving the revised Shewhart-CUSUM limit using baseline data collected during January 2000 till December 2001. Finally, data obtained during the 2-year trial evaluation period (March or June 2002 till September 2003) are compared with the revised Shewhart-CUSUM control limits. Some wells (i.e., 399-1-10A and 399-110B) and their respective control limits are not provided in the Ecology letter (see Appendix A.1). However, COC data from wells 399-1-10A and 399-1-10B were included in the evaluation for completeness.

\subsection{Background}

The 300 Area process trenches are located in the north portion of the 300 Area (Figure 8). The trenches received effluent discharges of dangerous mixed waste from fuel fabrication laboratories in the 300 Area from 1975 to 1994 . Uranium, cis-DCE, and TCE are the major contaminants of concern. In July 1991, the trenches were modified as part of an expedited response action that involved removing bottom sediment from the inflow end of the trench and placing it at the opposite end of the trench behind a berm. In December 1994, the trenches were administratively isolated and all discharges were terminated. Complete physical isolation occurred in January 1995. The 300 Area process trenches currently are in post-closure care and have a post-closure groundwater monitoring plan, as required by WAC 173-303-610(7).

The 300 Area process trenches groundwater monitoring program bypassed the RCRA detection-level stage and was placed directly in an interim-status groundwater quality assessment-level monitoring program in June 1985 because of elevated concentrations of chlorinated hydrocarbons and uranium. Monitoring wells were constructed in response to a Consent Agreement and Compliance Order issued jointly by Ecology and EPA (Ecology and EPA 1986). From 1988 until November 1996, groundwater monitoring was conducted in accordance with the assessment plan prepared by Schalla et al. (1988).

Final status compliance monitoring became effective in 1996 with modification B of the Hanford Facility RCRA Permit (Ecology 1994). Groundwater monitoring was conducted in accordance with a compliance-level monitoring plan prepared by Lindberg et al. (1995). Sampling results from the first four independent sampling events (December 1996, January, February, and March 1997) confirmed the exceedances of groundwater protection standards for TCE, cis-DCE, and uranium in several downgradient compliance wells. In accordance with WAC 173-303-645 (2)(a)(ii), a revised groundwater monitoring plan for corrective action was proposed to Ecology in 1998. The revised groundwater monitoring plan was not approved by Ecology due to unresolved concerns over the proposed statistical procedures (i.e., the combined Shewhart-CUSUM control chart approach). The compliance-level monitoring plan (Lindberg et al. 1995) remained in effect even though groundwater concentrations exceeded the groundwater protection standards because it has been incorporated by reference at Part VI, Chapter I of the Hanford Facility RCRA Permit (Ecology 1994). In February 1999, Washington State 


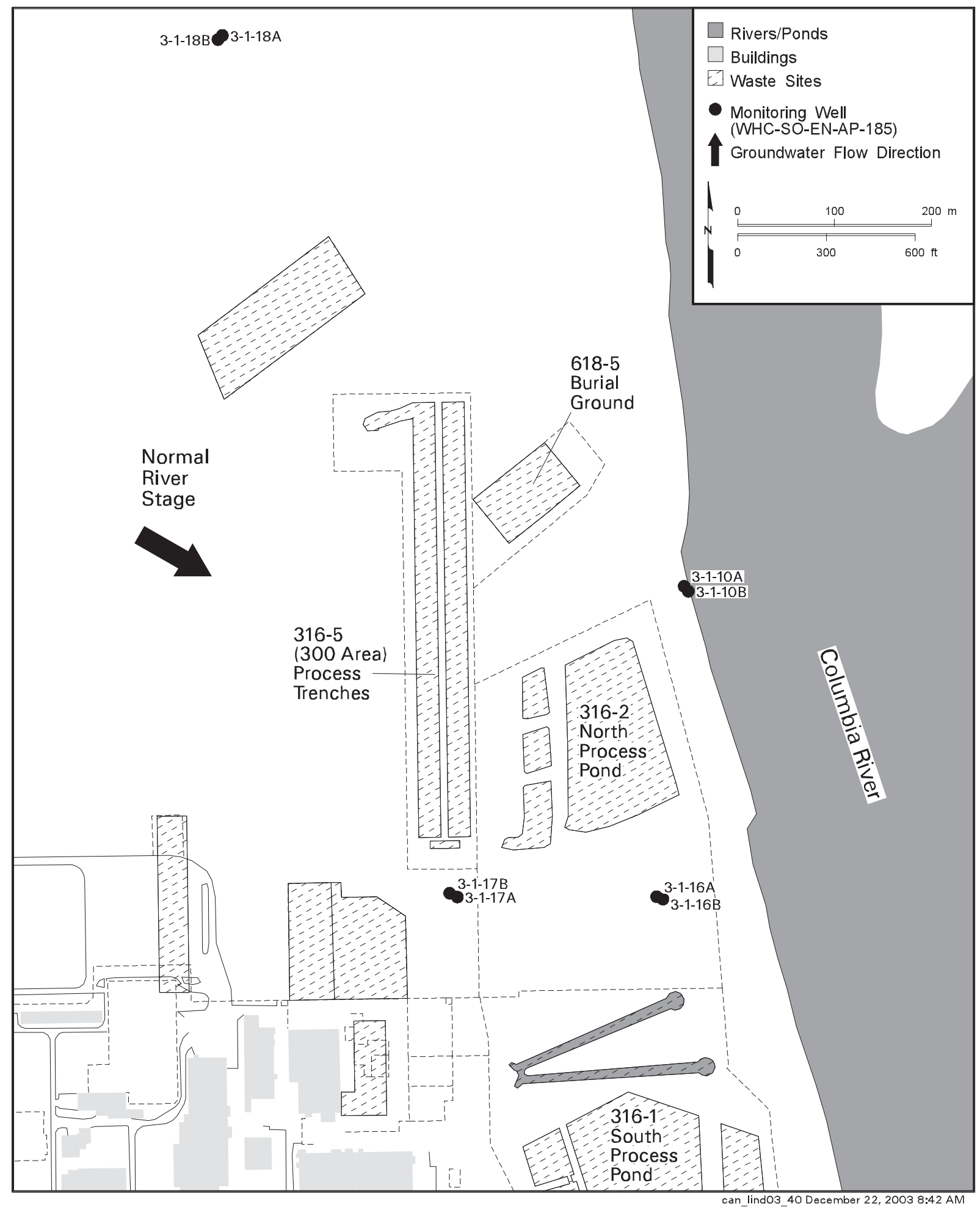

Figure 8. Locations of Groundwater Monitoring Wells at the 300 Area Process Trenches (Lindberg et al. 1995) 
University (WSU) statisticians completed evaluation of the efficacy of the proposed combined ShewhartCUSUM control chart approach for monitoring groundwater quality and endorsed the method (WSU 1999). In May 2001 Ecology issued a letter that approved the proposed combined Shewhart-CUSUM control chart approach and control limits (see Table 1 of Appendix A.1) to be applied at the 300 Area process trenches for a trial period of 2 years, which began in December 2001.

A new groundwater monitoring plan (Lindberg and Chou 2001) was written in August 2001 that included changes in the groundwater monitoring network and introduced the Shewhart-CUSUM statistical method. In December 2001, DOE requested a permit modification and a temporary authorization for changes in post-closure monitoring at the 300 Area process trenches. Ecology denied approval of the proposed plan (Lindberg and Chou 2001). Subsequently, Ecology granted two temporary authorizations allowing the use of the revised groundwater monitoring plan (Lindberg and Chou 2001) to collect data necessary to evaluate the proposed method. The second temporary authorization expired on December 9, 2002. Lindberg et al. (1995) has been in effect since 2002 to meet permit requirements. After September 2003, the 300 Area process trenches is required to revert to the groundwater monitoring regime as described in Part VI, Chapter I of the Hanford Facility RCRA Permit (Ecology 1994).

The permit modification process sought for the 300 Area process trenches in December 2001 required public comments on the modification request. Two key statistical areas of concern raised during the public comment process were:

1. The influence of the Columbia River on groundwater contaminant concentrations (i.e., dilution of groundwater contamination caused by infiltrating Columbia River water) may require data to be segregated or normalized.

2. The assumption of normality of the data may be compromised due to the bimodal nature of the groundwater flow (i.e., groundwater flow direction is generally southeast when the river stage is lowto-normal and south to southwest during the higher river stages such as in June 2002).

The focus of this section is to address the above concerns for the 300 Area process trenches. Ecology will use the data obtained from implementation of Lindberg and Chou (2001) to decide whether the Shewhart-CUSUM statistical approach is appropriate at this regulated unit, pursuant to requirements specified in WAC 173-303-645(8)(i)(i).

\subsection{Independent Samples}

The assumption of independently distributed data was first checked in 1995 when the compliancelevel monitoring plan (Lindberg et al. 1995) for the 300 Area process trenches was written. Based on a well diameter of $0.1016 \mathrm{~m}$ (4-in) and ranges of average linear velocity of groundwater from $0.0645 \mathrm{~m} / \mathrm{d}$ or $0.086 \mathrm{~m} / \mathrm{d}$, sampling every other day would provide the required independent samples. To account for a larger disturbed zone due to purging, monthly sample frequency was used under the compliance monitoring plan (see Section 4.5.3 of Lindberg et al. 1995). The minimum time to obtain independent samples was re-calculated for this report using the most recent information (Hartman et al. 2003, Table A.2). Using a monitoring well diameter of $0.1016 \mathrm{~m}$ and the most recent Darcy flow rates of 0.016 to $48 \mathrm{~m} / \mathrm{d}$ 
(Hartman et al. 2003, Table A.2), Equation 2.2 yields a minimum time of less than 1 day $(0.1016 \mathrm{~m} /$ $48 \mathrm{~m} / \mathrm{d}=0.002 \mathrm{~d})$ to $\sim 7$ days $(0.1016 \mathrm{~m} / 0.016 \mathrm{~m} / \mathrm{d}=6.4 \mathrm{~d})$ to ensure sampling independence. Wells were sampled either on a quarterly or semiannual intervals in accordance with Lindberg and Chou (2001).

\subsection{Detection Status}

In order to arrive at appropriate control limits, the detection history for each COC at each well must first be evaluated. The detection status of constituents of concern was updated in Table 5 using data obtained from January 2000 through September 2003 (the detection status using earlier data was presented in Lindberg and Chou 2001, Table 7.3.1). The updated results are comparable with the data reported in Lindberg and Chou (2001). For statistical evaluation purposes, adjustments for non-detects such as using Cohen's method was not necessary for uranium because the laboratory reported the actual concentration for this analyte. This is often the case when a COC is also a naturally occurring constituent.

Table 5. Detection Status of Constituents of Concern Analyzed for the 300 Area Process Trenches (January 2001 through September 2003)

\begin{tabular}{|c|c|c|c|c|c|}
\hline $\begin{array}{l}\text { Constituent of } \\
\text { Concern }\end{array}$ & $\begin{array}{c}\text { Total Number of } \\
\text { Observations }\end{array}$ & $\begin{array}{l}\text { Number of } \\
\text { Detects }\end{array}$ & $\begin{array}{l}\text { Number of } \\
\text { Non-detects }\end{array}$ & $\begin{array}{c}\text { Detect }^{(a)}(\%) \\
\text { Frequency }^{(a)}(\%)\end{array}$ & $\begin{array}{c}\text { Maximum } \\
\text { Detected Value } \\
(\mu \mathrm{g} / \mathrm{L})\end{array}$ \\
\hline \multicolumn{6}{|c|}{ Well 399-1-16A } \\
\hline cis-DCE & 21 & 11 & 10 & 48 & 0.6 \\
\hline TCE & 21 & 20 & 1 & 95 & 0.65 \\
\hline Uranium & 21 & 21 & 0 & 100 & 136 \\
\hline \multicolumn{6}{|c|}{ Well 399-1-16B } \\
\hline cis-DCE & 21 & 21 & 0 & 100 & 175 \\
\hline TCE & 21 & 21 & 0 & 100 & 3.5 \\
\hline Uranium & 21 & 21 & 0 & 100 & 14.6 \\
\hline \multicolumn{6}{|c|}{ Well 399-1-17A } \\
\hline cis-DCE & 21 & 1 & 20 & 5 & 0.2 \\
\hline TCE & 21 & 19 & 2 & 90 & 0.52 \\
\hline Uranium & 21 & 21 & 0 & 100 & 126 \\
\hline \multicolumn{6}{|c|}{ Well 399-1-17B } \\
\hline cis-DCE & 18 & 18 & 0 & 100 & 4.7 \\
\hline TCE & 18 & 0 & 18 & 0 & ND \\
\hline Uranium & 18 & 11 & 7 & 61 & 3.16 \\
\hline \multicolumn{6}{|c|}{ Well 399-1-10A } \\
\hline cis-DCE & 21 & 2 & 19 & 10 & 0.43 \\
\hline TCE & 21 & 0 & 21 & 0 & ND \\
\hline Uranium & 22 & 22 & 0 & 100 & 235 \\
\hline \multicolumn{6}{|c|}{ Well 399-1-10B } \\
\hline cis-DCE & 19 & 1 & 18 & 5 & 0.25 \\
\hline TCE & 19 & 0 & 19 & 0 & ND \\
\hline Uranium & 18 & 14 & 4 & 78 & 3.19 \\
\hline
\end{tabular}




\subsection{Influence of River Water on Contaminant Concentrations}

To investigate the influence of Columbia River water on the mean concentration of contaminants in groundwater, contaminant data from three pairs of shallow and deep wells (399-1-17A/B, 399-1-16A/B, and 399-1-10A/B) were evaluated. Contaminant concentrations were normalized using methods described in Section 5.2. The term "normalized" as used in this report means the data were adjusted for potential dilution by infiltrating river water that mixes with the contaminated groundwater in the stream bank storage zone during seasonally high river stages (Figure 9).

Wells 399-1-17A, -16A, and -10A monitor the upper portion of the unconfined aquifer where the maximum uranium concentrations are expected to occur. Each of the above wells has a corresponding deeper well (399-1-17B, 399-1-16B, and 399-1-10B) screened in the lower portion of the unconfined aquifer where TCE and cis-DCE are of concern. These chlorinated hydrocarbons are thought to occur at greater depths due to settling of a dense non aqueous phase liquid to the bottom of the aquifer from prior releases. Well 399-1-17A ( $335 \mathrm{~m}$ from the shore line) is the closest to the inflow portion (i.e., the

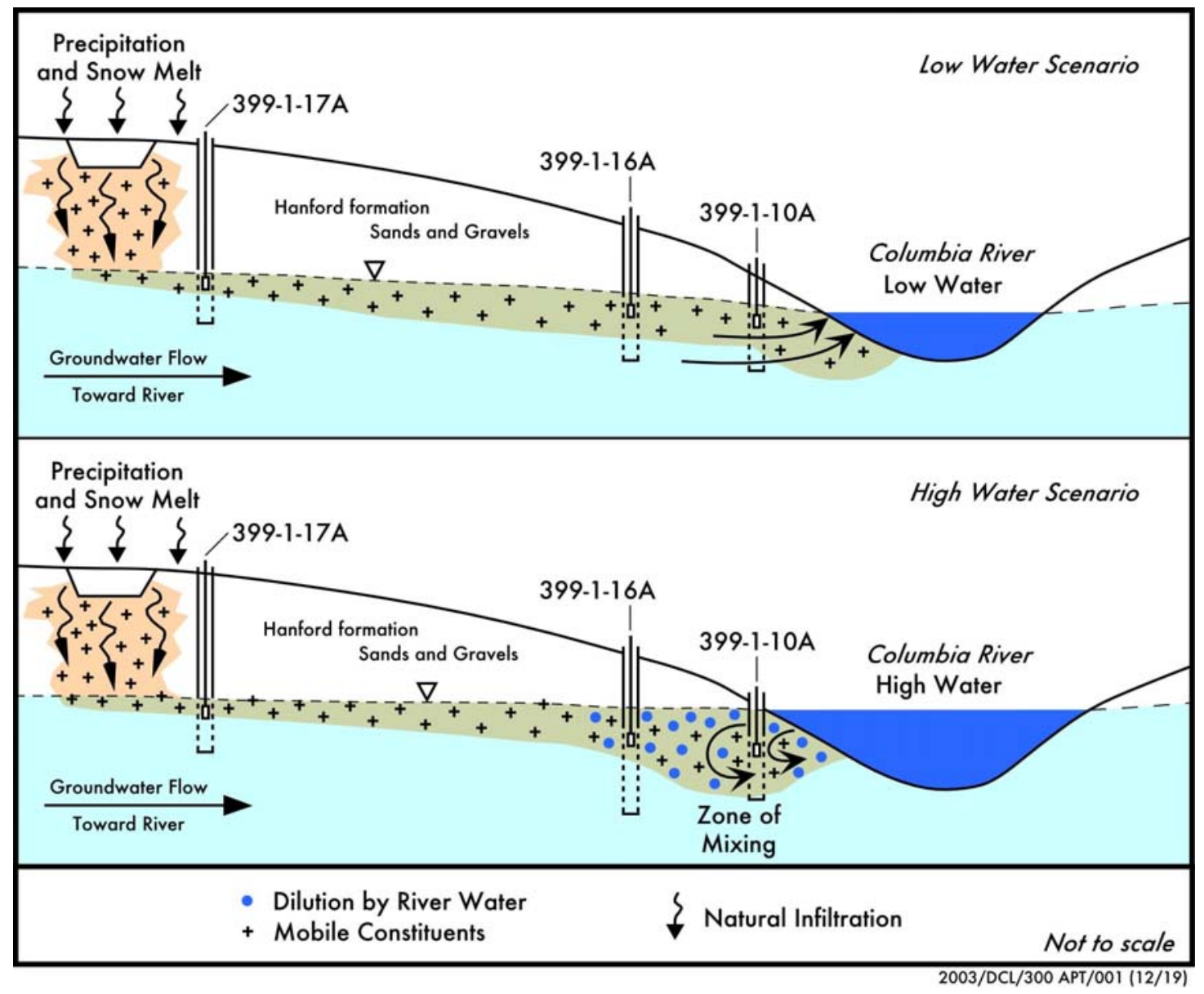

Figure 9. Conceptual Models Depicting Potential Dilution Effect on Contaminant Concentration for the 300 Area process trenches Due to Mixing of Columbia River Water with Groundwater 
source) of the process trenches. Well 399-1-10A (within $4 \mathrm{~m}$ of the shoreline), is closest to the river; and well 399-1-16A (122 m from the shoreline), is located between the source and the Columbia River (see Figure 8).

Table 6 presents the mean, standard deviation, and standard error of the original (unadjusted) data as well as the normalized or dilution-adjusted data. The comparisons were not made for cis-DCE in all shallow wells and in one deep well (399-1-10B) because essentially all of the data were non-detects. Similarly, the comparisons were not made for TCE in shallow well 399-1-10A and in two deep wells, 399-1-10B and 399-1-17B.

The dilution of contaminant concentrations due to mixing of Columbia River water with groundwater is evident for the COCs in wells 399-1-10A/B and 399-1-16 A/B because the unadjusted mean concentrations are lower than the normalized mean concentrations (see Table 6). In contrast, the dilution

Table 6. Comparisons of Mean Concentrations for the Original and Normalized (Adjusted for the Mixing Effect with River Water) Data

\begin{tabular}{|c|c|c|c|c|c|c|c|c|}
\hline \multirow[b]{2}{*}{ Well $^{(a)}$} & \multirow{2}{*}{$\begin{array}{c}\text { Number of } \\
\text { Observations }^{(b)}\end{array}$} & \multicolumn{3}{|c|}{ Original } & \multicolumn{3}{|c|}{ Normalized } & \multirow{2}{*}{$\begin{array}{l}\text { Impact } \\
(\%)^{(c)}\end{array}$} \\
\hline & & Mean & Std Dev & Std Error & Mean & Std Dev & Std Error & \\
\hline \multicolumn{9}{|c|}{ "Uranium $(\mu \mathrm{g} / \mathrm{L}):$ Shallow Wells } \\
\hline $1-10 \mathrm{~A}$ & 38 & 61.8 & 42.7 & 6.9 & 74.6 & 40.3 & 6.5 & -21 \\
\hline $1-16 \mathrm{~A}$ & 38 & 86.5 & 26.9 & 4.4 & 107.4 & 32.0 & 5.2 & -24 \\
\hline $1-17 \mathrm{~A}$ & 37 & 95.1 & 44.8 & 7.4 & 98.2 & 60.4 & 9.9 & -3 \\
\hline \multicolumn{9}{|c|}{ Uranium $(\mu \mathrm{g} / \mathrm{L})$ : Deep Wells } \\
\hline $1-10 \mathrm{~B}$ & 29 & 0.24 & 0.59 & 0.11 & 0.29 & 0.70 & 0.13 & -21 \\
\hline $1-16 \mathrm{~B}$ & 36 & 12.5 & 1.8 & 0.29 & 14.7 & 2.7 & 0.45 & -17 \\
\hline $1-17 \mathrm{~B}$ & 30 & 0.30 & 0.68 & 0.12 & 0.29 & 0.67 & 0.12 & -1 \\
\hline \multicolumn{9}{|c|}{ cis-DCE $(\mu \mathrm{g} / \mathrm{L}):$ Shallow Wells } \\
\hline $1-10 \mathrm{~A}$ & 37 & $\mathrm{NC}$ & $\mathrm{NC}$ & $\mathrm{NC}$ & $\mathrm{NC}$ & $\mathrm{NC}$ & $\mathrm{NC}$ & $\mathrm{NC}$ \\
\hline $1-16 \mathrm{~A}$ & 37 & $\mathrm{NC}$ & $\mathrm{NC}$ & $\mathrm{NC}$ & $\mathrm{NC}$ & $\mathrm{NC}$ & $\mathrm{NC}$ & $\mathrm{NC}$ \\
\hline $1-17 \mathrm{~A}$ & 36 & $\mathrm{NC}$ & $\mathrm{NC}$ & $\mathrm{NC}$ & $\mathrm{NC}$ & $\mathrm{NC}$ & $\mathrm{NC}$ & $\mathrm{NC}$ \\
\hline \multicolumn{9}{|c|}{ cis-DCE $(\mu \mathrm{g} / \mathrm{L}):$ Deep Wells } \\
\hline $1-10 \mathrm{~B}$ & 34 & $\mathrm{NC}$ & $\mathrm{NC}$ & $\mathrm{NC}$ & $\mathrm{NC}$ & $\mathrm{NC}$ & $\mathrm{NC}$ & $\mathrm{NC}$ \\
\hline $1-16 \mathrm{~B}$ & 37 & 148.8 & 18.3 & 3.0 & 172.3 & 23.5 & 3.9 & -16 \\
\hline $1-17 \mathrm{~B}$ & 30 & 2.5 & 0.98 & 0.18 & 2.5 & 0.98 & 0.18 & -0.1 \\
\hline \multicolumn{9}{|c|}{ TCE $(\mu \mathrm{g} / \mathrm{L}):$ Shallow Wells } \\
\hline $1-10 \mathrm{~A}$ & 37 & $\mathrm{NC}$ & $\mathrm{NC}$ & $\mathrm{NC}$ & $\mathrm{NC}$ & $\mathrm{NC}$ & $\mathrm{NC}$ & $\mathrm{NC}$ \\
\hline $1-16 \mathrm{~A}$ & 37 & 0.51 & 0.25 & 0.04 & 0.71 & 0.55 & 0.09 & -39 \\
\hline $1-17 \mathrm{~A}$ & 36 & 0.52 & 0.50 & 0.08 & 0.55 & 0.61 & 0.10 & -6 \\
\hline \multicolumn{9}{|c|}{ TCE $(\mu \mathrm{g} / \mathrm{L}):$ Deep Wells } \\
\hline $1-10 \mathrm{~B}$ & 34 & $\mathrm{NC}$ & $\mathrm{NC}$ & $\mathrm{NC}$ & $\mathrm{NC}$ & $\mathrm{NC}$ & $\mathrm{NC}$ & $\mathrm{NC}$ \\
\hline $1-16 \mathrm{~B}$ & 37 & 3.6 & 1.7 & 0.27 & 4.3 & 2.2 & 0.36 & -18 \\
\hline $1-17 \mathrm{~B}$ & 34 & $\mathrm{NC}$ & $\mathrm{NC}$ & $\mathrm{NC}$ & $\mathrm{NC}$ & $\mathrm{NC}$ & $\mathrm{NC}$ & $\mathrm{NC}$ \\
\hline \multicolumn{9}{|c|}{$\begin{array}{l}\text { (a) Well prefix } 399 \text { omitted. } \\
\text { (b) Number of observations are samples collected from } 1998 \text { to September } 2003 \text { where duplicate measurements } \\
\text { were averaged. } \\
\text { (c) Calculated as (original mean - normalized mean)/original mean. } \\
\text { NC = Not calculated because essentially all of the data are not detected. }\end{array}$} \\
\hline
\end{tabular}


of Columbia River water is negligible in well pair 399-1-17A/B; and normalized mean concentrations are essentially the same as those calculated based on original measurements.

Concentrations of normalized and original uranium data versus time in well 399-1-10A and 399-117A were plotted in Figures 10 and 11, respectively. Figure 10 demonstrates that dilution indeed occurs for well 399-1-10A; while Figure 11 shows that there is little, if any, dilution impact from the river for

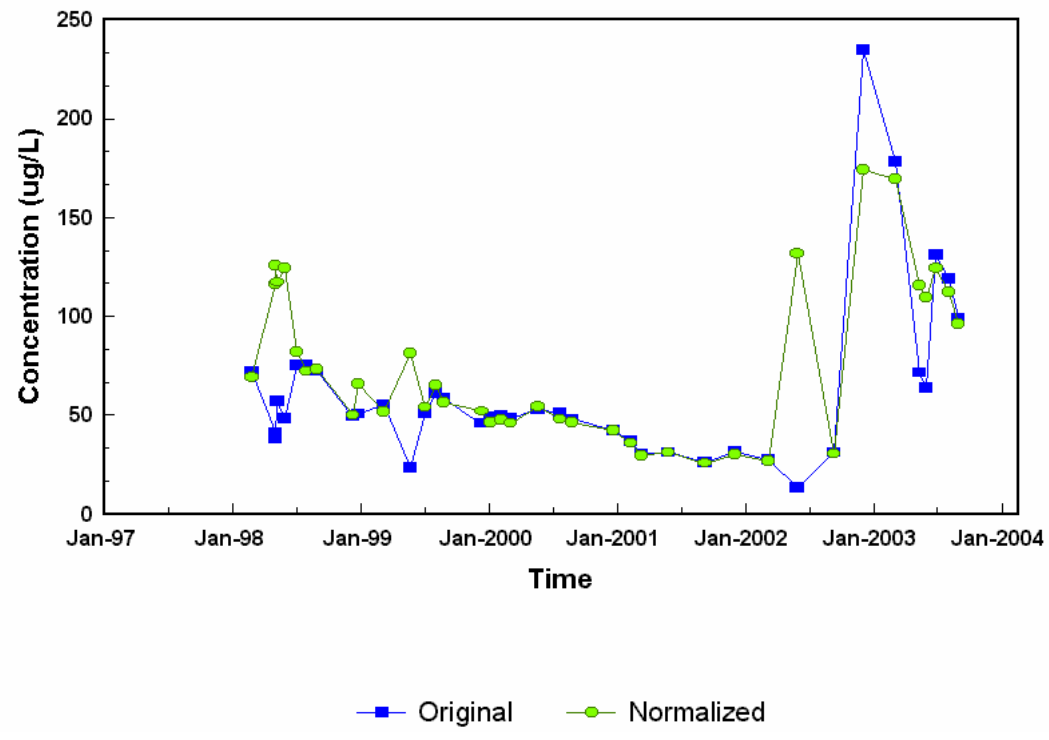

Figure 10. Normalized and Original Uranium Concentrations versus Time for Well 399-1-10A

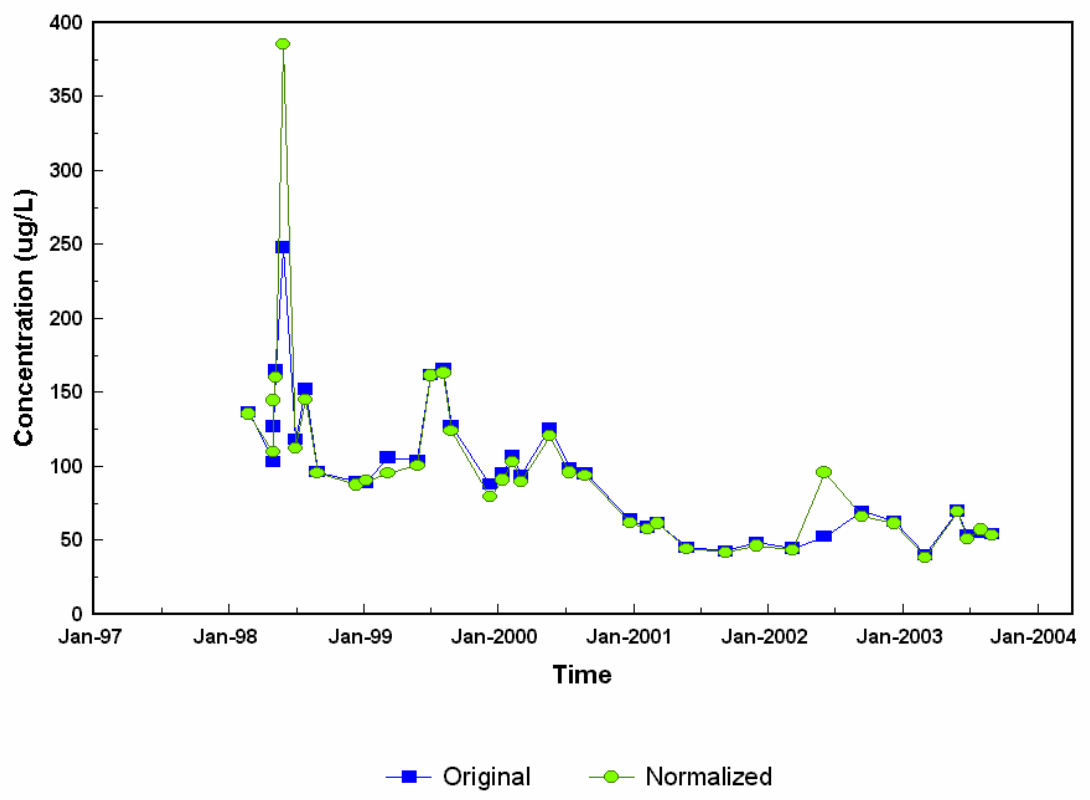

Figure 11. Normalized and Original Uranium Concentrations versus Time for Well 399-1-17A 
well 399-1-17A. The dilution correction after September 2002 shown in Figure 10 resulted in lowering the uranium concentrations rather than increasing the concentrations as would be expected for mixing with river water. This deviation is attributed to an additional input of dissolved salts that caused the specific conductance of the groundwater samples during this period to be higher than the background assumed for the dilution correction (see Section 5.2 for discussion of assumptions and conditions).

\subsection{Test for Normality}

Initial evaluation of the 300 Area process trenches monitoring network results (from 1995 to 1997) indicated that a normal distribution was a reasonable approximation of the data. This assumption was used in subsequent discussions with Ecology in reaching an agreement (see Appendix A.1) that led to the plan (Lindberg and Chou 2001). One public concern was that the assumption of normality may be compromised due to the bimodal nature of groundwater flow direction (i.e., high river stage reverses the groundwater flow direction for wells near the river resulting in mixing and dilution of groundwater with river water). To evaluate the impact of this effect, the original measured data as well as corresponding data adjusted for dilution were both tested for the normality assumption using Shapiro and Wilk's W test as described in Section 2.2. The results are presented in Table 7. It should be noted that the baseline periods shown in Table 7 are updates of that presented in Lindberg and Chou (2001; e.g., March 1995 to June 1997, Table 7.2). The normality assumption is not tested for: 1) cis-DCE in wells 399-1-10A, 3991-10B, 399-1-16A, and 399-1-17A; and 2) for TCE in wells 399-1-10A, 399-1-10B, and 399-1-17B because essentially all data collected during the baseline period were non-detects.

Table 7 shows that except for two cases, the normality test results are the same for dilution corrected data as for the uncorrected data. The exceptions were for TCE in following two wells:

1. Normal distribution is found to be a reasonable distribution based on the original data for well 3991-16A. However, a log-normal distribution is a better fit for the adjusted TCE data because the correction rendered the maximum baseline value (original value $=0.65 \mu \mathrm{g} / \mathrm{L}$, adjusted value $=$ $0.72 \mu \mathrm{g} / \mathrm{L}$ collected on March 21, 2000) too large (in relation to the rest of the baseline data) to represent a data point coming from a normal distribution. Therefore, the control limit for TCE in this well was calculated based on a log-normal distribution using data corrected for the dilution effect.

2. Neither normal nor log-normal distribution is a reasonable approximation for the unadjusted data in well 399-1-16B because too many sample values are exactly equal to each other (tied) for the original baseline data set. However, the problem of the tied values no longer exists for the adjusted data set; and normal distribution is found to be reasonable.

\subsection{Baseline Summary Statistics and Control Limits}

Summary statistics were calculated for the detected COCs using baseline data sets adjusted for the dilution impacts for well pairs 399-1-10A/B and 399-1-16A/B. Original measured values were used for well pair 399-1-17A/B because there is no evidence of dilution impact from the river water. Baseline summary statistics are presented in Table 8 . The combined Shewhart-CUSUM control limits were 
Table 7. Results of Shapiro-Wilk's Test for the 300 Area Process Trenches Using the Original and Adjusted Data

\begin{tabular}{|c|c|c|c|c|c|c|c|}
\hline \multirow[b]{2}{*}{ Constituent } & \multirow{2}{*}{$\begin{array}{c}\text { Baseline } \\
\text { Period }\end{array}$} & \multirow{2}{*}{$\begin{array}{c}\text { Baseline } \\
\text { Observation }\end{array}$} & \multirow{2}{*}{$\begin{array}{c}\text { Critical } \\
\text { Value }\end{array}$} & \multicolumn{2}{|c|}{ Original Data } & \multicolumn{2}{|c|}{ Adjusted Data } \\
\hline & & & & W-Stat. & Dist. & W-Stat. & Dist. \\
\hline \multicolumn{8}{|c|}{ Well 399-1-10A } \\
\hline Cis-DCE & \multirow{3}{*}{$\begin{array}{c}1 / 24 / 00 \text { to } \\
12 / 19 / 01\end{array}$} & $12^{(\mathrm{a})}$ & 0.859 & $\mathrm{NC}$ & $\mathrm{NC}$ & $\mathrm{NC}$ & $\mathrm{NC}$ \\
\hline TCE & & $12^{(\mathrm{a})}$ & 0.859 & $\mathrm{NC}$ & $\mathrm{NC}$ & $\mathrm{NC}$ & $\mathrm{NC}$ \\
\hline Uranium & & 12 & 0.859 & 0.877 & Normal & 0.909 & Normal \\
\hline \multicolumn{8}{|c|}{ Well 399-1-10B } \\
\hline Cis-DCE & \multirow{3}{*}{$\begin{array}{c}1 / 24 / 00 \\
\text { to } \\
12 / 19 / 01\end{array}$} & $11^{\text {(a) }}$ & 0.850 & $\mathrm{NC}$ & $\mathrm{NC}$ & $\mathrm{NC}$ & $\mathrm{NC}$ \\
\hline TCE & & $11^{(\mathrm{a})}$ & 0.850 & $\mathrm{NC}$ & $\mathrm{NC}$ & $\mathrm{NC}$ & $\mathrm{NC}$ \\
\hline Uranium & & 11 & 0.850 & 0.898 & Log-Normal & 0.898 & Log-Normal \\
\hline \multicolumn{8}{|c|}{ Well 399-1-16A } \\
\hline Cis-DCE & \multirow{3}{*}{$\begin{array}{c}1 / 25 / 00 \\
\text { to } 12 / 17 / 01\end{array}$} & 12 & 0.859 & $\mathrm{NC}$ & $\mathrm{NC}$ & $\mathrm{NC}$ & $\mathrm{NC}$ \\
\hline TCE & & 12 & 0.859 & 0.914 & Normal & 0.874 & Log-Normal \\
\hline Uranium & & 12 & 0.859 & 0.937 & Normal & 0.955 & Normal \\
\hline \multicolumn{8}{|c|}{ Well 399-1-16B } \\
\hline Cis-DCE & \multirow{3}{*}{$\begin{array}{c}1 / 25 / 00 \\
\text { to } 12 / 17 / 01\end{array}$} & 12 & 0.859 & 0.896 & Normal & 0.913 & Normal \\
\hline TCE & & 12 & 0.859 & 0.827 & Neither $^{(b)}$ & 0.921 & Normal \\
\hline Uranium & & 12 & 0.859 & 0.910 & Normal & 0.961 & Normal \\
\hline \multicolumn{8}{|c|}{ Well 399-1-17A } \\
\hline Cis-DCE & \multirow{3}{*}{$\begin{array}{c}2 / 1 / 00 \\
\text { to } 12 / 18 / 01\end{array}$} & $12^{(\mathrm{a})}$ & 0.859 & $\mathrm{NC}$ & $\mathrm{NC}$ & $\mathrm{NC}$ & $\mathrm{NC}$ \\
\hline TCE & & 12 & 0.859 & 0.981 & Normal & 0.973 & Normal \\
\hline Uranium & & 12 & 0.859 & 0.911 & Normal & 0.914 & Normal \\
\hline \multicolumn{8}{|c|}{ Well 399-1-17B } \\
\hline Cis-DCE & \multirow{3}{*}{$\begin{array}{l}1 / 25 / 00 \\
\text { to } 12 / 18 / 01\end{array}$} & 11 & 0.850 & 0.940 & Normal & 0.944 & Normal \\
\hline TCE & & $11^{(\mathrm{a})}$ & 0.850 & $\mathrm{NC}$ & $\mathrm{NC}$ & $\mathrm{NC}$ & $\mathrm{NC}$ \\
\hline Uranium & & 11 & 0.850 & 0.679 & Neither $^{(b)}$ & 0.680 & Neither $^{(b)}$ \\
\hline \multicolumn{8}{|c|}{$\begin{array}{l}\text { (a) Shapiro-Wilk's test for normalit } \\
\text { Table } 8 \text { for details). } \\
\text { (b) Neither normal nor log-normal. } \\
\text { NC = Not calculated. }\end{array}$} \\
\hline
\end{tabular}

revised based on the updated baseline data set after considering the potential dilution impact from Columbia River water and the normality test results. A summary of various control limits for the 300 Area process trenches is presented in Table 9.

One of the $\mathrm{COC}$, uranium, has a natural background resulting from water-rock reaction during evolution of the ambient groundwater. For the upper unconfined aquifer the maximum observed background concentration (unfiltered samples) for the Hanford Site is $13.4 \mu \mathrm{g} / \mathrm{L}$ (see Table 5-2, page 5-23 of DOE 1997). If computed control limits fall below this concentration, then the natural background should become the control limit. However, for wells completed in the deeper portion of the unconfined aquifer where reducing conditions often prevail, the natural uranium concentrations are maintained at much lower concentrations (typically $<0.1 \mu \mathrm{g} / \mathrm{L}$ ). Since there is no established background for this portion of the 
Table 8. Baseline Summary Statistics for Detected Constituents of Concern Analyzed for the 300 Area Process Trenches

\begin{tabular}{|c|c|c|c|c|c|c|c|}
\hline Constituent & Baseline Period & $\begin{array}{c}\text { Baseline } \\
\text { Observation }\end{array}$ & Detected & $\begin{array}{l}\text { Non- } \\
\text { Detect }\end{array}$ & Detect $\%$ & $\begin{array}{c}\bar{x} \\
(1 \mathrm{~g} / \mathrm{L})\end{array}$ & $\begin{array}{c}\mathrm{s} \\
(1 \mathrm{~g} / \mathrm{L})\end{array}$ \\
\hline \multicolumn{8}{|c|}{ PWell 399-1-10A } \\
\hline Cis-DCE & \multirow[t]{3}{*}{$1 / 24 / 00$ to $12 / 19 / 01$} & 12 & 1 & 11 & 8 & $\mathrm{NC}$ & $\mathrm{NC}$ \\
\hline TCE & & 12 & 0 & 12 & 0 & $\mathrm{NC}$ & $\mathrm{NC}$ \\
\hline Uranium $^{(a)}$ & & 12 & 12 & 0 & 100 & 40.4 & 9.25 \\
\hline \multicolumn{8}{|c|}{ Well 399-1-10B } \\
\hline Cis-DCE & \multirow[t]{3}{*}{$1 / 24 / 00$ to $12 / 19 / 01$} & 11 & 1 & 10 & 9 & $\mathrm{NC}$ & $\mathrm{NC}$ \\
\hline TCE & & 11 & 0 & 11 & 0 & $\mathrm{NC}$ & $\mathrm{NC}$ \\
\hline Uranium $^{(a)}$ & & 11 & 7 & 4 & 64 & $0.19^{(\mathrm{b})}$ & $0.24^{(\mathrm{b})}$ \\
\hline \multicolumn{8}{|c|}{ Well 399-1-16A } \\
\hline Cis-DCE & \multirow[t]{3}{*}{$1 / 25 / 00$ to $12 / 17 / 01$} & 12 & 4 & 8 & 33 & $\mathrm{NC}$ & $\mathrm{NC}$ \\
\hline $\mathrm{TCE}^{(\mathrm{a})}$ & & 12 & 12 & 0 & 100 & $0.49^{(\mathrm{b})}$ & $0.085^{(\mathrm{b})}$ \\
\hline Uranium $^{(a)}$ & & 12 & 12 & 0 & 100 & 101.7 & 26.5 \\
\hline \multicolumn{8}{|c|}{ Well 399-1-16B } \\
\hline Cis-DCE $^{(a)}$ & \multirow[t]{3}{*}{$1 / 25 / 00$ to $12 / 17 / 01$} & 12 & 12 & 0 & 100 & 173.59 & 22.21 \\
\hline $\mathrm{TCE}^{(\mathrm{a})}$ & & 12 & 12 & 0 & 100 & 2.99 & 0.54 \\
\hline Uranium $^{(a)}$ & & 12 & 12 & 0 & 100 & 14.28 & 2.58 \\
\hline \multicolumn{8}{|c|}{ Well 399-1-17A } \\
\hline cis-DCE & \multirow[t]{3}{*}{$2 / 1 / 00$ to $12 / 18 / 01$} & 12 & 0 & 12 & 0 & $\mathrm{NC}$ & $\mathrm{NC}$ \\
\hline TCE & & 12 & 11 & 1 & 92 & 0.32 & 0.10 \\
\hline Uranium & & 12 & 12 & 0 & 100 & 78.1 & 27.7 \\
\hline \multicolumn{8}{|c|}{ Well 399-1-17B } \\
\hline cis-DCE & \multirow[t]{3}{*}{$1 / 25 / 00$ to $12 / 18 / 01$} & 11 & 11 & 0 & 100 & 2.99 & 0.94 \\
\hline TCE & & 11 & 0 & 11 & 0 & $\mathrm{NC}$ & $\mathrm{NC}$ \\
\hline Uranium & & 11 & 5 & 6 & 45 & 0.174 & 0.264 \\
\hline \multicolumn{8}{|c|}{$\begin{array}{l}\text { (a) Calculated based on data corrected for river dilutio } \\
\text { (b) Calculated based on log-normal distribution. } \\
\mathrm{NC}=\text { Not calculated because essentially all data were } \mathrm{n}\end{array}$} \\
\hline
\end{tabular}

aquifer, the maximum observed value (adjusted or unadjusted) will be the control limit. For constituents other than uranium where the majority of the baseline data were non-detects (i.e., cis-DCE in wells 399-110A, 399-1-10B and 399-1-17A; and TCE in wells 399-1-10A, 399-1-10B, and 399-1-17B), the most recently determined quantitation limit (e.g., Hartman et al. 2003, Table B.24) will be used as control limits.

\subsection{Data Comparisons}

Uranium, cis-DCE, and TCE data collected during March 2002 to September 2003 were evaluated against the revised control limits established in the previous section. For each well under evaluation, there were seven to ten sampling events during the 2-year trial period. Tables 10 through 11 provide the 
Table 9. Summary of Various Control Limits at the 300 Area Process Trenches

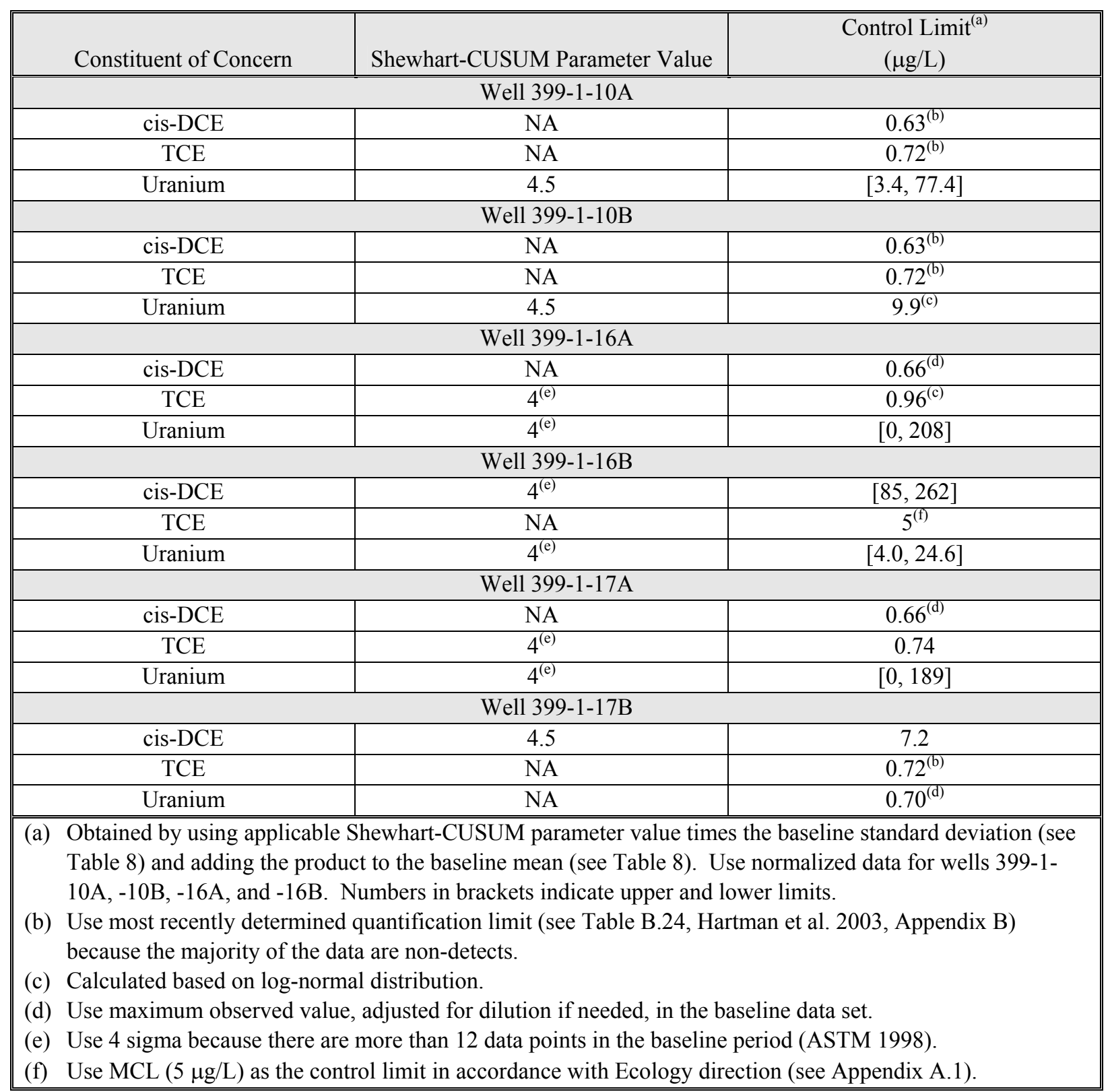


Table 10. Uranium Control Limits and 2-Year Trial Evaluation Data for the 300 Area Process Trenches

\begin{tabular}{|c|c|c|c|c|c|c|}
\hline Well & $\begin{array}{c}399-1-10 \mathrm{~A}^{(\mathrm{a})} \\
(\mu \mathrm{g} / \mathrm{L})\end{array}$ & $\begin{array}{c}399-1-10 \mathrm{~B}^{(\mathrm{a})} \\
(\mu \mathrm{g} / \mathrm{L})\end{array}$ & $\begin{array}{c}399-1-16 \mathrm{~A}^{(\mathrm{a})} \\
(\mu \mathrm{g} / \mathrm{L})\end{array}$ & $\begin{array}{c}399-1-16 \mathrm{~B}^{(\mathrm{a})} \\
(\mu \mathrm{g} / \mathrm{L})\end{array}$ & $\begin{array}{c}399-1-17 \mathrm{~A} \\
(\mu \mathrm{g} / \mathrm{L})\end{array}$ & $\begin{array}{c}399-1-17 \mathrm{~B} \\
(\mu \mathrm{g} / \mathrm{L})\end{array}$ \\
\hline Control Limit $^{(\mathrm{b})}$ & {$[3.4,77.4]$} & 9.9 & {$[0,208]$} & {$[4,24.6]$} & {$[0,189]$} & 0.70 \\
\hline \multicolumn{7}{|c|}{ 2-Year Trial Evaluation Data Subsequent to Baseline Period } \\
\hline $\begin{array}{l}\text { First } \\
\text { Sampling } \\
(03 / 02)\end{array}$ & 26.9 & NA & 68.2 & 15.9 & 44.7 & NA \\
\hline $\begin{array}{l}\text { Second } \\
\text { Sampling } \\
(06 / 02)\end{array}$ & $132.0^{(\mathrm{c})}$ & 0.122 & 124.9 & 15.9 & 52.5 & 0.570 \\
\hline $\begin{array}{l}\text { Third Sampling } \\
(09 / 02)\end{array}$ & 30.6 & NA & 75.6 & 12.3 & 69.6 & NA \\
\hline $\begin{array}{l}\text { Fourth Sampling } \\
(12 / 02)\end{array}$ & $174.5^{(\mathrm{c})}$ & 0.127 & 90.2 & 14.1 & 62.8 & 0.721 \\
\hline $\begin{array}{l}\text { Fifth Sampling } \\
(03 / 03)\end{array}$ & $169.5^{(\mathrm{c})}$ & 0.212 & 62.7 & 14.6 & 40.0 & $3.16^{(c)}$ \\
\hline $\begin{array}{l}\text { Sixth Sampling } \\
(05 / 03)\end{array}$ & $115.7^{(c)}$ & NA & NA & NA & NA & NA \\
\hline $\begin{array}{l}\text { Seventh } \\
\text { Sampling } \\
(06 / 03)\end{array}$ & $109.7^{(\mathrm{c})}$ & 0.128 & 83.2 & 15.5 & 69.7 & 0.0085 \\
\hline $\begin{array}{l}\text { Eighth Sampling } \\
(07 / 03)\end{array}$ & $124.4^{(c)}$ & 0.937 & 77.4 & 12.9 & 53.4 & $2.02^{(\mathrm{c})}$ \\
\hline $\begin{array}{l}\text { Ninth Sampling } \\
(08 / 03)\end{array}$ & $112.3^{(c)}$ & 3.803 & 84.3 & 12.8 & 55.4 & 0.161 \\
\hline $\begin{array}{l}\text { Tenth Sampling } \\
(09 / 03)\end{array}$ & $96.5^{(\mathrm{c})}$ & 0.230 & 79.0 & 10.5 & 54.5 & 0.220 \\
\hline $\begin{array}{l}\text { (a) Concentratio } \\
\text { (b) Control limit } \\
\text { (c) Bold indicate } \\
\mathrm{NA}=\text { Not availab }\end{array}$ & $\begin{array}{l}\text { were normali } \\
\text { are obtained fr } \\
\text { exceedance of }\end{array}$ & $\begin{array}{l}\text { d (adjusted) fo } \\
\text { n Table } 9 . \\
\text { pper control li }\end{array}$ & the mixing of $r$ & er water with & undwater. & \\
\hline
\end{tabular}


Table 11. cis1,2-Dichloroethene Control Limits and 2-Year Trial Evaluation Data for the 300 Area Process Trenches

\begin{tabular}{|c|c|c|c|c|c|c|}
\hline Well & $\begin{array}{l}399-1-10 \mathrm{~A}^{(\mathrm{a})} \\
\quad(\mu \mathrm{g} / \mathrm{L})\end{array}$ & $\begin{array}{l}399-1-10 \mathrm{~B}^{(\mathrm{a})} \\
(\mu \mathrm{g} / \mathrm{L})\end{array}$ & $\begin{array}{l}399-1-16 \mathrm{~A}^{(\mathrm{a})} \\
(\mu \mathrm{g} / \mathrm{L})\end{array}$ & $\begin{array}{l}399-1-16 B^{(a)} \\
(\mu \mathrm{g} / \mathrm{L})\end{array}$ & $\begin{array}{c}\begin{array}{l}399-1-17 \mathrm{~A} \\
(\mu \mathrm{g} / \mathrm{L})\end{array}\end{array}$ & $\begin{array}{c}\begin{array}{l}399-1-17 \mathrm{~B} \\
(\mu \mathrm{g} / \mathrm{L})\end{array}\end{array}$ \\
\hline $\begin{array}{l}\text { Control } \\
\text { Limit }^{(b)}\end{array}$ & 0.63 & 0.63 & 0.66 & {$[85,262]$} & 0.66 & 7.2 \\
\hline \multicolumn{7}{|c|}{ 2-Year Trial Evaluation Data Subsequent to Baseline Period } \\
\hline $\begin{array}{l}\text { First } \\
\text { Sampling } \\
(03 / 02)\end{array}$ & $\overline{0.24 \mathrm{U}}$ & NA & 0.48 & 155.8 & $0.24 \mathrm{U}$ & NA \\
\hline $\begin{array}{l}\text { Second } \\
\text { Sampling } \\
(06 / 02)\end{array}$ & $0.24 \mathrm{U}$ & $0.24 \mathrm{U}$ & $0.24 \mathrm{U}$ & 180.8 & $0.24 \mathrm{U}$ & 1.4 \\
\hline $\begin{array}{l}\text { Third } \\
\text { Sampling } \\
(09 / 02)\end{array}$ & $0.24 \mathrm{U}$ & NA & $0.24 \mathrm{U}$ & 171.3 & $0.24 \mathrm{U}$ & NA \\
\hline $\begin{array}{l}\text { Fourth } \\
\text { Sampling } \\
(12 / 02)\end{array}$ & $0.06 \mathrm{U}$ & $0.06 \mathrm{U}$ & 0.28 & 160.7 & $0.06 \mathrm{U}$ & 0.8 \\
\hline $\begin{array}{l}\text { Fifth } \\
\text { Sampling } \\
(03 / 03)\end{array}$ & $0.06 \mathrm{U}$ & $0.06 \mathrm{U}$ & 0.37 & 180.8 & $0.06 \mathrm{U}$ & 1.2 \\
\hline $\begin{array}{l}\text { Sixth } \\
\text { Sampling } \\
(06 / 03)\end{array}$ & $0.06 \mathrm{U}$ & $0.06 \mathrm{U}$ & 0.54 & 157.4 & $0.06 \mathrm{U}$ & 1.0 \\
\hline $\begin{array}{l}\text { Seventh } \\
\text { Sampling } \\
(07 / 03)\end{array}$ & 0.14 & $0.06 \mathrm{U}$ & 0.35 & 157.4 & $0.06 \mathrm{U}$ & 1.8 \\
\hline $\begin{array}{l}\text { Eighth } \\
\text { Sampling } \\
(08 / 03)\end{array}$ & $0.06 \mathrm{U}$ & $0.06 \mathrm{U}$ & 0.40 & 147.7 & $0.06 \mathrm{U}$ & 2.7 \\
\hline $\begin{array}{l}\text { Ninth } \\
\text { Sampling } \\
(09 / 03)\end{array}$ & $0.06 \mathrm{U}$ & $0.06 \mathrm{U}$ & 0.25 & 182.7 & 0.20 & 2.8 \\
\hline $\begin{array}{l}\text { (a) Conce } \\
\text { not pe } \\
\text { (b) Contr } \\
\mathrm{NA}=\text { not }\end{array}$ & \multicolumn{5}{|c|}{$\begin{array}{l}\text { (a) Concentrations were normalized (adjusted) for the mixing of river water with groundwater. Correction was } \\
\text { not performed when data were marked with U qualifier (i.e., not detected). }\end{array}$} & rection was \\
\hline
\end{tabular}


Table 12. Trichloroethene Control Limits and 2-Year Trial Evaluation Data for the 300 Area Process Trenches

\begin{tabular}{|c|c|c|c|c|c|c|}
\hline & $\begin{array}{c}399-1-10 \mathrm{~A}^{(\mathrm{a})} \\
(\mu \mathrm{g} / \mathrm{L})\end{array}$ & $\begin{array}{c}399-1-10 \mathrm{~B}^{(\mathrm{a})} \\
(\mu \mathrm{g} / \mathrm{L})\end{array}$ & $\begin{array}{c}399-1-16 \mathrm{~A}^{(\mathrm{a})} \\
(\mu \mathrm{g} / \mathrm{L})\end{array}$ & $\begin{array}{c}399-1-16 \mathrm{~B}^{(\mathrm{a})} \\
(\mu \mathrm{g} / \mathrm{L})\end{array}$ & $\begin{array}{c}399-1-17 \mathrm{~A} \\
(\mu \mathrm{g} / \mathrm{L}) \\
\end{array}$ & $\begin{array}{c}\text { 399-1-17B } \\
(\mu \mathrm{g} / \mathrm{L}) \\
\end{array}$ \\
\hline $\begin{array}{l}\text { Control } \\
\text { Limit }^{(b)} \\
\end{array}$ & 0.72 & 0.72 & 0.96 & 5 & 0.74 & 0.72 \\
\hline \multicolumn{7}{|c|}{ 2-Year Trial Evaluation Data Subsequent to Baseline Period } \\
\hline $\begin{array}{l}\text { First } \\
\text { Sampling } \\
(03 / 02)\end{array}$ & $0.29 \mathrm{U}$ & NA & 0.57 & 2.67 & 0.46 & NA \\
\hline $\begin{array}{l}\text { Second } \\
\text { Sampling } \\
(06 / 02)\end{array}$ & $0.29 \mathrm{U}$ & $0.29 \mathrm{U}$ & $0.29 \mathrm{U}$ & 2.94 & 0.35 & $0.29 \mathrm{U}$ \\
\hline $\begin{array}{l}\text { Third } \\
\text { Sampling } \\
(09 / 02)\end{array}$ & $0.29 \mathrm{U}$ & NA & 0.32 & 2.28 & 0.32 & NA \\
\hline $\begin{array}{l}\text { Fourth } \\
\text { Sampling } \\
(12 / 02)\end{array}$ & $0.16 \mathrm{U}$ & $0.16 \mathrm{U}$ & 0.54 & 3.21 & 0.31 & $0.16 \mathrm{U}$ \\
\hline $\begin{array}{l}\text { Fifth } \\
\text { Sampling } \\
(03 / 03)\end{array}$ & $0.16 \mathrm{U}$ & $0.16 \mathrm{U}$ & 0.63 & 2.94 & 0.42 & $0.16 \mathrm{U}$ \\
\hline $\begin{array}{l}\text { Sixth } \\
\text { Sampling } \\
(06 / 03)\end{array}$ & $0.16 \mathrm{U}$ & $0.16 \mathrm{U}$ & 0.68 & 2.92 & 0.19 & $0.16 \mathrm{U}$ \\
\hline $\begin{array}{l}\text { Seventh } \\
\text { Sampling } \\
(07 / 03)\end{array}$ & $0.16 \mathrm{U}$ & $0.16 \mathrm{U}$ & 0.53 & 3.04 & 0.23 & $0.16 \mathrm{U}$ \\
\hline $\begin{array}{l}\text { Eighth } \\
\text { Sampling } \\
(08 / 03)\end{array}$ & $0.16 \mathrm{U}$ & $0.16 \mathrm{U}$ & 0.42 & 3.18 & 0.30 & $0.16 \mathrm{U}$ \\
\hline $\begin{array}{l}\text { Ninth } \\
\text { Sampling } \\
(09 / 03)\end{array}$ & $0.16 \mathrm{U}$ & $0.16 \mathrm{U}$ & 0.40 & 3.77 & 0.33 & $0.16 \mathrm{U}$ \\
\hline \multicolumn{7}{|c|}{$\begin{array}{l}\text { (a) Concentrations were normalized (adjusted) for the mixing of river water with groundwater. Correction was } \\
\text { not performed when data were marked with U qualifier (i.e., not detected). } \\
\text { (b) Control limits are obtained from Table } 9 .\end{array}$} \\
\hline
\end{tabular}


respective control limits, subsequent trial evaluation data (adjusted for dilution, if necessary), and exceedances for the three COCs. The most important observations are summarized below:

- The control limit for uranium in well 399-1-10A was exceeded in 8 out of the 10 sampling events (see Table 10) during the trial evaluation period. The consistent exceedances clearly indicate a nonrandom departure from the baseline condition. Further investigation revealed that dust suppression watering during excavation of the 618-5 burial ground, a waste site located immediately east of the 300 Area process trenches (see Figure 8), most likely transported ionic uranium in the vadose zone to groundwater.

- The control limit for uranium in well 399-1-17B was exceeded twice for some unknown reason. The two exceedances $(3.16 \mu \mathrm{g} / \mathrm{L}$ sampled in March 2003 and $2.02 \mu \mathrm{g} / \mathrm{L}$ sampled in July 2003, see Table 10) are an order of magnitude below the MCL (30 $\mu \mathrm{g} / \mathrm{L})$ for uranium.

- There are no exceedances of control limits for cis-DCE (see Table 11) and TCE (see Table 12) in the 300 Area process trenches monitoring wells. 


\subsection{Special Conditions Encountered}

This section describes special conditions encountered at each facility during the statistical evaluation process. Useful techniques and/or approaches as suggested by Gibbons (1994, page 165) and others (Horsey et al. 2001) are provided to address these special conditions.

\subsection{Pre-Existing Trends in Baseline Data Set}

The consistent small increases in specific conductance observed in B Pond well 699-43-45 suggest a return of this parameter to pre-disposal levels in groundwater. The depressed specific conductance is a result of dilute effluent discharges to the B Pond facility, which ended in 1997. In addition, some other regulated units at the Hanford Site (e.g., 200 East and West Areas low-level burial grounds) have preexisting COCs, and the pre-existing background concentration may show an increasing or decreasing trend due to a prior release from the regulated unit and/or an upgradient source. Nevertheless, the small but gradual trend noted during the baseline period is a serious concern when applying the control chart method. If the trend is not corrected, the calculated control limits will be grossly overstated and render the control chart method less effective to detect real changes. While caution must be used in applying the control chart method, there are supplemental statistical techniques and approaches that can be used to account for pre-existing trends observed in the background COC concentration. For example, Horsey et al. (2001) used an approach that consisted of screening intrawell historical data sets for statistical outliers, temporal trends, seasonal effects, and the presence of anthropogenic compounds (e.g., volatile organic compounds). The resulting data sets were then used to establish the intrawell control limits. Gibbons (1994, page 165) describes a technique for removing the effects of an upward trend (or downward trend) in a single monitoring well. Once the data are "de-trended," the previously described control chart method can be applied.

\subsubsection{Estimating Trend Using Non-Parametric Method}

If a concentration versus time plot suggests the presence of a linear trend, one may estimate the true slope (change in concentration per unit of time) and the intercept (concentration at time zero) by the least squares method as described by Montgomery and Peck (1982, pages 8-50). The underlying assumptions of the linear regression method are normally and independently distributed error terms with mean zero and constant variance. Gross violation of these assumptions may yield an unstable model. In addition, other disadvantages of linear least squares fit are poor extrapolation properties and sensitivity to outliers or gross errors. Furthermore, the presence of non-detects in the data will often invalidate the estimators (e.g., the intercept and the slope) obtained by the least squares regression method. Sen (1968) developed 
a robust non-parametric procedure that is not greatly influenced by the presence of outliers, missing data, and non-detects. Step-by-step procedures to obtain Sen's estimator of trend and to test the hypothesis of zero slope (i.e., no trend) are provided below:

1. Compute the $S_{i j}$ sample slope estimates for each well as in Equation 5.1 as follows:

$$
S_{i j}=\frac{y_{j}-y_{i}}{j-i}
$$

where $i<j$ and $y_{j}$ and $y_{i}$ are concentration values measured at time $j$ and $i$, respectively. If some of the concentration data $\left(y_{i}\right.$ 's) are nondetects, we may use one half the detect limit for these not detected data (Gilbert 1987, page 218).

2. The median of these $N^{\prime}$ values of $S_{i j}$ is Sen's estimator of trend. Let $S_{[1]} \leq S_{[2]} \leq \ldots \leq S_{\left[N^{\prime}\right]}$ denote the ordered values of $S_{i j}$. Then Sen's estimator denoted as $S$ is:

$$
\begin{array}{ll}
S=S_{\left[\left(N^{\prime}+1\right) / 2\right]} & \text { if } N^{\prime} \text { is odd, or } \\
S=\frac{1}{2}\left[S_{\left[N^{\prime} / 2\right]}+S_{\left[\left(N^{\prime}+2\right) / 2\right]}\right] & \text { if } N^{\prime} \text { is even }
\end{array}
$$

If a single measurement is collected from each well during each sampling event, then in this case $N^{\prime}=\frac{n(n-1)}{2}$, where $n$ is the number of sampling periods.

3. After obtaining the ordered values $S_{[1]} \leq S_{[2]} \leq \ldots \leq S_{\left[N^{\prime}\right]}$ of the $N^{\prime}$ slopes $S_{i j}$, a $(1-\alpha) \%$ distribution-free confidence interval for the true slope can be obtained as below (see Gilbert 1987, page 218). This procedure is based on normal theory and is valid for small sample sizes (i.e., $n \leq 10)$.

(a) Compute $\operatorname{VAR}(S)=\frac{1}{18}[n(n-1)(2 n+5)]$, or

$$
\operatorname{VAR}(S)=\frac{1}{18}\left[n(n-1)(2 n+5)-\sum_{p=1}^{g} t_{p}\left(t_{p}-1\right)\left(2 t_{p}+5\right)\right]
$$

Use Equation 5.4 if there is no tied value (i.e., nondetects or same concentration values). Otherwise, use Equation 5.5, where $g$ is the number of tied groups and $t_{p}$ is the number of occurrences of a particular tied value. 
where $Z_{1-\alpha / 2}$ is the $(1-\alpha / 2)^{\text {th }} \%$ quantile of the standard normal distribution.

(c) Set $M_{1}=\frac{N^{\prime}-C_{\alpha}}{2}$ and $M_{2}=\frac{N^{\prime}+C_{\alpha}}{2}$

(d) The lower confidence limit is $\beta_{L}=S_{\left[M_{1}\right]}$ and the upper confidence limit is

$$
\beta_{U}=S_{\left[M_{2}+1\right]}
$$

4. To test the hypothesis of zero slope (no trend) against the alternative hypothesis of an upward trend, $\operatorname{ASTM}$ (1998, Section 6.3.6.1, page 13) recommends first compute a one-sided $99 \%$ lower confidence limit (i.e., use $Z_{0.99}=2.326$ ) and reject the hypothesis of no trend if $\beta_{L}=S_{\left[M_{1}\right]}$ is greater than zero. If the alternative hypothesis is the presence of a decreasing trend, then one should reject the hypothesis of no trend and in favor of the alternative hypothesis when $\beta_{U}=S_{\left[M_{2}+1\right]}$ is less than zero.

5. If a significant trend is found, one may use the methods discussed in the next section to remove the trend in the background data set.

\subsubsection{Trend Removal Method}

When a pre-existing trend is observed in the background data set, the calculated background mean and standard deviation will be overstated and render the control chart method insensitive to detect real changes. Gibbons (1994, page 165) suggests using the following transformation to remove a pre-existing trend. Prior to proceeding with the transformation, a significant trend must be established using the method discussed in Section 5.1.1

$$
\begin{aligned}
y_{i}^{*} & =\beta_{0}+\left[y_{i}-\left(\beta_{0}+\beta_{1} * t\right)\right] \\
& =y_{i}-\beta_{1} * t
\end{aligned}
$$

where $y_{i}$ and $y_{i}{ }^{*}$ denote the original and the transformed data values, respectively; and $i=1,2, \ldots, n$ denotes the sampling periods, $\beta_{0}$ and $\beta_{1}$ are the intercept and the slope of the trend line. Noted in the above transformation we only need an estimate of the true slope of the trend line, which can be obtained by the Sen's estimator. The next section illustrates how a trend observed in the background data set of well 699-43-45 is removed using the transformation suggested by Gibbons (1994).

\subsubsection{Case Study}

Table 13 presents specific conductance data collected during the baseline period (November 1999 to June 2001) from well 699-43-45. This well is sampled approximately each quarter because it is also co-sampled by a nearby facility. The observed upward specific conductance trend is due to returning to 
Table 13. Baseline and De-Trended Specific Conductance Data in Well 699-43-45

\begin{tabular}{||c|c|c|c||}
\hline $\begin{array}{c}\text { Baseline } \\
\text { Sample Date }\end{array}$ & $\begin{array}{c}\text { Time Period } \\
\left(t_{i}\right)\end{array}$ & $\begin{array}{c}\text { Specific Conductance } \\
(\mu \mathrm{S} / \mathrm{cm})\end{array}$ & $\begin{array}{c}\text { De-trended Specific Conductance } \\
(\mu \mathrm{S} / \mathrm{cm})\end{array}$ \\
\hline \hline $11 / 10 / 99$ & 1 & 217.75 & 215.54 \\
\hline $01 / 27 / 00$ & 2 & 217.50 & 213.08 \\
\hline $04 / 17 / 00$ & 3 & 225.50 & 218.88 \\
\hline $06 / 07 / 00$ & 4 & 224.00 & 215.17 \\
\hline $10 / 18 / 00$ & 5 & 226.00 & 214.96 \\
\hline $01 / 18 / 01$ & 6 & 232.50 & 219.25 \\
\hline $04 / 10 / 01$ & 7 & 233.00 & 217.54 \\
\hline $06 / 13 / 01$ & 8 & 232.00 & 214.33 \\
\hline
\end{tabular}

natural groundwater conditions as the influence of the relatively dilute pond water subsides. Using procedures described in Section 5.1.1, we calculated $N^{\prime}=28$ slopes (using Equation 5.1) and arranged them in increasing order. From the ordered sets of calculated slopes, we calculated their median value (i.e., Sen's slope estimator) $S$ is $2.208 \mu \mathrm{S} / \mathrm{cm}$ per quarter (using Equation 5.3), and the lower 99\% confidence limit $S_{\left[M_{1}\right]}=S_{[4.94]}=0.23 \mu \mathrm{S} / \mathrm{cm}$ per quarter (using Equations 5.5, 5.6, and 5.7). We concluded significant trend exist in this well because the lower $99 \%$ confidence limit on the slope $\beta_{L}=S_{\left[M_{1}\right]}$ is greater than zero.

Substituting Sen's slope estimator into Equation 5.8 for this well, we can remove the trend effect from the original specific conductance data and obtain the following de-trended data:

$$
y_{i}^{*}=y_{i}-2.208 * t_{i}
$$

where $y_{i}$ are original specific conductance data from well 699-43-45 and $t_{i}=1,2,3, \ldots 8$. The de-trended specific conductance data is presented also in Table 13.

For comparison purposes, the original specific conductance data (collected during the baseline period and the 2-year trial evaluation period) and their de-trended data were plotted in Figure 12. Figure 12 shows that after we remove the trend effect from this well, the baseline data are stable for the application of the control chart method (and accordingly various control limits are calculated using de-trended baseline data). Furthermore, the previously noted exceedances (see Figure 5) are no longer present. However, the rate of increase in specific conductance obtained during the 2-year trial evaluation period is not as steep as that observed in the baseline period for this well. Hence, the de-trended specific conductance data (obtained in the 2-year evaluation period) are consistently below the de-trended baseline mean value of $216.1 \mu \mathrm{S} / \mathrm{cm}$ indicating that the baseline period needs to be re-established approximately every 2 years to adjust for the changing condition that may happen at the site. 

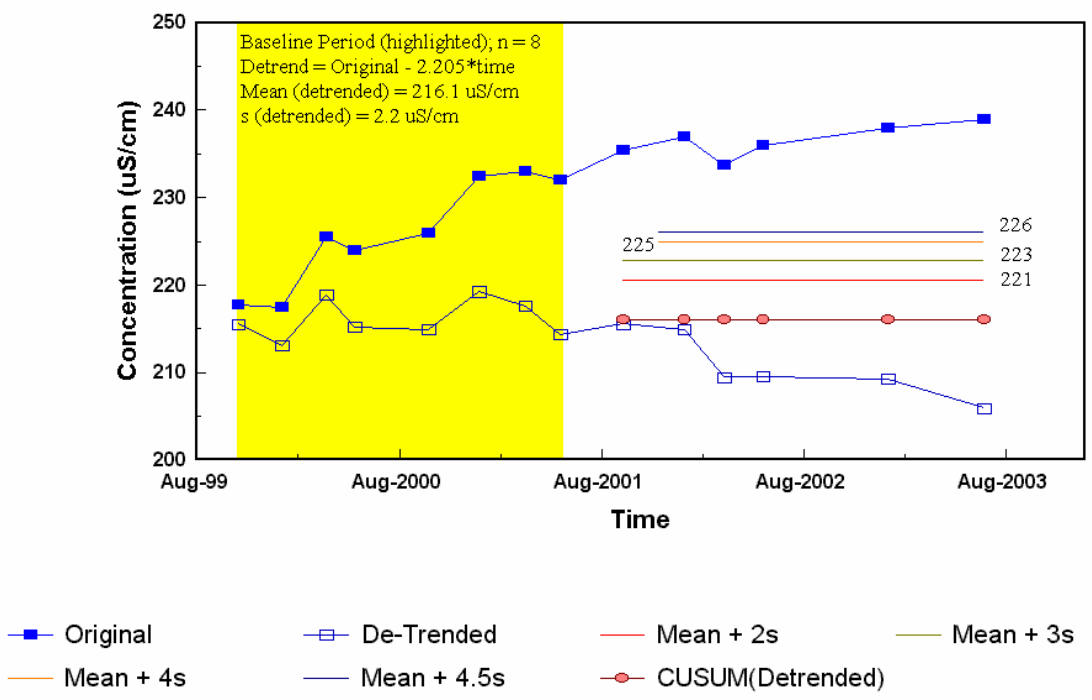

Figure 12. Original and De-Trended Specific Conductance Data from Well 699-43-45

\subsection{Dilution Correction}

As previously noted, a correction for mixing of river water with groundwater at those monitoring wells located within the bank storage zone near the shoreline was deemed necessary to account for potential bimodal distribution effects. Accordingly, this section describes one approach to remove the effect of mixing or dilution of groundwater by river water.

If the ambient total dissolved solids or specific conductance of groundwater in the study area is markedly different than the average specific conductance of river water, a simple two component mixing equation can be used to estimate the amount of river water present in the groundwater sample from a particular well. The contaminant concentration can then be adjusted to the concentration it would be if dilution by river water had not occurred. The following mixing equation can be used to calculate a dilution correction factor or mixing fraction, "a" that can then be used for this purpose.

$$
M_{i, j}=a_{i, j} X+\left(1-a_{i, j}\right) Y
$$

where: $\quad \mathrm{M}_{\mathrm{i}, \mathrm{j}}=$ the observed specific conductance (the mixture) of a water sample consisting of component $\mathrm{X}$ (groundwater) and component $\mathrm{Y}$ (river water) collected on the $\mathrm{i}^{\text {th }}$ sampling time $i(i=1,2,3, \ldots .$.$) from the j^{\text {th }}$ well $j(j=1,2,3, \ldots)$

$\mathrm{X}=$ average concentration of specific conductance of ambient groundwater from the source

$\mathrm{Y}=$ average concentration of specific conductance of Columbia River water

$\mathrm{a}_{\mathrm{i}} \mathrm{j}=$ mixing fraction at $\mathrm{i}^{\text {th }}$ sampling time for $\mathrm{j}^{\text {th }}$ well

Rearranging Equation 1 and solving for "a" yields

$$
a_{i, j}=\left(M_{i, j}-Y\right) /(X-Y)
$$


The observed concentration $\mathrm{C}_{\mathrm{obs}}(\mathrm{i}, \mathrm{j})$ of contaminant $\mathrm{C}$ at $\mathrm{i}^{\text {th }}$ sampling event from $\mathrm{j}^{\text {th }}$ well is then adjusted (corrected) for dilution using the mixing fraction:

$$
\mathrm{C}_{\mathrm{adj}}(\mathrm{i}, \mathrm{j})=\mathrm{C}_{\mathrm{obs}}(\mathrm{i}, \mathrm{j}) / \mathrm{a}_{\mathrm{i}, \mathrm{j}}
$$

where: $\quad \mathrm{C}_{\mathrm{adj}}(\mathrm{i}, \mathrm{j})=$ dilution corrected concentration of contaminant, $\mathrm{C}$ at $\mathrm{i}^{\text {th }}$ sampling event from $\mathrm{j}^{\text {th }}$ well

$\mathrm{C}_{\mathrm{obs}}(\mathrm{i}, \mathrm{j})=$ observed contaminant concentration of contaminant $\mathrm{C}$ at $\mathrm{i}^{\text {th }}$ sampling event from $\mathrm{j}^{\text {th }}$ well

In order to apply the above dilution correction method, the following steps are provided:

1. Prior knowledge of the concentrations of specific conductance of ambient groundwater from the source (i.e., $X$ in Equation 5.10) and that from the river water (i.e., $Y$ in Equation 5.10) are needed. The $\mathrm{Y}$ value was obtained using the median Columbia River water specific conductance concentration ( $143 \mu \mathrm{S} / \mathrm{cm}$, which was rounded to $140 \mu \mathrm{S} / \mathrm{cm}$ in this study) of 5 samples collected by U.S. Geological Survey at Richland Pumphouse in year 2001 (PNNL-13910, Table B.5). Average concentrations of specific conductance of water samples collected during the period March 1998 to September 2003 from wells 399-1-17A and 399-1-17B were used as X values for shallow $(460 \mu \mathrm{S} / \mathrm{cm})$ and deep $(357 \mu \mathrm{S} / \mathrm{cm})$ well, respectively.

2. After obtaining values of $X$ and $Y$, values of specific conductance data $\left(M_{i, j}\right)$ collected on a particular sample date from a particular well are needed to calculate the mixture fraction $a_{i, j}$ using Equation 5.11.

3. After obtaining values of mixture fraction $\mathrm{a}_{\mathrm{i}, \mathrm{j}}$, original values of contaminant data $\left[\mathrm{C}_{\mathrm{obs}}(\mathrm{i}, \mathrm{j})\right]$ are corrected $\left[\mathrm{C}_{\mathrm{adj}}(\mathrm{i}, \mathrm{j})\right]$ using Equation 5.12.

Table 14 was prepared to demonstrate the application of above procedures. Specific conductance values measured in June 1999 from wells 399-1-10A/B, 399-1-16A/B, and 399-1-17A/B were used for this illustration. All COC data were adjusted in accordance with the above dilution correction procedures and later used for statistical testing presented in Section 4.0.

Although the computation for the mixing correction is straight forward, there are important assumptions and conditions that must be met for reliable use of the above approach, summarized as follows:

1. The ambient groundwater specific conductance remains relatively constant at the source area.

2. There are no sources of dilution water in the study area that could influence groundwater composition (e.g., leaking utility water lines). 
Table 14. Using Specific Conductance Values Measured in June 1999 to Illustrate the Application of Dilution Correction Procedures

\begin{tabular}{|c|c|c|c|c|c|c|}
\hline Well & $\begin{array}{l}\text { Sample } \\
\text { Date }\end{array}$ & $\begin{array}{c}\text { Observed } \\
\text { Uranium } \\
(\mu \mathrm{g} / \mathrm{L})\end{array}$ & $\begin{array}{c}\text { Specific } \\
\text { Conductance }^{(\mathrm{a})} \\
(\mu \mathrm{S} / \mathrm{cm})\end{array}$ & $\begin{array}{c}\text { Mixture } \\
\text { Fraction }^{(b)}, a_{i, j}\end{array}$ & $\begin{array}{l}\text { Adjusted } \\
\text { Uranium }^{(c)} \\
(\mu \mathrm{g} / \mathrm{L})\end{array}$ & $\begin{array}{l}\text { Difference }^{(\mathrm{d})} \\
\quad(\mu \mathrm{g} / \mathrm{L})\end{array}$ \\
\hline $399-1-10 \mathrm{~A}$ & 6/10/1999 & 23.6 & 233 & 0.29 & 81.2 & -57.6 \\
\hline 399-1-16A & 6/10/1999 & 61.5 & 297 & 0.49 & 125.4 & -63.9 \\
\hline $399-1-17 \mathrm{~A}$ & 6/15/1999 & 104.0 & 470 & 100.8 & 100.8 & 3.2 \\
\hline 399-1-10B & 6/10/99 & 0.062 & 309 & 0.78 & 0.079 & 0.018 \\
\hline 399-1-16B & 6/10/99 & 12.6 & 327 & 0.86 & 14.6 & -2.0 \\
\hline $399-1-17 B$ & 6/10/99 & 0.0089 & 354 & 0.99 & 0.009 & -0.0001 \\
\hline \multicolumn{7}{|c|}{$\begin{array}{l}\text { (a) Representing } \mathrm{M}_{\mathrm{i}, \mathrm{j}} \text { values used in Equation } 5.10 \text {. } \\
\text { (b) } \text { Calculated by }\left(\mathrm{M}_{\mathrm{i} . \mathrm{j}}-140\right) /(460-140) \text { for shallow wells and }\left(\mathrm{M}_{\mathrm{i} . \mathrm{j}}-140\right) /(357-140) \text { for deep wells. } \\
\text { (c) Equals observed uranium concentration/mixture fraction. } \\
\text { (d) Equals observed - adjusted uranium concentration. }\end{array}$} \\
\hline
\end{tabular}

3. There are no episodic events that recharge the aquifer with contaminant and or salt from another waste site that could alter specific conductance.

4. Representative specific conductance must be used for the portion of the aquifer being tested.

5. Representative samples of the aquifer are obtained (i.e., there are no strong vertical gradients in concentration in the vicinity of the pump intake).

A summary of how these conditions were satisfied for the application presented in this paper, along with comments or suggestions for other conditions are as follows.

\section{Condition 1}

The specific conductance (Figure 13 and Figure 14) in the most inland monitoring location near the source (wells 399-1-17A and B) demonstrates that specific conductance is fairly constant over the period of interest with a mean value of $460 \mu \mathrm{S} / \mathrm{cm}$ in the A well and $357 \mu \mathrm{S} / \mathrm{cm}$ in the B well except for two sampling events for well 399-1-17A in June 1997 and June 2002 (Figure 13). If the specific conductance shows either a decreasing or an increasing trend, it may be possible to first detrend the data using procedures described in Section 5.1 and Chou (2004) or segregate the data into smaller time increments (e.g., use annual average versus an average over 5 years) to minimize the effect of a trend.

\section{Condition 2}

There were no leaking water lines in the immediate vicinity of the 300 APT that could alter the flow regime and composition. However, in other areas of the Hanford Site, leaking utility lines have created 
399-1-17A Specific Conductance (uS/cm)

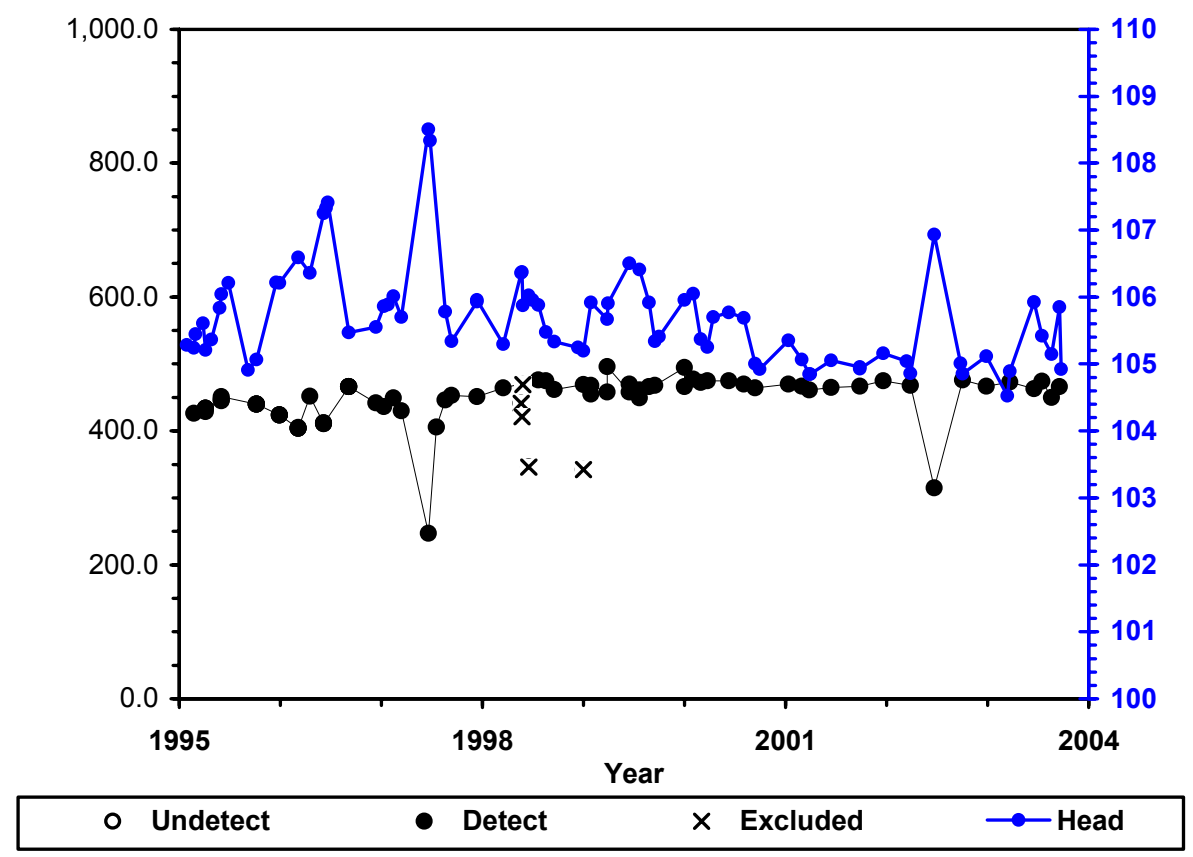

Figure 13. Specific Conductance and Head versus Time for Well 399-1-17A

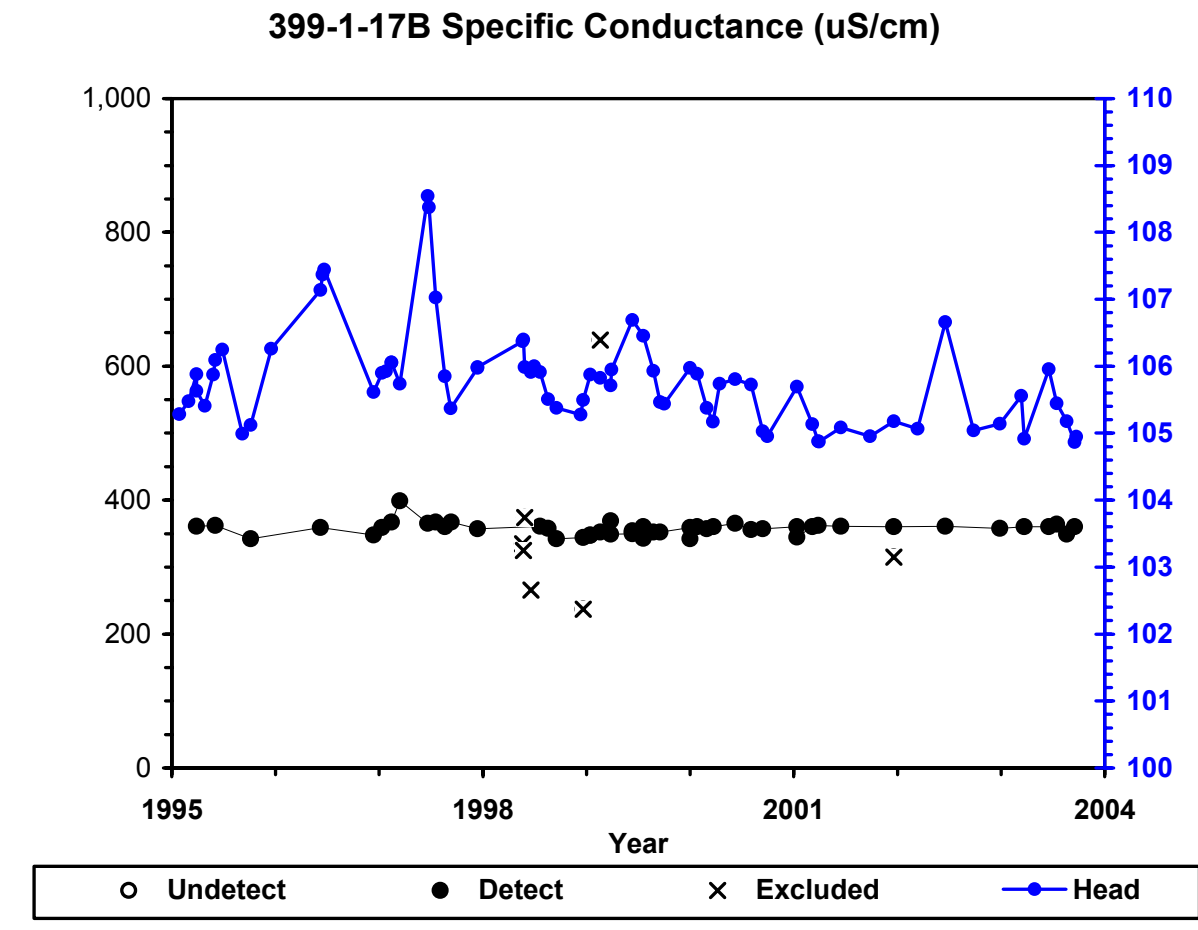

Figure 14. Specific Conductance and Head versus Time for Well 399-1-17B 
anomalously low groundwater specific conductance which would invalidate application of the dilution correction. Because leaking utility lines are a world wide problem, this possibility must be kept in mind for application of the method elsewhere.

\section{Condition 3}

There was one well in the study area that did not meet this condition. For example, the impact of a recharge event associated with the 618-5 burial ground (see Figure 8 for burial ground location) dust suppression watering was evident in the corrected or adjusted concentrations (as shown in Figure 10) because the adjusted uranium concentration (for well 399-1-10A) was less than the observed or unadjusted concentration. This was because the observed specific conductance values $(571 \mu \mathrm{S} / \mathrm{cm}$ on December 19, 2002 and $476 \mu \mathrm{S} / \mathrm{cm}$ on March 21, 2003) were greater than the ambient value $(460 \mu \mathrm{S} / \mathrm{cm})$ used for the uppermost part of the aquifer. Apparently the dust suppression water also mobilized salts as well as uranium from the vadose zone. While the effect of this type of impact cannot be removed, it can be easily recognized by noting if the adjusted contaminant concentrations are less than the unadjusted concentrations.

\section{Condition 4}

There were two zones of the unconfined aquifer at this site with different major chemical composition and specific conductance that required separate treatment. For example, as shown in Figures 13 and 14, wells completed in the deeper portion of the aquifer (B wells) in the present study had an average specific conductance that was more than $100 \mu \mathrm{S} / \mathrm{cm}$ lower than the uppermost portion of the aquifer (A wells). Thus, as noted above, two different values for $\mathrm{X}$ in the mixing equation were used. That is, average specific conductance values of $357 \mu \mathrm{S} / \mathrm{cm}$ for $399-1-17 \mathrm{~B}$ and $460 \mu \mathrm{S} / \mathrm{cm}$ for 399-1-17A, respectively, for the bottom and top of the aquifer.

\section{Condition 5}

This condition was tested by sampling the very top of the aquifer with a special device that collected a water sample near the air-water interface in the wells. Uranium concentrations for interface samples from the wells used for this study were nearly identical to the concentrations obtained with the sample pumps which are set much deeper in the upper aquifer ( $5-7 \mathrm{ft}$ below static water level). This was taken as evidence of relatively uniform concentrations within the zone of influence of the sample pumps. Additional work may be needed to test this assumption under differing hydrologic conditions (river stage). 



\subsection{Conclusions and Recommendations}

Conclusions and recommendations based on the results of evaluating groundwater monitoring data obtained during the 2-year trial period for the two test cases addressed in this study are summarized as follows:

\section{B Pond Case (Detection Status)}

- For this detection status site, the Shewhart-CUSUM control chart approach is superior (more powerful) than the AR t-test method to detect a change in mean concentration above baseline while keeping the overall network-wide false positive rate at acceptably low levels $(\sim 5 \%)$. These levels are consistent with EPA (1992) and ASTM guidance (1998).

- When deciding appropriate control limits, one needs to consider 1) the power of the proposed test in relation to EPA (1992) reference power curve and ASTM guidance (1998); 2) the risk posed to human health and the environment, and 3) natural background conditions. For the B Pond case, it is recommended that both the SCL and the CCL be set at 4.5 sigma units above the baseline concentrations for the following reasons:

(i) It provides the lowest false positive rate and yet provides adequate power ( $\sim 95 \%)$ to detect a difference that is at 4 standard deviation units above the baseline mean in the second sampling event.

(ii) The power is close to 1 at the third, fourth, and fifth sampling events to detect a difference that is approximately 4 standard deviation units above the mean.

(iii) If the concentrations are close to the drinking water standards (and thus poses a risk to human health), the proposed control limits will have power to detect the high concentration with probability 1 ( 0 false negative rate) even in the first sampling event.

(iv) The highest control limits (set at $\bar{x}+4.5 \mathrm{~s}$ level) for specific conductance is $364 \mu \mathrm{S} / \mathrm{cm}$ for well 699-44-39B (see Appendix B, Table B.1) which is about half of the drinking water standard for this parameter; for gross alpha is $5.78 \mathrm{pCi} / \mathrm{L}$ for well 699-43-44 (see Appendix B, Table B.2) which is less than half of the drinking water standard; and for gross beta is $16.45 \mathrm{pCi} / \mathrm{L}$ for well 699-44-39B (see Appendix B, Table B.3) which is about one third of the drinking water standard for this parameter.

- The control chart method will be insensitive to detect real changes if a pre-existing trend (caused by a prior release from the regulated unit and/or an upgradient source) is observed in the background data set. A pre-existing trend could be removed using a transformation suggested by Gibbons (1994). Once the trends are removed from the data the control chart method can be applied.

- Update baseline data periodically. A moving window of 8 to 12 baseline observations using most recent data is recommended. 


\section{Area Process Trenches Case (Corrective Action Status)}

In addition to the general conclusions regarding the Shewhart-CUSUM control chart method noted above, the following findings and conclusions apply to the 300 Area process trenches case due to the fluctuating water table:

- Concerns that groundwater flow direction (and related mixing and dilution) could result in a bimodal contaminant distribution at the 300 Area process trenches, and thus invalidate application of the Shewart-CUSUM control chart method, were addressed by conducting statistical tests for normality on both dilution corrected and non-corrected data. It was found that the data followed either normal or log-normal distribution pattern for either dilution corrected or uncorrected data.

- It is concluded that the combined Shewhart-CUSUM method, an acknowledged method having superior statistical power, is a viable alternative for application to 300 Area process trenches as well as at other RCRA sites with similar dynamic hydrologic conditions.

- For wells in close proximity to the river at any site, the approach provided in Section 5.2 could be applied to adjust contaminant concentrations to remove or minimize effects of river water infiltration and dilution before statistical analysis of the data. 


\subsection{References}

40 CFR 265. U.S. Environmental Protection Agency. "Interim Status Standards for Owners and Operators of Hazardous Waste Treatment, Storage, and Disposal Facilities." U.S. Code of Federal Regulations.

ASTM 1996. Provisional Standard Guide for Developing Appropriate Statistical Approaches for Ground-Water Detection Monitoring Programs. PS 64-96, American Society for Testing and Materials, West Conshohocken, Pennsylvania.

ASTM 1998. Standard Guide for Developing Appropriate Statistical Approaches for Ground-Water Detection Monitoring Programs. D 6312-98, American Society for Testing and Materials, West Conshohocken, Pennsylvania.

Barnett DB, RM Smith, and CJ Chou. 2000. Groundwater Monitoring Plan for the Hanford Site 216-B-3 Pond RCRA Facility, Interim Change Notice 1. PNNL-13667-ICN1, Pacific Northwest National Laboratory, Richland, Washington.

Cameron K, M.D. 1996. "RCRA Leapfrog: How Statistics Shape and in Turn Are Shaped by Regulatory Mandates.” Remediation 7(1)15-25.

Chou CJ. 2004. "Groundwater Monitoring Statistical Methods for Testing Special Background Conditions," Chapter 8 in Environmental Monitoring, GB Wiersma (ed.), pp. 239-255. CRC Press, Boca Raton, Florida.

Chou CJ, RF O'Brien, and DB Barnett. 2001. “Application of Intrawell Testing of RCRA Groundwater Monitoring Data When No Upgradient Well Exists," Environmental Monitoring and Assessment 71:91-106.

Conover WJ. 1980. Practical Nonparametric Statistics, Second Edition, John Wiley and Sons, New York, New York.

Draper NR and H Smith. 1980. Applied Regression Analysis, Second Edition, John Wiley and Sons, New York, New York.

Davis CB and RJ McNichols. 1994. "Groundwater Monitoring Statistics Update: Part I: Progress since 1988." Groundwater Monitoring Review, pp 148-158.

DOE. 1997. Hanford Site Background: Part 3, Groundwater Background. DOE/RL-96-61, U.S. Department of Energy, Richland, Washington.

Draper NR and H Smith. 1980. Applied Regression Analysis, Second Edition. John Wiley and Sons, New York, New York. 
Ecology and EPA. 1986. Consent Agreement and Compliance Order. Ecology No. DE 86-113, Washington State Department of Ecology and the U.S. Environmental Protection Agency, Olympia, Washington.

Ecology. 1994. Dangerous Waste Portion of the Resource Conservation and Recovery Act Permit for the Treatment, Storage, and Disposal of Dangerous Waste, as amended, August 1994. Washington State Department of Ecology, Olympia, Washington.

EPA. 1989. Statistical Analysis of Groundwater Monitoring Data at RCRA Facilities Interim Final Guidance. EPA/530-R-93-003, U.S. Environmental Protection Agency, Washington, D.C.

EPA. 1992. Statistical Analysis of Groundwater Monitoring Data at RCRA Facilities - Draft Addendum to Interim Final Guidance. EPA/530-R-93-003, U.S. Environmental Protection Agency, Washington, D.C.

Freeze RA and JA Cherry. 1979. Groundwater. Prentice-Hall, Inc., Englewood Cliffs, New Jersey.

Gilbert RO. 1987. Statistical Methods for Environmental Pollution Monitoring, Van Nostrand Reinhold, New York, New York.

Gibbons RD. 1994. Statistical Methods for Groundwater Monitoring. John Wiley \& Sons, New York, New York.

Hartman MJ, LF Morasch, and WD Webber (eds). 2003. Hanford Site Groundwater Monitoring for Fiscal Year 2002. PNNL-14187, Pacific Northwest National Laboratory, Richland, Washington.

Horsey HR, P Carosone-Link, MR Sullivan, J Loftis. 2001. The Effectiveness of Intrawell Ground Water Monitoring Statistics at Older Subtitle D Facilities. NIC The eGovernment Company, Indianapolis, Indiana. Available URL: http://www.environmental-center.com/articles/article1019/article1019.htm.

Lindberg JW and CJ Chou. 2001. 300 Area Process Trenches Groundwater Monitoring Plan. PNNL-13645, Pacific Northwest National Laboratory, Richland, Washington.

Lindberg JW, CJ Chou, and VG Johnson. 1995. Groundwater Monitoring Plan for the 300 Area Process Trenches. WHC-SD-EN-AP-185, Westinghouse Hanford Company, Richland, Washington.

Lucas JM. 1982. “Combined Shewhart-CUSUM Quality Control Schemes,” Journal of Quality Technology, Vol. 14, No. 2, 51-59.

Mandansky A. 1988. Prescriptions for Working Statisticians. New York: Springer-Verlag.

Miller RG. 1986. Beyond ANOVA, Basics of Applied Statistics, New York, John Wiley \& Sons.

Montgomery DC. 1991. Introduction to Statistical Quality Control, $3^{\text {rd }}$ Edition, John Wiley, New York, New York. 
Montgomery DC and EA Peck. 1982. Introduction to Linear Regression Analysis. John Wiley, New York, New York.

Ostle B and LC Malone. 1988. Statistics in Research: Basic Concepts and Techniques for Research Workers, fourth edition. Iowa State University Press, Ames, Iowa, pp. 66-67.

Poston TM, RW Hanf, RL Dirkes, and LF Morasch (eds.). 2002. Hanford Site Environmental Report for Calendar Year 2001. PNNL-13910, Pacific Northwest National Laboratory, Richland, Washington.

RCRA - Resource Conservation and Recovery Act (1976), Public Law 94-580, as amended, 90 Stat. 2795, 42 USC 6901 et seq.

Sen PK. 1968. Estimates of the Regression Coefficient Based on Kendall's Tau, Journal of the American Statistical Association 63:1379-1389.

Schalla R, RL Aaberg, DJ Bates, JVM Carlile, MD Freshley, TL Liikala, PJ Mitchell, KB Olsen, and JT Rieger. 1988. Revised Ground-Water Monitoring Compliance Plan for the 300 Area Process Trenches. PNL-6671, Rev. 0, Pacific Northwest Laboratory, Richland, Washington.

Shapiro SS and MB Wilk. 1965. "An Analysis of Variance Test for Normality (Complete Samples)," Biometrika 52:591-611.

Shapiro SS. 1980. Volume 3: How to Test Normality and Other Distributional Assumptions, in the ASQC Basic References in Quality Control: Statistical Techniques, EJ Dudewicz, Editor, American Society for Quality Control, Milwaukee, Wisconsin.

Starks TH. 1989. "Evaluation of Control Chart Methodologies for RCRA Waste Sites," EPA/600/4-88/040, U.S. Environmental Protection Agency Office of Research and Development, Las Vegas, Nevada.

WAC 173-303-400. Interim Status Facility Standards. Washington Administrative Code, Olympia, Washington.

WAC 173-303-610(7). Closure and Post-Closure; Post-Closure Care and Use of Property. Washington Administrative Code, Olympia, Washington.

WAC 173-303-645(a)(ii). Releases from Regulated Units. Washington Administrative Code, Olympia, Washington.

WAC 173-303-645(8)(i)(i). Releases from Regulated Units; General Ground Water Monitoring Requirements. Washington Administrative Code, Olympia, Washington.

WAC 173-303-645(8)(h). Releases from Regulated Units; General Ground Water Monitoring Requirements. Washington Administrative Code, Olympia, Washington. 
Westgard JO, T Groth, T Aronson, and C De Verdier. 1977. "Combined Shewhart-CUSUM Control Chart for Improved Quality Control in Clinical Chemistry," Clinical Chemistry, Vol. 28, No. 10, 1881-1887.

WSU. 1999. Report on Statistical Analysis for B-Pond Groundwater Monitoring Program, Prepared by V. Krishna Jandhyala and Hao Zhang, Program in Statistics, Washington State University, Pullman, Washington. 


\section{Appendix A}

\section{Communications with Ecology}




\title{
Appendix A
}

\section{Communications with Ecology}

\section{A.1 Letter from D. Goswami to M. J. Furman}

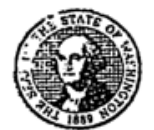 \\ STAIE OF WASHINGTON \\ DEPARTMENT OF ECOLOGY \\ 1315 W. 4th Avenue - Kennewick, Washington 99336-6018 • (509) 735-7581
}

May 7, 2001

Mr. Marvin Furman

U.S. Department of Energy

Richland Operations Office

P.O. Box 550, MSIN A5-13

Richland, Washington 99352

Dear Mr. Furman:

Re: Statistical Assessment for the 300 Area Resource Conservation and Recovery Act of 1976 (RCRA) Ground Water Monitoring Plan

The Washington State Department of Ecology (Ėcology) has evaluated the proposal presented by the United States Department of Energy (USDOE) requesting "variance" from applying interim status regulations at B-Pond and other Treatment, Storage, and Disposal (TSD) units, and their request to apply the Shewhart-CUSUM control limits for the 300 Area Process Trenches (APT). The purpose of this letter is to present regulatory guidance regarding the proposed "variance" from applying interim status regulations and to denote the requirements for achieving acceptable control limits for the 300 APT. This letter does not negate the current status of the site, but allows for variance.

B-Pond - "Variance" from applying interim status regulations. The following guidance is provided to the USDOE regarding the request for "variance" from applying interim status regulations for the RCRA monitoring network at B Pond monitored under interim indicator evaluation status. The appropriate indicators of ground-water contamination and statistical evaluation methods will be proposed by Pacific Northwest National Laboratory (PNNL) and submitted for approval by Ecology on a case-by-case basis.

The following criteria must be met prior to receiving approval of a variance from applying interim status regulations.

1. Identification of appropriate indicators of ground-water contamination and suitable statistical evaluation methods will be achieved by utilizing best professional judgement (i.e., waste source terms, conceptual models), expertise, and site-specific knowledge to: (a) determine the best technical approach based on hydrogeology and (b) tailor statistical approach to each individual site as necessary (i.e., consider type of monitoring, the nature of the data, the proportions of non-detects, spatial and temporal variations in the selection of appropriate statistical methods). A list of the appropriate indicators will be provided to Ecology for approval prior to implementation of the proposed plan. 
Mr. Marvin Furman

May 7, 2001

Page 2

2. The selection of quality background data and data sets for identification of an appropriate baseline period. Once baseline data has been obtained, outliers will be properly addressed to avoid substantial bias in the statistical analysis.

3. American Society for Testing and Materials (ASTM) guidance will be utilized for circumstances regarding non-detects and outliers.

4. The utilization of probability plots in order to maintain normal distribution of data.

5. Input parameter values (e.g., k, h, and SCL) will be proposed and submitted to Ecology for approval prior to implementation of this plan.

6. Variance from applying interim status requirements for the RCRA monitoring network at B Pond and other TSD units currently monitored under interim indicator evaluation status will be allowed for a period to cover four sampling events. Upon completion of the four sampling events and statistical evaluation of the data, the submitted proposal shall be reevaluated by Ecology for subsequent approval.

300 Area Process Trenches (300-APT) - Calculation of control limits. The following table. depicts the control limits and special conditions to be applied for each constituent of concern at the 300-APT as proposed in the USDOE/Ecology meeting held December 11, 2000.

Table 1. Summary of Various Control Limits at the 300 APT

\begin{tabular}{|c|c|c|}
\hline $\begin{array}{c}\text { Constituent } \\
\text { of Concern }\end{array}$ & $\begin{array}{c}\text { Shewhart CUSUM } \\
\text { Parameter Value }\end{array}$ & $\begin{array}{c}\text { Control Limit } \\
(\mu \mathrm{g} / \mathrm{L})\end{array}$ \\
\hline \multicolumn{3}{|c|}{ Well \# 3-1-16A } \\
\hline cis-DCE $(\mu \mathrm{g} / \mathrm{L})$ & 4.5 & 0.803 \\
\hline TCE $(\mu \mathrm{g} / \mathrm{L})$ & 4.5 & 1.72 \\
\hline \multicolumn{3}{|c|}{ Well \# 3-1-16B } \\
\hline cis-DCE $(\mu \mathrm{g} / \mathrm{L})$ & 4.5 & {$[39,262]^{(\mathrm{b})}$} \\
\hline TCE $(\mu \mathrm{g} / \mathrm{L})$ & $\mathrm{NA}$ & 5 \\
\hline \multicolumn{3}{|c|}{ Well \# 3-1-17A } \\
\hline Uranium $(\mu \mathrm{g} / \mathrm{L})$ & $4^{(\mathrm{a})}$ & {$[7,218]$} \\
\hline \multicolumn{3}{|c|}{ Well \# 3-1-17B } \\
\hline Uranium $(\mu \mathrm{g} / \mathrm{L})$ & 4.5 & 0.67 \\
\hline
\end{tabular}

(a) Use 4 sigma because there are 16 data points in the baseline period (ASTM 1996).

(b) Numbers in brackets indicate upper and lower limits. 
Mr. Marvin Furman

May 7, 2001

Page 3

Specific procedures to be used are as follows:

1. For wells where the Maximum Contamination Level (MCL) has been and still is exceeded, quarterly monitoring will be conducted. One sample will be collected from each well during each sampling event and compared to the agreed upon control limits for each identified constituent of concern (i.e., cis- . DCE, TCE, and uranium). If a control limit is exceeded (pronf by verification sampling), a notification process will be followed.

2. For wells where the MCL has not been exceeded, semiannual monitoring will be conducted. One sample will be collected from each well during each sampling event and compared to the agreed upon control limits for each identified constituent of concern (i.e., cis-DCE, TCE, and uranium). A notification process will be followed after a confirmed exceedance (by verification sampling).

3. Currently tetrachloroethene (PCE) is not detected in the $300 \mathrm{APT}$ wells. However, it has been detected in the past. PNNL will continue to monitor PCE and report detected results.

The proposed statistical approach shall be in effect for a period of two years or four sampling events. Based on the results of this trial application, Ecology would decide whether to continue, modify, or abandon the proposed approach in these facilities or to apply the approach to other facilities. The USDOE is therefore requested not to apply this variance or similar procedures/methods at other facilities with out Ecology's prior approval.

If further discussion is necessary, please contact Deborah Singleton at (509) 736-5722 or me at (509) 736-3015.

Sincerely,

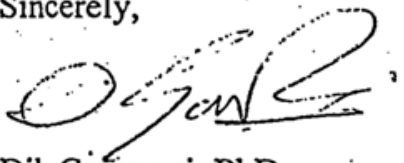

Dib Goswami, PhD

Nuclear Waste Program

DG:lkd

cc: Doug Hildebrand, USDOE

John Morse, USDOE

Charissa Chou, PNL

Stuart Luttrell, PNL 


\section{A.2 Letter from J. G. Morse to J. Hedges}

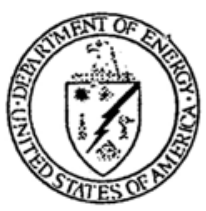

02-GWVZ-004

\author{
Department of Energy \\ Richland Operations Office \\ P.O. Box 550 \\ Richland, Washington 99352
}

Ms. Jane Hedges

Perimeter Areas Section Manager

Nuclear Waste Program

State of Washington

Department of Ecology

1315 W. Fourth Avenue

Kennewick, Washington 99336

Dear Ms. Hedges:

PROPOSAL FOR GROUNDWATER MONTTORING AT THE 216-B-3 POND SYSTEM RESOURCE CONSERVATION AND RECOVERY ACT (RCRA) FACILITY

In accordance with the State of Washington Department of Ecology (Ecology) letter to Marvin Furman from Dib Goswami, "Statistical Assessment for the 300 Area Resource Conservation and Recovery Act of 1976 (RCRA) Ground Water Monitoring Plan," dated May 7, 2001, and based on subsequent meetings with Ecology held on May 16, 2001, and August 2, 2001 , the proposal for groundwater monitoring at the 216-B-3 Pond system RCRA facility is attached (Attachment 1 and 2).

The revised approach for groundwater monitoring at the B Pond system is based upon mutual agreement that the standard indicator-parameters evaluation and accompanying interim-status statistical approach are inappropriate for detecting potential B Pond-derived contaminants in groundwater at this facility.

The specific elements of the proposal, as stated in the above-mentioned letter and in agreement with our subsequent discussions with Ecology, are as follows:

Well Network:

1. The well network (see map, Attachment 1) will consist of one upgradient well (699-44-39B) and three downgradient wells (699-42-42B, 699-43-44, and 699-43-45).

2. Because data from the relatively new well 699-43-44 are limited, data from nearby well 699-43-43 will be used as a historical surrogate for 699-43-44, per your direction. To establish data comparability between the wells, well 699-43-43 will be added to the network, and sampled as long as it remains serviceable. Well 699-43-44 is a replacement for well 699-43-43, which is going dry. 


\section{Constituents List}

The constituents will be the same as in the May 17,2001, presentation and are shown in the attached table (Attachment 2). The attached table will replace Table 5.1 in PNNL-13367, "Groundwater Monitoring Plan for the Hanford Site 216-B-3 Pond RCRA Facility," (Barnett et al., 2000). As we agreed, total and dissolved concentrations of mercury, cadmium, lead, and silver will be analyzed annually for four years. Analysis for these metals will be discontinued after four years if no anomalous concentrations or trends are revealed.

\section{Statistical Analysis}

1. Only site-specific parameters (gross alpha, gross beta and specific conductance) will be subject to statistical evaluations on a semiannual basis.

2. The combined Shewhart-CUSUM control chart method will be applied to the three site specific-parameters. The appropriate baseline period for the data will be identified and baseline data evaluated. Outliers will be addressed to avoid bias in the statistical analysis.

3. American Society for Testing and Materials guidance will be used to evaluate non-detect results and outliers.

4. Normal probability plots will be used to verify normal distribution of data.

5. Input parameter values ( $k, h$, and SCL) will be proposed and submitted to Ecology for approval prior to implementation of the groundwater monitoring plan. Power curves illustrating probabilities for false positive and false negative will be submitted.

\section{Reporting}

In accordance with the meeting held on August 3, 2001, the groundwater analytical and hydrologic data from nearby facilities, such as the Liquid Effluent Retention Facility, Treated Effluent Disposal Facility, and 216-A-29 Ditch, will be examined for results that may lend understanding to the B Pond hydro geologic system and will be discussed in the Hanford Site Annual Groundwater Report, as appropriate. This discussion will be accompanied by recommendations for modifications of the well network and/or constituent list, as necessary.

Upon receipt of Ecology's agreement to these changes, the information will be incorporated into an Interim Change Notice and applied to the proposed groundwater monitoring plan cited above. 
Ms. Jane Hedges

$-3-$

NOV 202001

02-GWVZ-004

If you want to discuss this matter further or require additional information, please contact Marvin J. Furman at (509) 373-9630.

Sincerely,

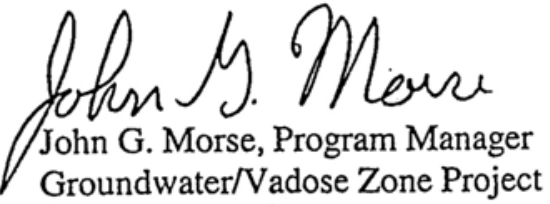

\section{GWVZ:MJF}

Groundwater/Vadose Zone Project

Attachments

cc w/attachs:

J. Caggianno, Ećology

D. N. Goswami, Ecology

S. P. Luttrell, PNNL

B. Barnett, PNNL 


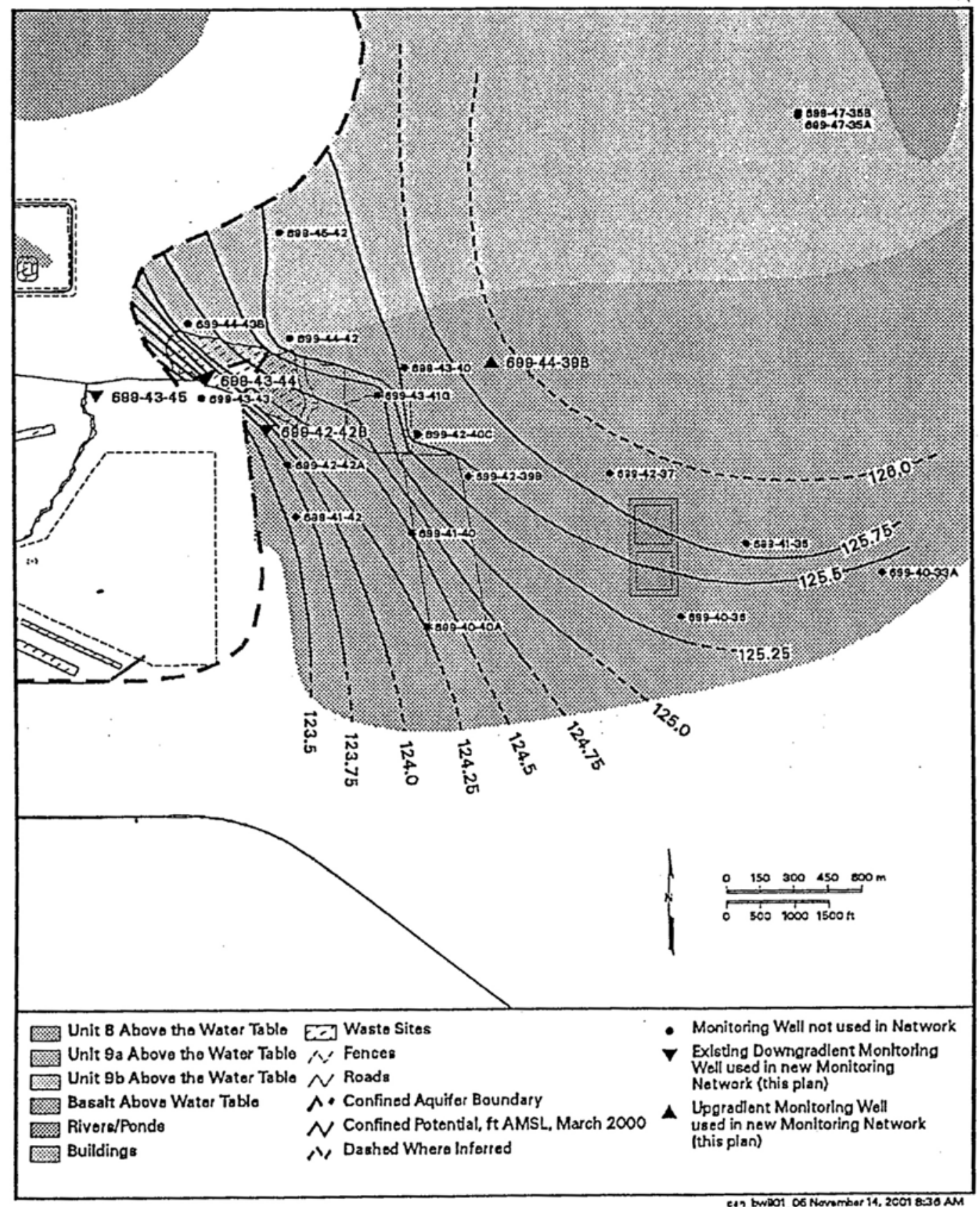

Location of proposed monitoring wells in relation to head distribution at the B Pond System (After Barnett et al. 2000). 
Constituent List for the B Pond Facility (From Barnett et al. 2000)

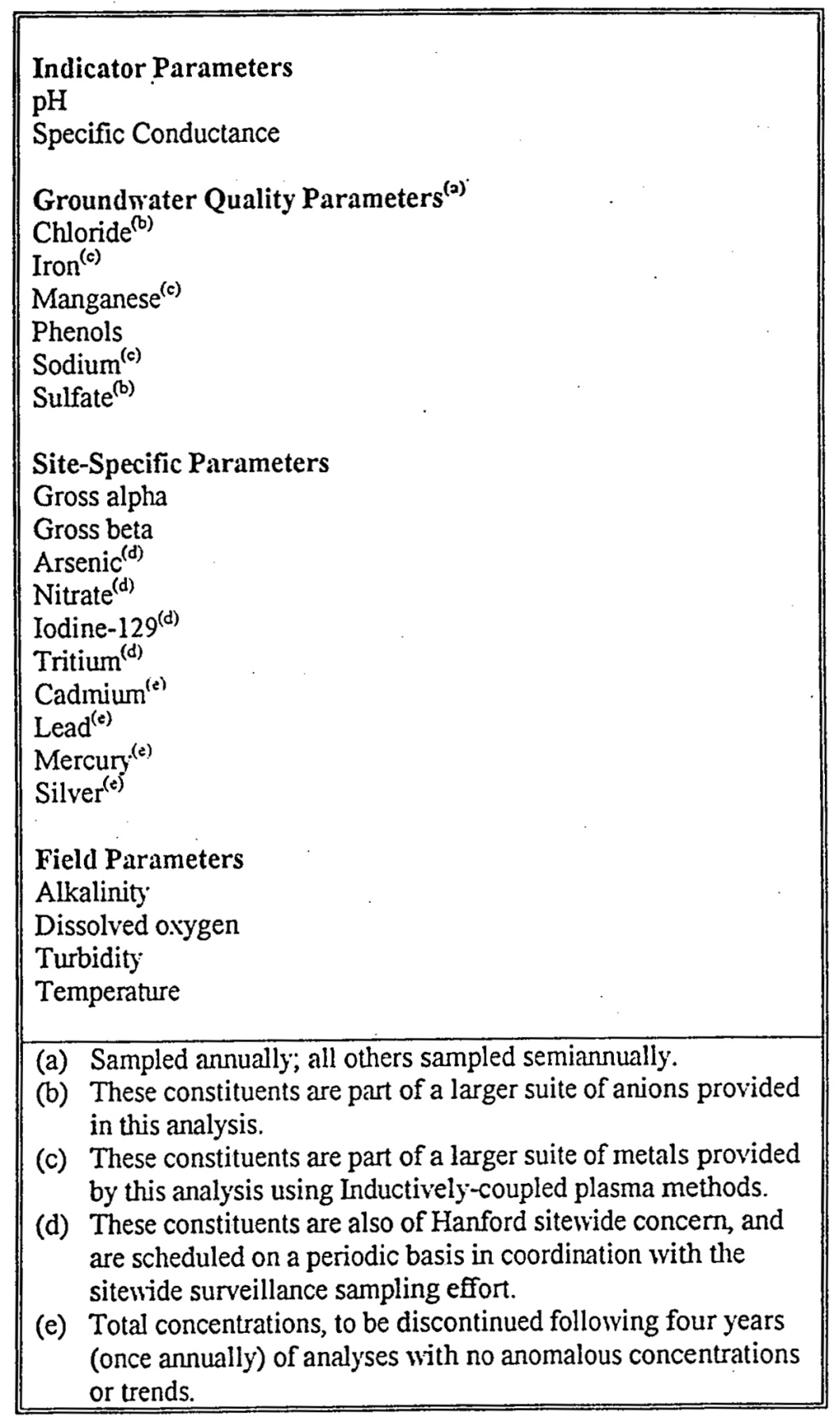




\section{Appendix B}

\section{B Pond Power Curves Evaluation}




\section{Appendix B}

\section{B Pond Power Curves Evaluation}

This appendix presents results of the power curves evaluations for the combined Shewhart and CUSUM control limit (SCL and CCL) and the results for the Average-Replicate t-test method. The latter is the required statistical analysis method for Resource Conservation and Recover Act (RCRA)-regulated sites in detection status. Based on power curve evaluations and human health risk considerations, appropriate control limits are also provided.

\section{B.1 EPA Reference Power Curves}

To assist the regulatory community in selecting alternative tests to the default analysis of variance (ANOVA) procedure, the U. S. Environmental Protection Agency (EPA) provides reference power curves EPA (1992, page B-6) that correspond to 8, 16, 24, and 32 background samples (Figure B.1) for comparisons with the power curves of proposed tests. Figure B.1 shows the probability (referred to by EPA as the effective power) of detecting a shift from 0 to 5 sigma units in mean concentration for a single water quality parameter in any well in the network. The power at 0 sigma unit, called the false positive rate or size of the test, is the probability of falsely concluding that a well has increased concentrations of a water quality parameter, when, in fact, it is at baseline concentrations.

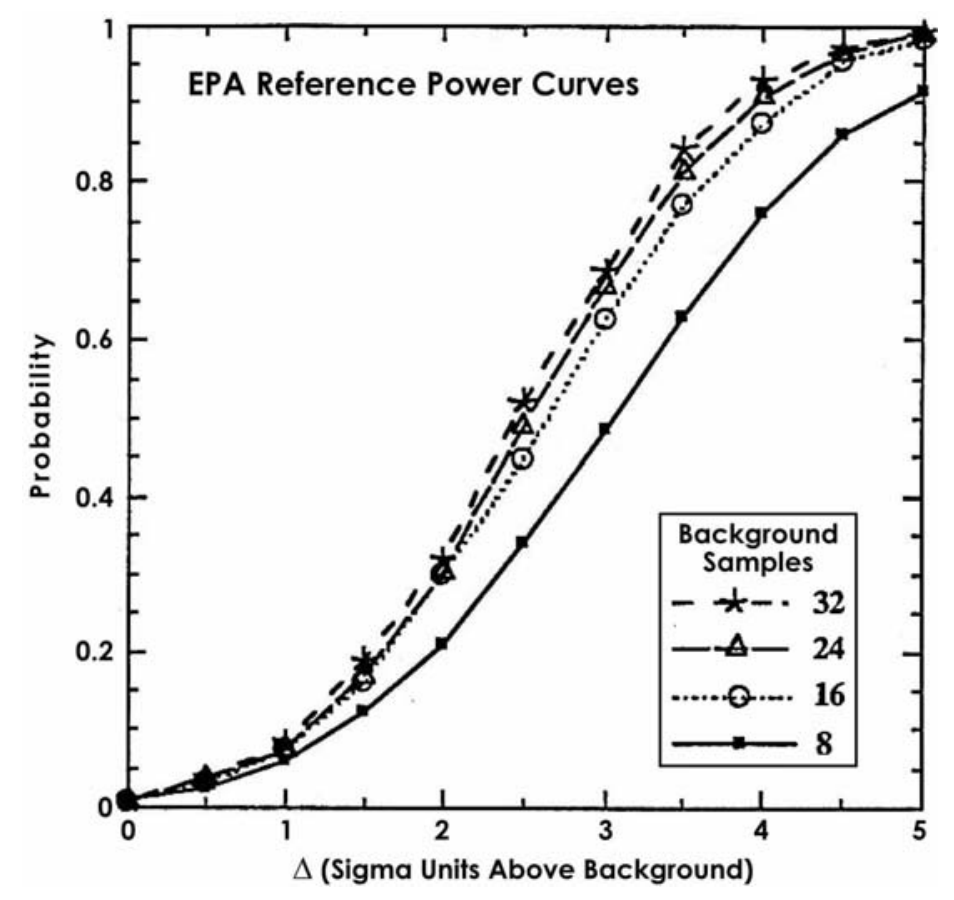

Figure B.1. EPA Power Curves (EPA 1992, page B-6) 
A probability of approximately $1 \%$ near ' 0 ' sigma unit is shown in Figure B.1. This is the requirement mandated by EPA for any individual comparison; however, EPA also mandates a 5\% overall network-wide false positive rate (across all wells and constituents) be kept by any testing scheme during each sampling event (EPA 1992, pages 62-66). A test is judged to be acceptable if its power is comparable to the EPA reference power curves while maintaining an approximate $5 \%$ overall false positive rate. In the following sections the power curves of the combined Shewhart-CUSUM method are compared with the EPA reference power curve and ASTM (1998) guidance.

\section{B.2 The Combined Shewhart-CUSUM Control Chart Method}

Monte Carlo simulations were conducted to find appropriate Shewhart and CUSUM control limits that would attain various false positive and false negative rates for the current B Pond network that consists of four monitoring wells and three site-specific water quality parameters. The objective in these simulations was to find control limits that will: 1) keep the site-wide false positive rate (4 wells and 3 constituents or 12 comparisons) at approximately $5 \%$ when water quality is at baseline levels, and 2) provide adequate power (low false negative rate that is similar to EPA reference power curves) to detect real contamination when it occurs. Power curves were computed by Dr. R. F. O’Brien, of Pacific Northwest National Laboratory's Statistical and Quantitative Science Group, for five control limit cases and are presented in Figures B.2 through B.6:

- Case 1: $\mathrm{SCL}=2$ and $\mathrm{CCL}=2$

- Case 2: $\mathrm{SCL}=3$ and $\mathrm{CCL}=3$

- Case 3: $\mathrm{SCL}=3.5$ and $\mathrm{CCL}=3.5$

- Case 4: $\mathrm{SCL}=4$ and $\mathrm{CCL}=4$

- Case 5: $\mathrm{SCL}=4.5$ and $\mathrm{CCL}=4.5$

In all five cases evaluated for the B Pond system, the $\mathrm{k}$ value is fixed at 1 sigma unit because the number of baseline samples is less than 12. Additionally, one verification sample after the initial exceedance is considered in the Monte Carlo simulations.

The power curves in each case in Figures B.2 through B.6 show the probability, or equivalently the power, of detecting a shift of various sigma (baseline standard deviation) units above baseline mean in each of five consecutive (the first, second, third, fourth, and fifth) sampling periods that are assumed to provide independent samples. The power curves in Figures B.2 through B.6 show the probability (vertical axis) of detecting a shift from 0 to 5 sigma units (horizontal axis) in mean concentration from a single groundwater quality parameter in any of the four monitoring wells in the network. If a constituent of concern from a particular well has a standard deviation of $1.5 \mathrm{pCi} / \mathrm{L}$, then the standardized sigma units (horizontal axis) in Figures B.2 through B.6 would translate into a shift of $1.5 \mathrm{pCi} / \mathrm{L}$ at 1 sigma unit, $3.0 \mathrm{pCi} / \mathrm{L}$ at 2 sigma units, $4.5 \mathrm{pCi} / \mathrm{L}$ at 3 sigma units, $6.0 \mathrm{pCi} / \mathrm{L}$ at 4 sigma units, and $7.5 \mathrm{pCi} / \mathrm{L}$ at 5 sigma units. 


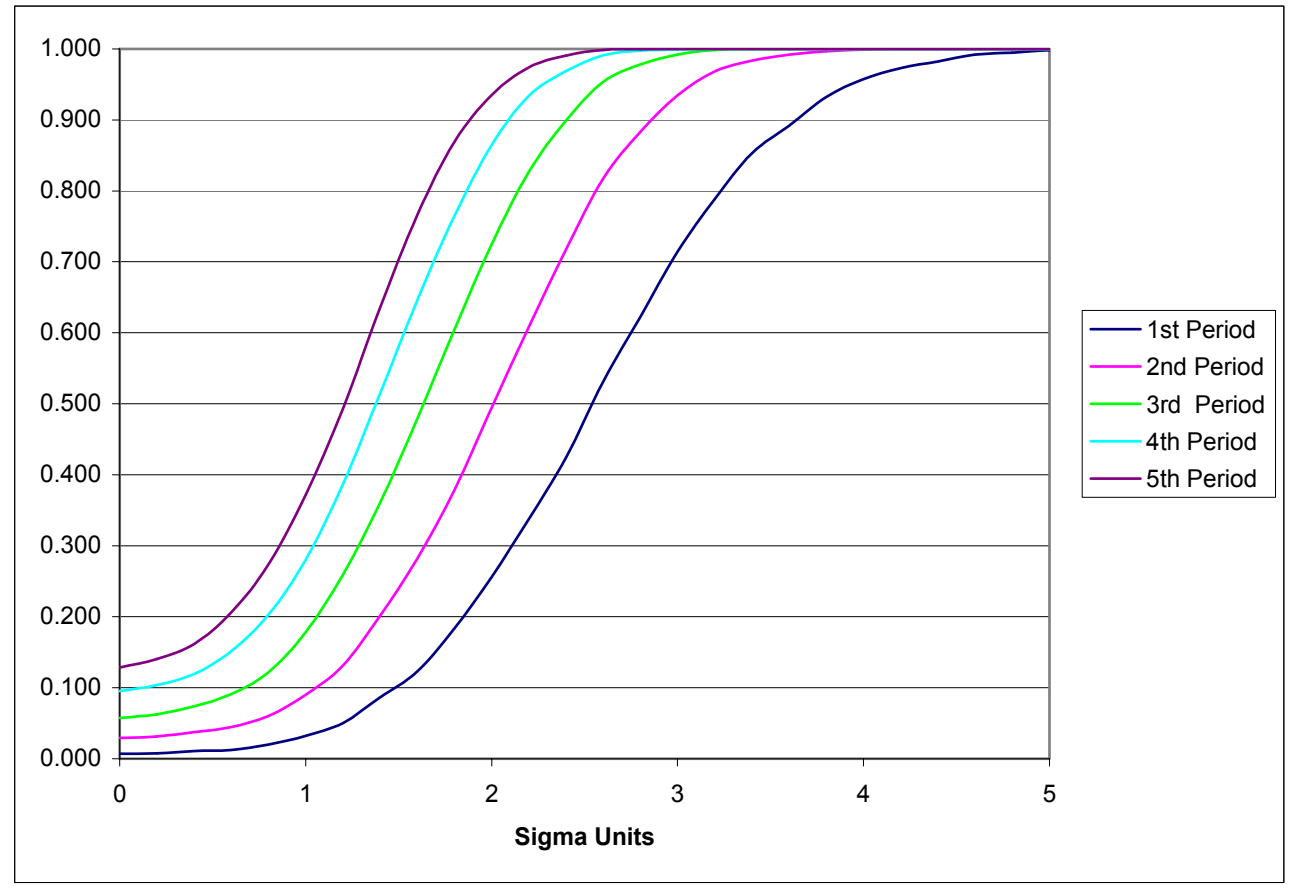

Figure B.2. Power Curves for Three Constituents, Four Wells, SCL $=2$ and $C C L=2$

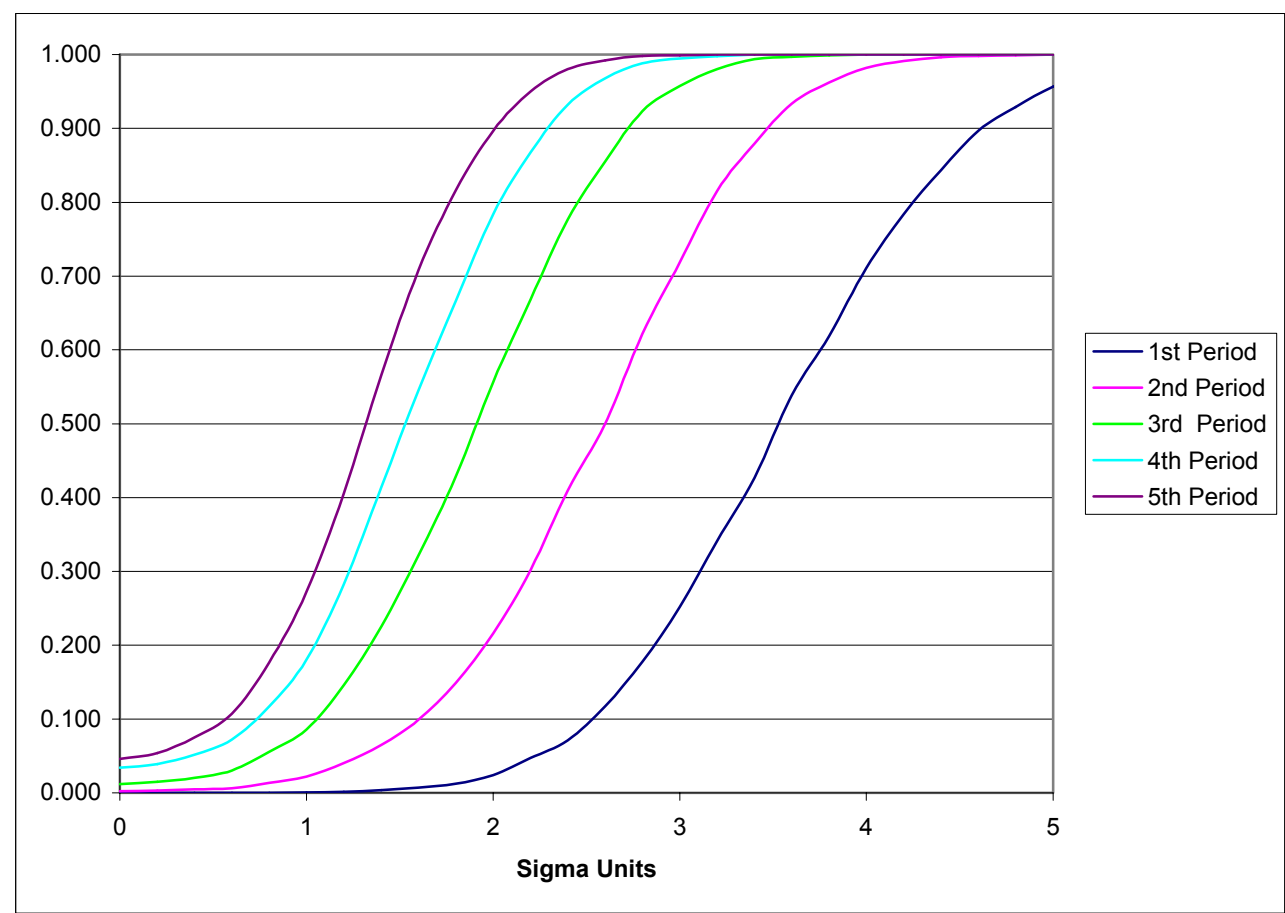

Figure B.3. Power Curves for Three Constituents, Four Wells, SCL $=3$ and $C C L=3$ 


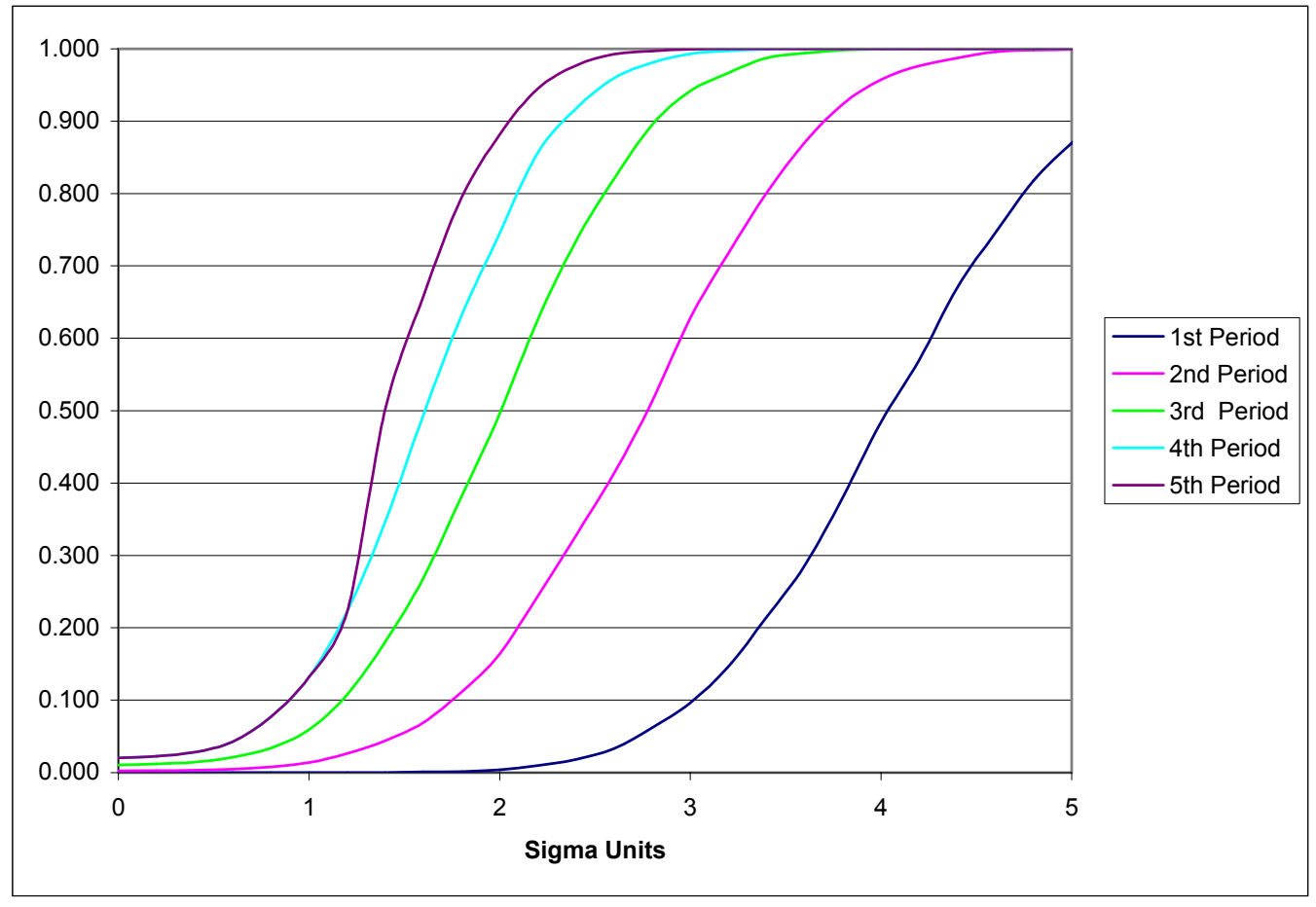

Figure B.4. Power Curves for Three Constituents, Four Wells, SCL $=3.5$ and CCL $=3.5$

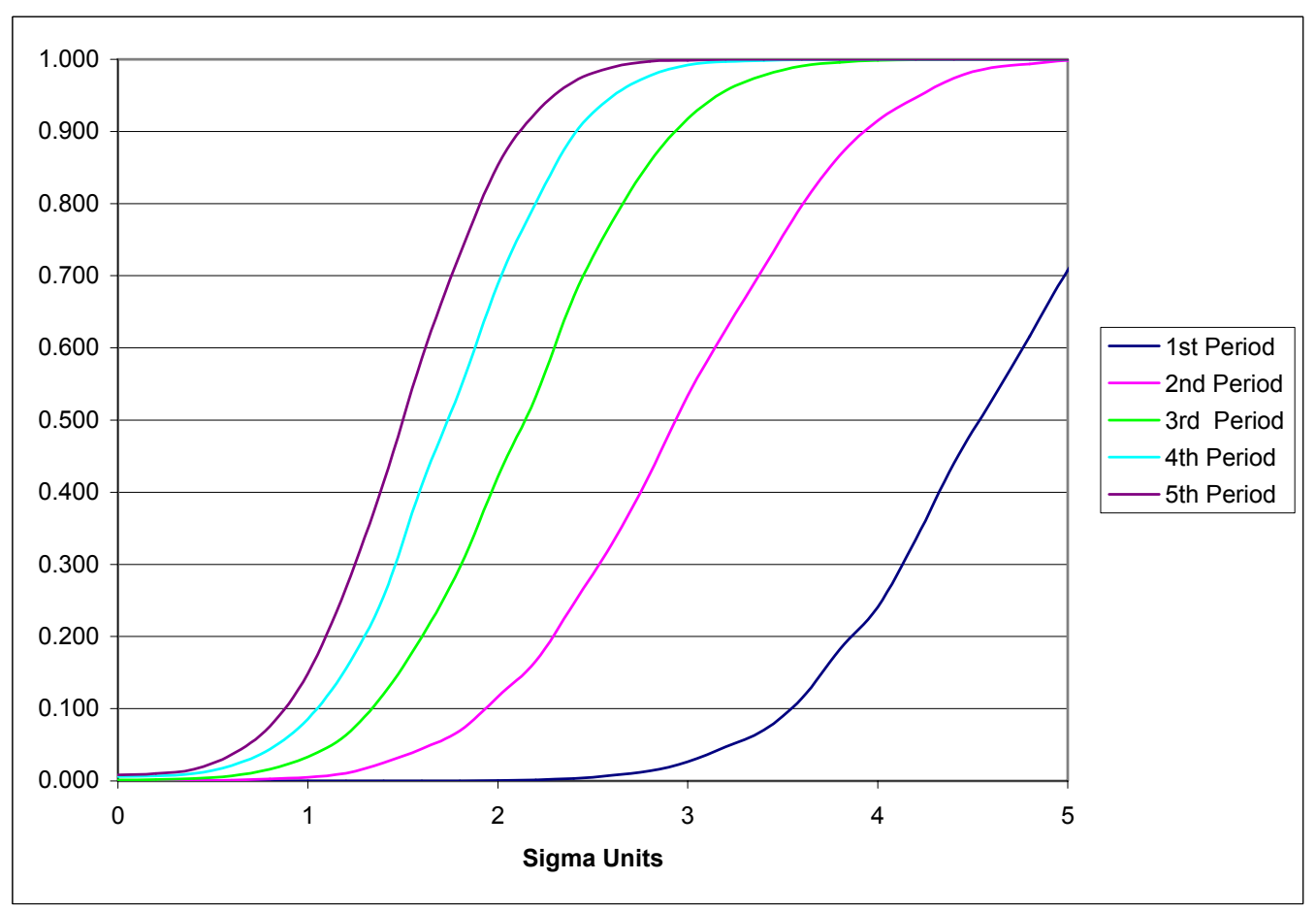

Figure B.5. Power Curves for Three Constituents, Four Wells, SCL $=4$ and CCL $=4$ 


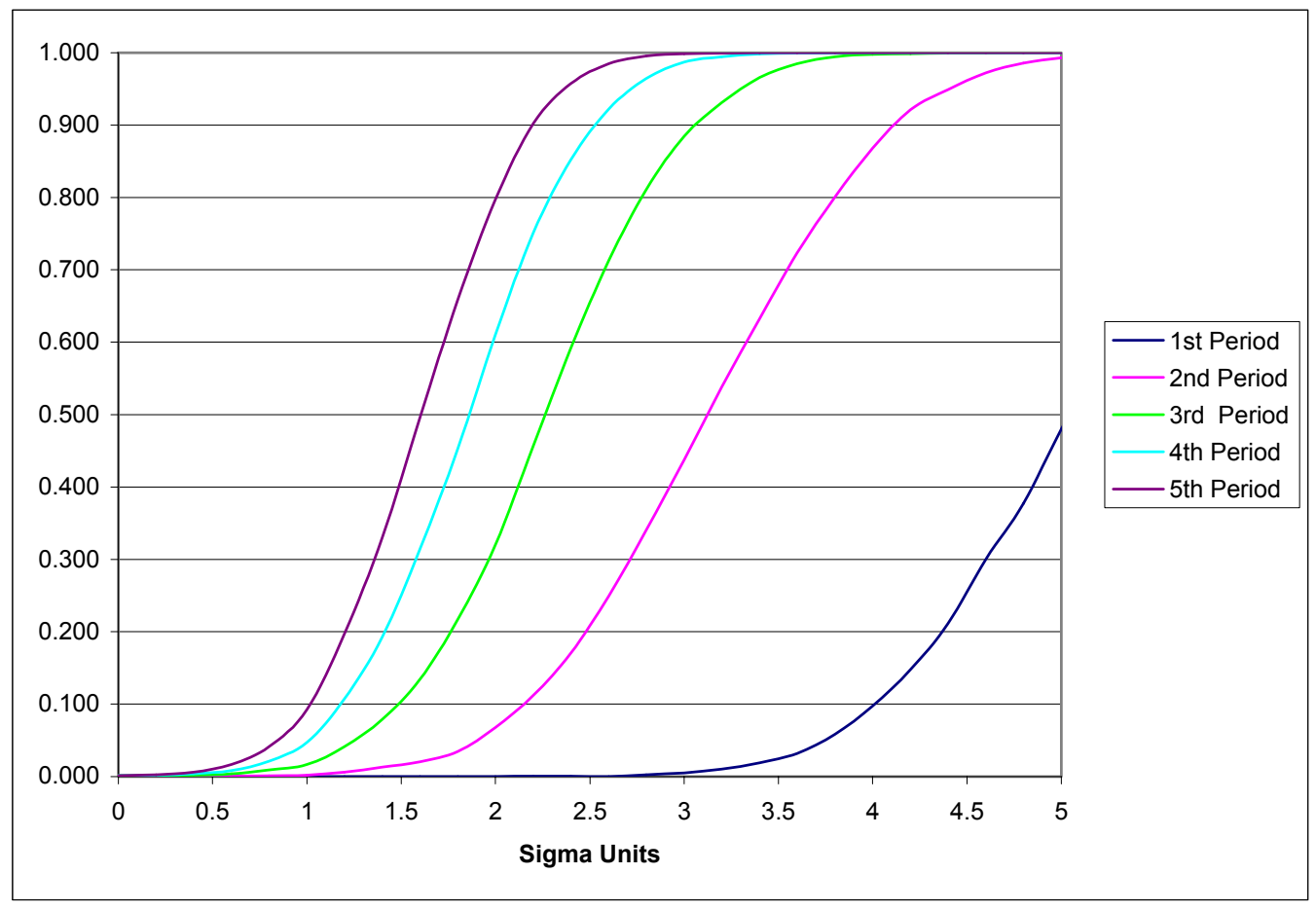

Figure B.6. Power Curves for Three Constituents, Four Wells, SCL $=4.5$ and CCL $=4.5$

It is important to notice the condition where monitoring is at baseline levels (sigma units $=0$ ). The power at 0 sigma units is called the false positive rate (i.e., size of the test). This is the probability of falsely concluding that a well has increased concentrations of a groundwater quality parameter when, in fact, it is at baseline concentrations. ASTM (1998, section 5.1.4.3, page 10) stated that, as a general rule, a site-wide false positive rate of $5 \%$ and a false negative rate of approximately $5 \%$ (i.e., $95 \%$ power) for differences on the order of 3 to 4 standard deviation units (sigma units) are recommended. Therefore, ASTM recommendations and EPA guidance (1992, pages 62-66) are used to first screen the power curves plotted (Figures B.2 through B.6) for the five cases listed above. The results are discussed in the following paragraphs.

Case 1 (where $\mathrm{SCL}=2$ and CCL at 2) is not considered because of the site-wide false positive rate is more than 5\% as recommended by ASTM and EPA (1992, page 64). A site-wide false positive rate of $6 \%, 10 \%$, and $13 \%$ (Figure B.2) are indicated at the third, fourth, and fifth sampling event for Case 1, respectively. This means that the site will be falsely triggered into assessment more than 1 out of 10 times, by chance alone, under Case 1 conditions. Case 2 (where SCL $=3$ and CCL $=3$ ), Case 3 (where $\mathrm{SCL}=3.5$ and $\mathrm{CCL}=3.5$ ), Case 4 (where $\mathrm{SCL}=4$ and $\mathrm{CCL}=4$ ), and Case 5 (where $\mathrm{SCL}=4.5$ and $\mathrm{CCL}$ $=4.5$ ) passed the $5 \%$ site-wide false positive rate test. These four cases are further evaluated for false negative rate as described below.

None of these cases (Cases 2, 3, 4, and 5) provide a false negative rate of approximately 5\% (or approximately $95 \%$ power), in the first and second sampling events, for detecting differences on the order of 3 standard deviation units (Figures B.3 through B.6). However, all cases achieve the ASTM guidance 
of having a false negative rate approximately $5 \%$ (or $95 \%$ power) to detect a difference that is at 4 standard deviation units above the baseline mean in the second sampling event. Furthermore, the power is close to 1 at the third, fourth, and fifth sampling events to detect a difference that is about 4 standard deviation units above the mean.

Because Case 2, 3, 4, and 5 are essentially tied with regard to the false negative rate evaluations, another criterion, the human health risk factor, is used to assist in the selection of proposed control limits for the B Pond system. This is achieved by standardizing the drinking water standards (DWS) as provided in Washington State primary or secondary maximum contaminant levels (WAC 246-290-310) in relation to the baseline statistics to calculate standardized units or sigma units [i.e., sigma units $=(\mathrm{DWS}-$ baseline mean)/baseline standard deviation] for each constituent and for each monitoring well in the network. These standardized results are shown at the bottom of Tables B.1 through B.3 for the three sitespecific parameters as described below.

The secondary maximum contaminant level for specific conductance is $7001 \mathrm{~S} / \mathrm{cm}$ (WAC 246-290310). The calculated baseline mean is $255.51 \mathrm{~S} / \mathrm{cm}$ and baseline standard deviation is $11.21 \mathrm{~S} / \mathrm{cm}$ (see Table B.1) for well 699-42-42B. Thus, the DWS is about 40 [(700 - 255.5)/11.2 = 39.6] standard deviation units above the baseline mean concentration for well 699-42-42B. In other words, when the standardized units approach 40 , the specific conductance concentration will be at about the DWS for this well and could have an adverse effect on human health.

Table B.1. Specific Conductance Baseline Summary Statistics, Various Control Limits, and Drinking Water Standards for the B Pond System Wells

\begin{tabular}{|c|c|c|c|c|}
\hline & $\begin{array}{c}\text { 699-42-42B } \\
(\mu / \mathrm{cm})\end{array}$ & $\begin{array}{c}\text { 699-43-44 } \\
(\mu / \mathrm{cm})\end{array}$ & $\begin{array}{c}\text { 699-43-45 } \\
(\mu / \mathrm{cm})\end{array}$ & $\begin{array}{c}\text { 699-44-39B } \\
(\mu / \mathrm{cm})\end{array}$ \\
\hline \multicolumn{5}{|l|}{ Baseline Statistics $^{(a)}$} \\
\hline Mean $(\bar{x})$ & 255.50 & 267.41 & 226.03 & 262.22 \\
\hline Standard Deviation $(\mathrm{s})$ & 11.23 & 9.50 & 6.23 & 22.55 \\
\hline \multicolumn{5}{|l|}{ Shewhart-CUSUM Control Limits ${ }^{(a)}$} \\
\hline Control Limit $(\bar{x}+2 s)$ & 278 & 286 & 238 & 307 \\
\hline Control Limit $(\bar{x}+3 s)$ & 289 & 296 & 245 & 330 \\
\hline Control Limit $(\bar{x}+3.5 \mathrm{~s})$ & 295 & 301 & 248 & 341 \\
\hline Control Limit $(\bar{x}+4 s)$ & 300 & 305 & 251 & 352 \\
\hline Control Limit $(\bar{x}+4.5 \mathrm{~s})$ & 306 & 310 & 254 & 364 \\
\hline \multicolumn{5}{|l|}{ Groundwater Protection Standard } \\
\hline Drinking Water Standard (DWS) ${ }^{(\mathrm{b})}$ & 700 & 700 & 700 & 700 \\
\hline DWS in Sigma Units above Mean ${ }^{(\mathrm{c})}$ & 40 & 46 & 76 & 19 \\
\hline \multicolumn{5}{|c|}{$\begin{array}{l}\text { (a) Obtained from Table } 2 \text { in main body of this report. } \\
\text { (b) Secondary maximum contaminant levels, WAC 246-290-310. } \\
\text { (c) Sigma units = (DWS - mean)/standard deviation. }\end{array}$} \\
\hline
\end{tabular}


Table B.2. Gross Alpha Baseline Summary Statistics, Various Control Limits, and Drinking Water Standards for the B Pond System Wells

\begin{tabular}{|c|c|c|c|c|}
\hline & $\begin{array}{c}699-42-42 \mathrm{~B} \\
(\mathrm{pCi} / \mathrm{L})\end{array}$ & $\begin{array}{c}699-43-44 \\
(\mathrm{pCi} / \mathrm{L})\end{array}$ & $\begin{array}{c}699-43-45 \\
(\mathrm{pCi} / \mathrm{L})\end{array}$ & $\begin{array}{c}\text { 699-44-39B } \\
(\mathrm{pCi} / \mathrm{L})\end{array}$ \\
\hline \multicolumn{5}{|l|}{ Baseline Statistics $^{(\mathrm{a})}$} \\
\hline Mean $(\bar{x})$ & 1.76 & 1.99 & 1.03 & 1.65 \\
\hline Standard Deviation (s) & 0.64 & 0.84 & 0.52 & 0.52 \\
\hline \multicolumn{5}{|l|}{ Shewhart-CUSUM Control Limits ${ }^{(\mathrm{a})}$} \\
\hline Control Limit $(\bar{x}+2 s)$ & 3.04 & 3.67 & 2.07 & 2.68 \\
\hline Control Limit $(\bar{x}+3 s)$ & 3.68 & 4.52 & 2.59 & 3.20 \\
\hline Control Limit $(\bar{x}+3.5 \mathrm{~s})$ & 4.00 & 4.93 & 2.85 & 3.46 \\
\hline Control Limit $(\bar{x}+4 s)$ & 4.32 & 5.36 & 3.11 & 3.72 \\
\hline Control Limit $(\bar{x}+4.5 \mathrm{~s})$ & 4.65 & 5.78 & 3.37 & 3.97 \\
\hline \multicolumn{5}{|l|}{ Groundwater Protection Standard } \\
\hline Drinking Water Standard (DWS) ${ }^{(\mathrm{b})}$ & 15 & 15 & 15 & 15 \\
\hline DWS in Sigma Units above Mean ${ }^{(\mathrm{c})}$ & 21 & 16 & 27 & 26 \\
\hline \multicolumn{5}{|c|}{ (a) Obtained from Table 3 in main body of this report. } \\
\hline \multicolumn{5}{|c|}{ (b) Maximum contaminant level for gross alpha particle activity (excluding uranium), WAC 246-290-310. } \\
\hline
\end{tabular}

Table B.3. Gross Beta Baseline Summary Statistics, Various Control Limits, and Drinking Water Standards for the B Pond System Wells

\begin{tabular}{|c|c|c|c|c|}
\hline & $\begin{array}{c}\text { 699-42-42B } \\
(\mathrm{pCi} / \mathrm{L})\end{array}$ & $\begin{array}{c}699-43-44 \\
(\mathrm{pCi} / \mathrm{L})\end{array}$ & $\begin{array}{c}\text { 699-43-45 } \\
(\mathrm{pCi} / \mathrm{L})\end{array}$ & $\begin{array}{c}\text { 699-44-39B } \\
(\mathrm{pCi} / \mathrm{L})\end{array}$ \\
\hline \multicolumn{5}{|l|}{ Baseline Statistics $^{(\mathrm{a})}$} \\
\hline $\operatorname{Mean}(\bar{x})$ & 6.51 & 6.06 & 5.91 & 5.88 \\
\hline Standard Deviation (s) & 1.11 & 1.04 & 1.09 & 2.35 \\
\hline \multicolumn{5}{|l|}{ Shewhart-CUSUM Control Limits ${ }^{(a)}$} \\
\hline Control Limit $(\bar{x}+2 s)$ & 9.00 & 8.13 & 8.08 & 10.58 \\
\hline Control Limit $(\bar{x}+3 s)$ & 10.66 & 9.17 & 9.17 & 12.93 \\
\hline Control Limit $(\bar{x}+3.5 \mathrm{~s})$ & 11.60 & 9.70 & 9.72 & 14.10 \\
\hline Control Limit $(\bar{x}+4 s)$ & 12.62 & 10.21 & 10.26 & 15.28 \\
\hline Control Limit $(\bar{x}+4.5 \mathrm{~s})$ & 13.73 & 10.73 & 10.80 & 16.45 \\
\hline \multicolumn{5}{|l|}{ Groundwater Protection Standard } \\
\hline Drinking Water Standard (DWS $)^{(\mathfrak{b})}$ & $\overline{50}$ & 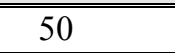 & $\overline{50}$ & $\overline{50}$ \\
\hline DWS in Sigma Units above Mean ${ }^{(\mathrm{c})}$ & 12 & 60 & 40 & 19 \\
\hline \multicolumn{5}{|c|}{ (a) Obtained from Table 4 in main body of this report. } \\
\hline \multicolumn{5}{|c|}{ (b) Maximum contaminant level for gross beta particle activity, WAC 246-290-310. } \\
\hline \multicolumn{5}{|c|}{ (c) Sigma Units $=($ DWS - mean $) /$ standard deviation. } \\
\hline
\end{tabular}


Similar calculations were made for gross alpha and gross beta. Examining these standardized units (see bottom of Tables B.1 through B.3), the smallest number is 12 (see Table B.3). Therefore, another figure (Figure B.7), which is the same power curves as Case 5 (where $\mathrm{SCL}=\mathrm{CCL}=4.5$ ) except for the $\mathrm{x}$ axis, is extended from 5 to 8 sigma units. This figure shows that the power (for Case 5) to detect a difference that is on the order of 8 sigma units or larger approaches 1 even in the first sampling event.

\section{B.3 The Average-Replicate t-test Method}

The variance to depart from interim status requirement as allowed by Ecology (see Appendix A.1) is for a two-year trial period or four sampling events starting January 2002. In January 2004, B Pond will revert to interim status requirement and will be subject to the use of AR t-test method for statistical evaluations. The fundamental question is:

Is the AR t-test a better method (i.e., more protective to human health and risk to the environment)?

To provide an answer to the above question, the power curve for the AR t-test method for the B Pond system (four wells and three constituents of concern) is provided in Figure B.8. The site-wide false positive rate is set at $\alpha=0.01 / 12=0.0008333$ as required by 40 CFR 265.93 (b) [and referenced by WAC 173-303-400].

As shown in Figure B.8, the power of the AR t-test is near zero (i.e., false negative rate is close to 1) to detect a difference that is about 4 standard deviation units above the mean. In contrast, all cases evaluated under control chart method achieve the ASTM guidance of having a false negative rate approximately $5 \%$ (or $95 \%$ power) to detect a difference that is at 4 standard deviation units above the baseline mean in the second sampling event. Furthermore, the power is close to 1 at the third, fourth, and

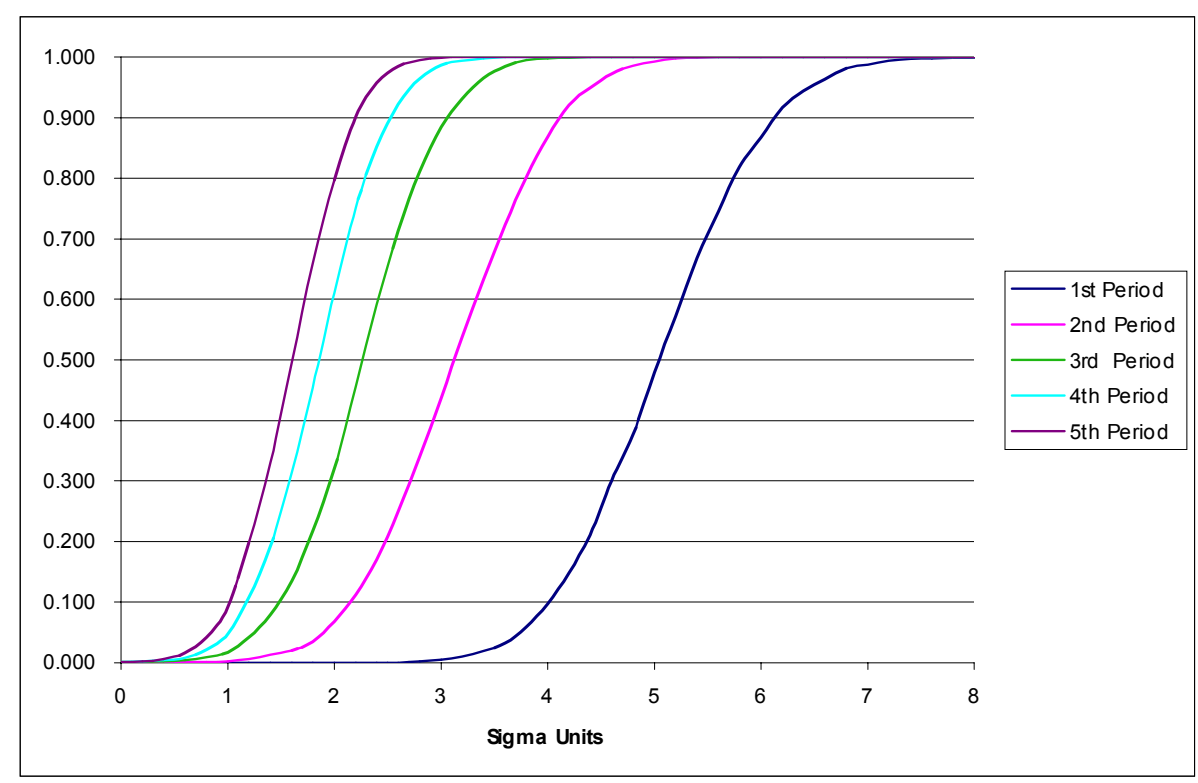

Figure B.7. Power Curves for Three Constituents and Four Wells, SCL $=4.5$ and $C C L=4.5$ 


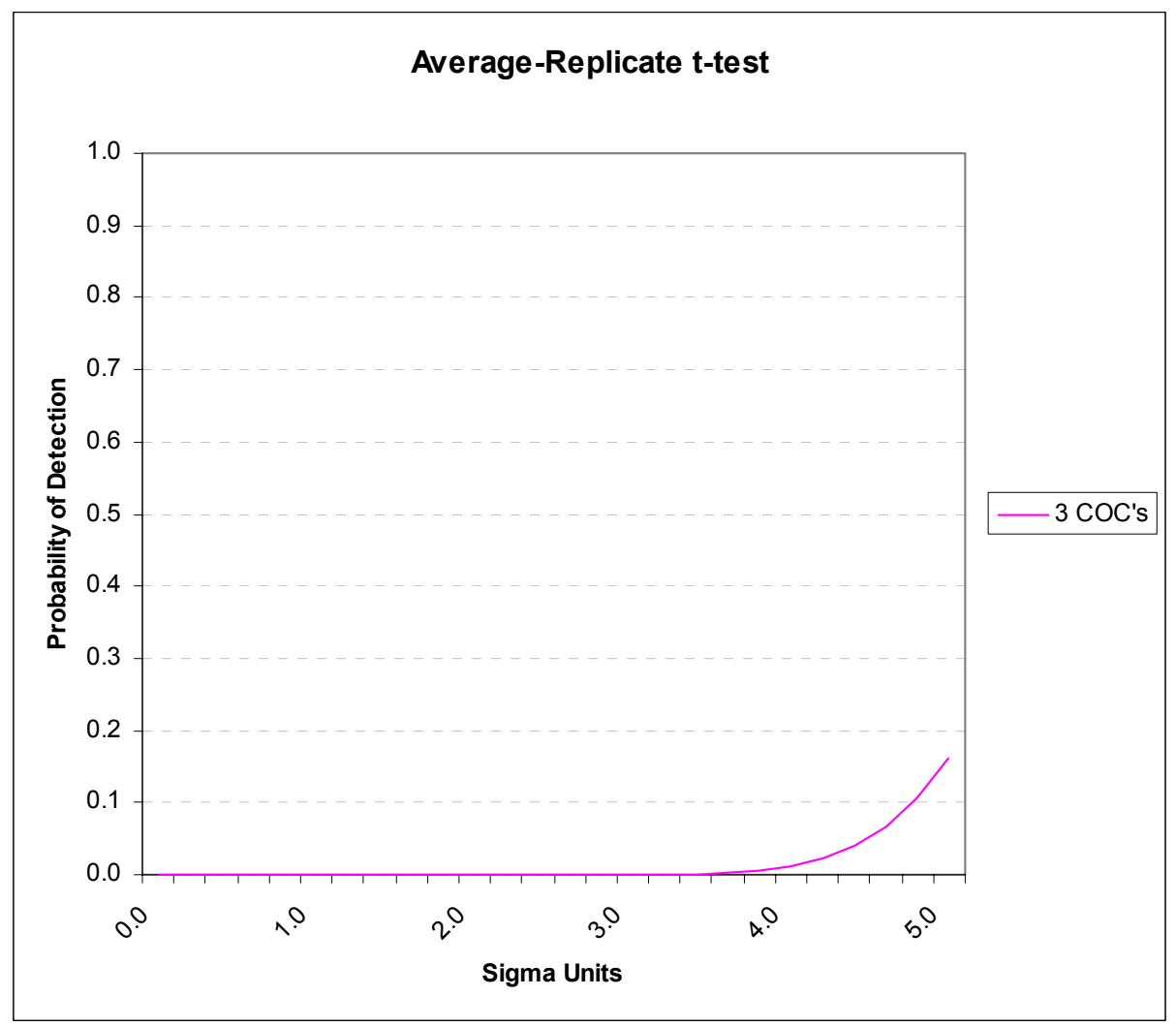

Figure B.8. Average-Replicate t-test Method Power Curve Using Three Constituents and Four Wells

fifth sampling events to detect a difference that is about 4 standard deviation units above the mean. Thus, from the view point of the ability (i.e., power) of the statistical test to detect real contamination when it occurs alone, the AR t-test (for two-well comparisons case) or the analysis of variance procedures (for multiple well comparisons) obviously are not the methods of choice.

\section{B.4 Conclusions}

Based on power evaluations, it is recommended not to use the AR t-test method or the analysis of variance procedure. The combined Shewhart-CUSUM control chart method has a higher power to detect real contamination if it occurs. Furthermore, it is recommended that both the SCL and CCL be set at 4.5 sigma units above the baseline concentration (see Tables B.1 through B.3) for the B Pond system for the following reasons:

- It provides the lowest false positive rate and yet provides adequate power $(\sim 95 \%)$ to detect a difference that is at 4 standard deviation units above the baseline mean in the second sampling event.

- The power is close to 1 at the third, fourth, and fifth sampling events to detect a difference that is about 4 standard deviation units above the mean. 
- If the concentration is close to the drinking water standards (and thus poses a risk to human health), the proposed control limits will have power to detect the high concentration with probability 1 ( 0 false negative rate) even in the first sampling event.

- The highest control limits (set at $\bar{x}+4.5 \mathrm{~s}$ level) for specific conductance is $364 \mu \mathrm{S} / \mathrm{cm}$ for well 699 44-39B (see Table B.1), which is about half of the DWS for this parameter; for gross alpha is 5.78 $\mathrm{pCi} / \mathrm{L}$ for well 699-43-44 (see Table B.2), which less than half of the DWS; and for gross beta is $16.45 \mathrm{pCi} / \mathrm{L}$ for well $699-44-39 \mathrm{~B}$ (see Table B.3), which is approximately one third of the DWS for this parameter.

The power curve simulations were conducted for the most conservative case of a release scenario that affects a single constituent in a single downgradient well. A more likely or realistic release event might involve multiple constituents in multiple wells. Therefore, the actual power may be considerably larger than that estimated by this study. The proposed sampling and statistical approach for the B Pond case is superior to the interim-status required AR t-test method.

From the standard point of risk assessment, the control limits set at $\mathrm{SCL}=\mathrm{CCL}=4.5$ will produce upper control limits far below the DWS for each of the constituent of concern for all the wells in the B Pond system. Finally, the proposed sampling and statistical approach will result in a less costly monitoring scheme while achieving the desired power and maintaining the EPA-recommended overall network-wide false positive decision error rate $(\sim 5 \%)$.

\section{B.5 References}

40 CFR 265.93(b). U.S. Environmental Protection Agency. “Ground-Water Monitoring." Code of Federal Regulations.

ASTM. 1998. Standard Guide for Developing Appropriate Statistical Approaches for Ground-Water Detection Monitoring Programs. D 6312-98, American Society for Testing and Materials, West Conshohocken, Pennsylvania.

EPA. 1992. Statistical Analysis of Groundwater Monitoring Data at RCRA Facilities - Draft Addendum to Interim Final Guidance. EPA/530-R-93-003, U.S. Environmental Protection Agency, Washington, D.C.

RCRA - Resource Conservation and Recovery Act. 1976. Public Law 94-580, as amended, 90 Stat. 2795, 42 USC 6901 et seq.

WAC 173-303-400. Interim Status Facility Standards. Washington Administrative Code, Olympia, Washington.

WAC 246-290-310. Public Water Supplies; Maximum Contaminant Levels (MCLs) and Maximum Residual Disinfectant Levels (MRDLs). Washington Administrative Code, Olympia, Washington. 


\section{Appendix C}

Normal Probability Plots for B Pond System 


\section{Appendix C}

\section{Normal Probability Plots for B Pond System}

One of the assumptions for the combined Shewhart-CUSUM control chart approach is that the data are normally distributed. One simple and easy way to evaluate whether a sample can reasonably be regarded as having come from a normal distribution is through the use of a normal probability plot. The plot is constructed so that if data points fall on a straight line, then these data can be assumed as drawn from a normal distribution. Following the Washington State Department of Ecology guidance letter (Appendix A.1), normal probability plots were generated and are presented here for each of the sitespecific parameters in each B Pond system well using monitoring data obtained from January 1995 through June 2001. The normal probability plots suggest that the normal distribution is a reasonable assumption except for gross beta in 699-42-42B, which is better represented by a log-normal distribution. (Note: the normal probability plot for gross beta from well 699-42-42B was plotted twice, the original scale is shown on the first figure, and log-transformed scale is shown on the second figure.) 

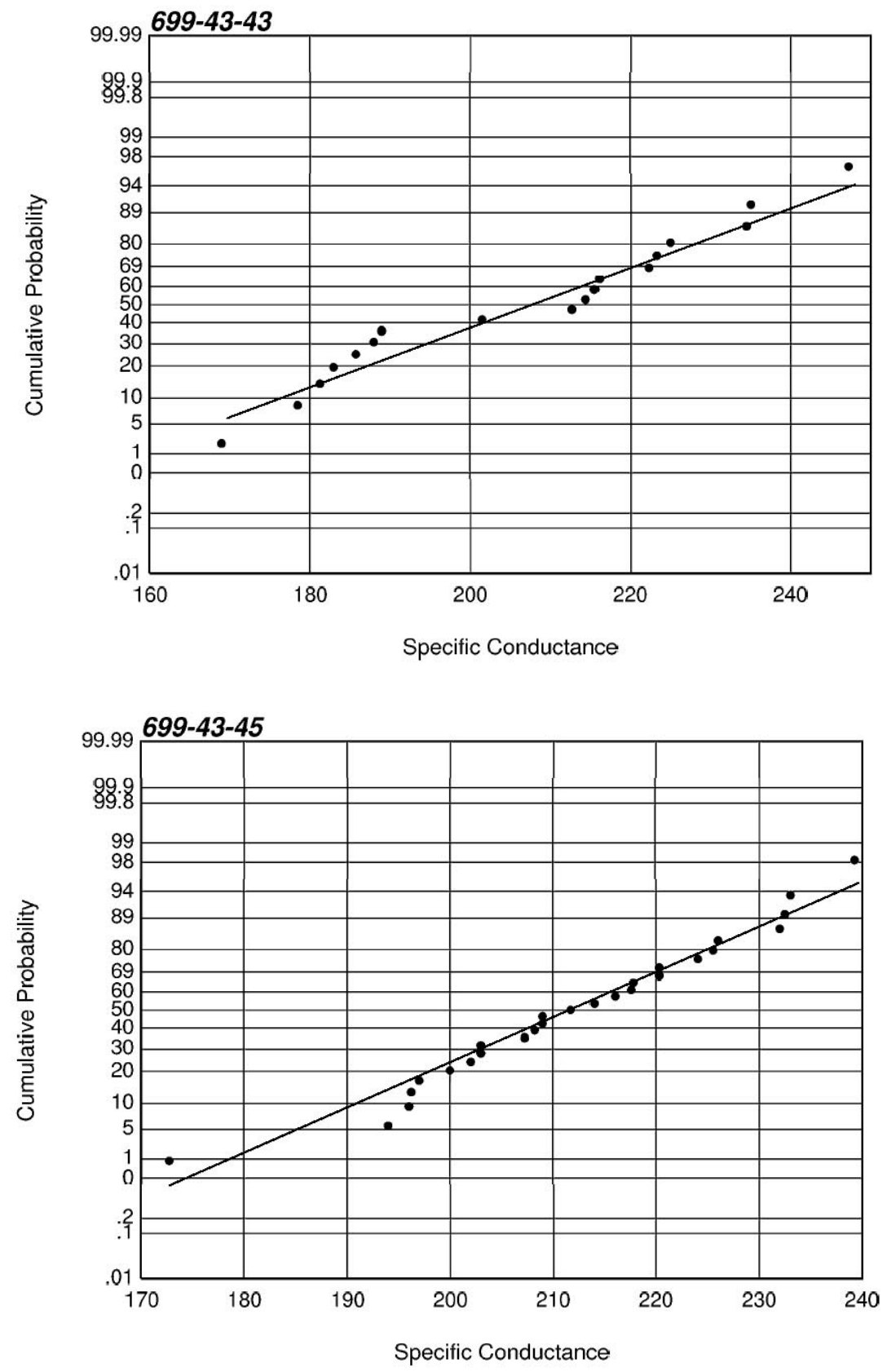

C. 2 

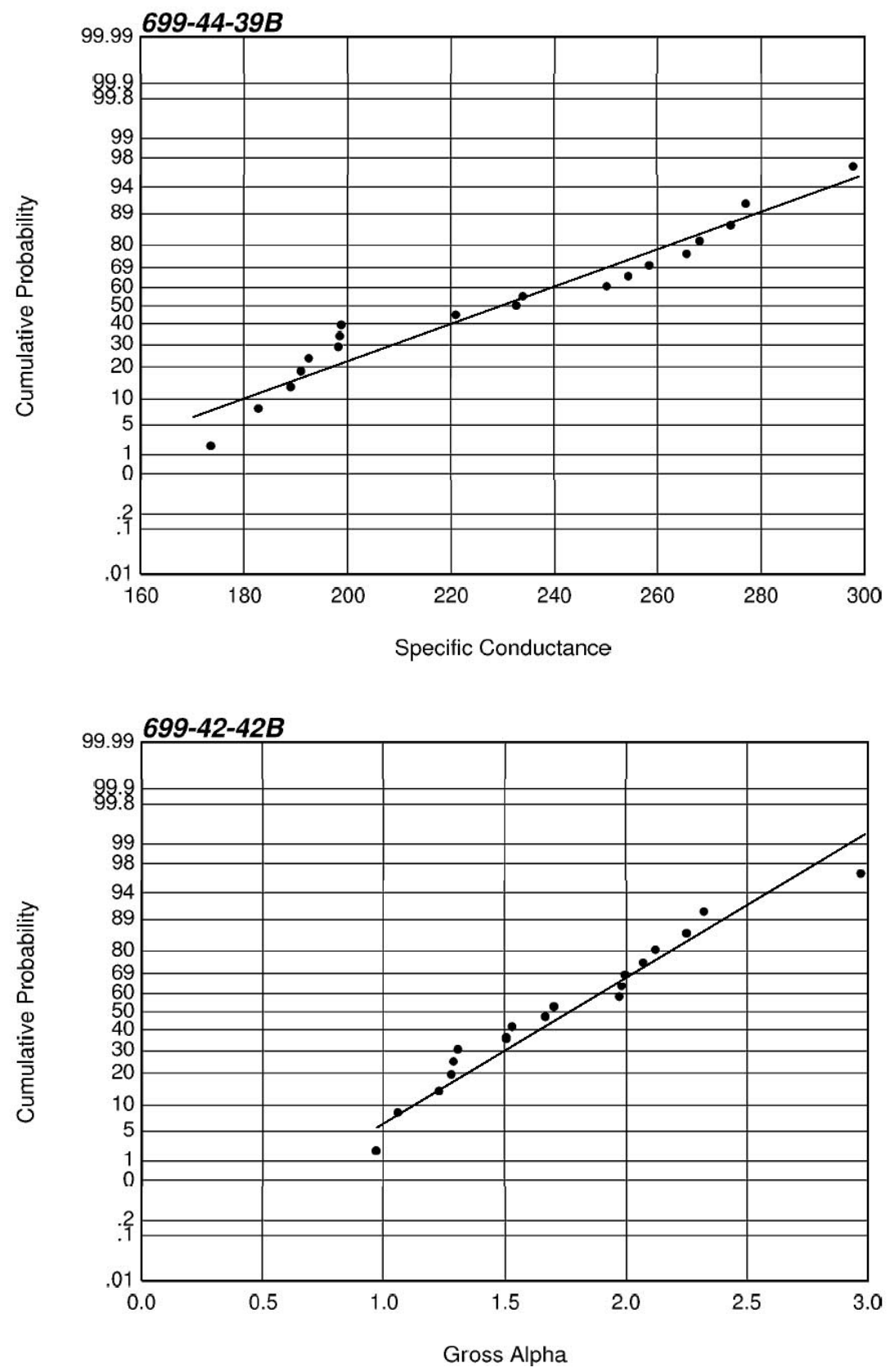

C. 3 

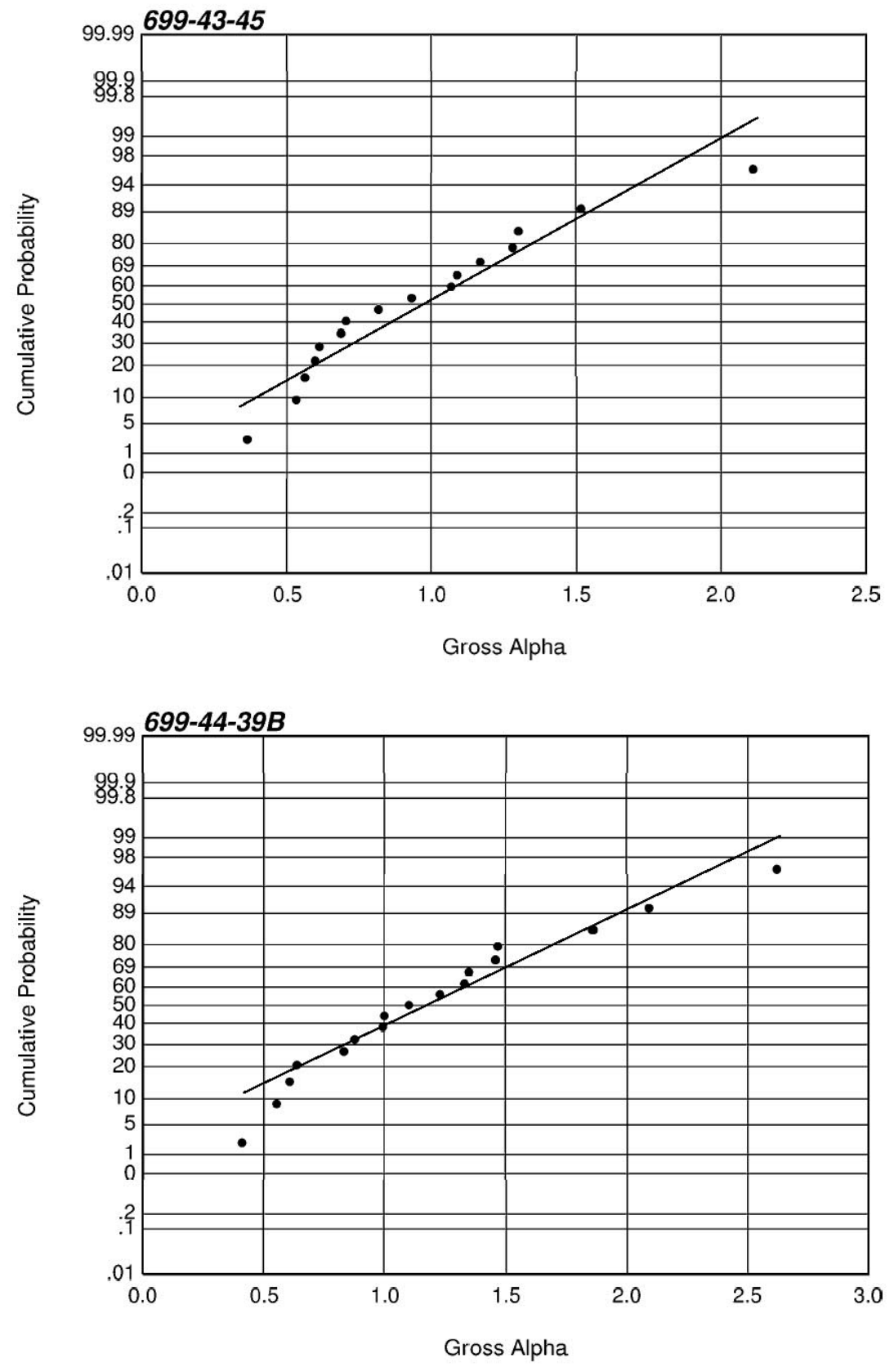

C. 4 

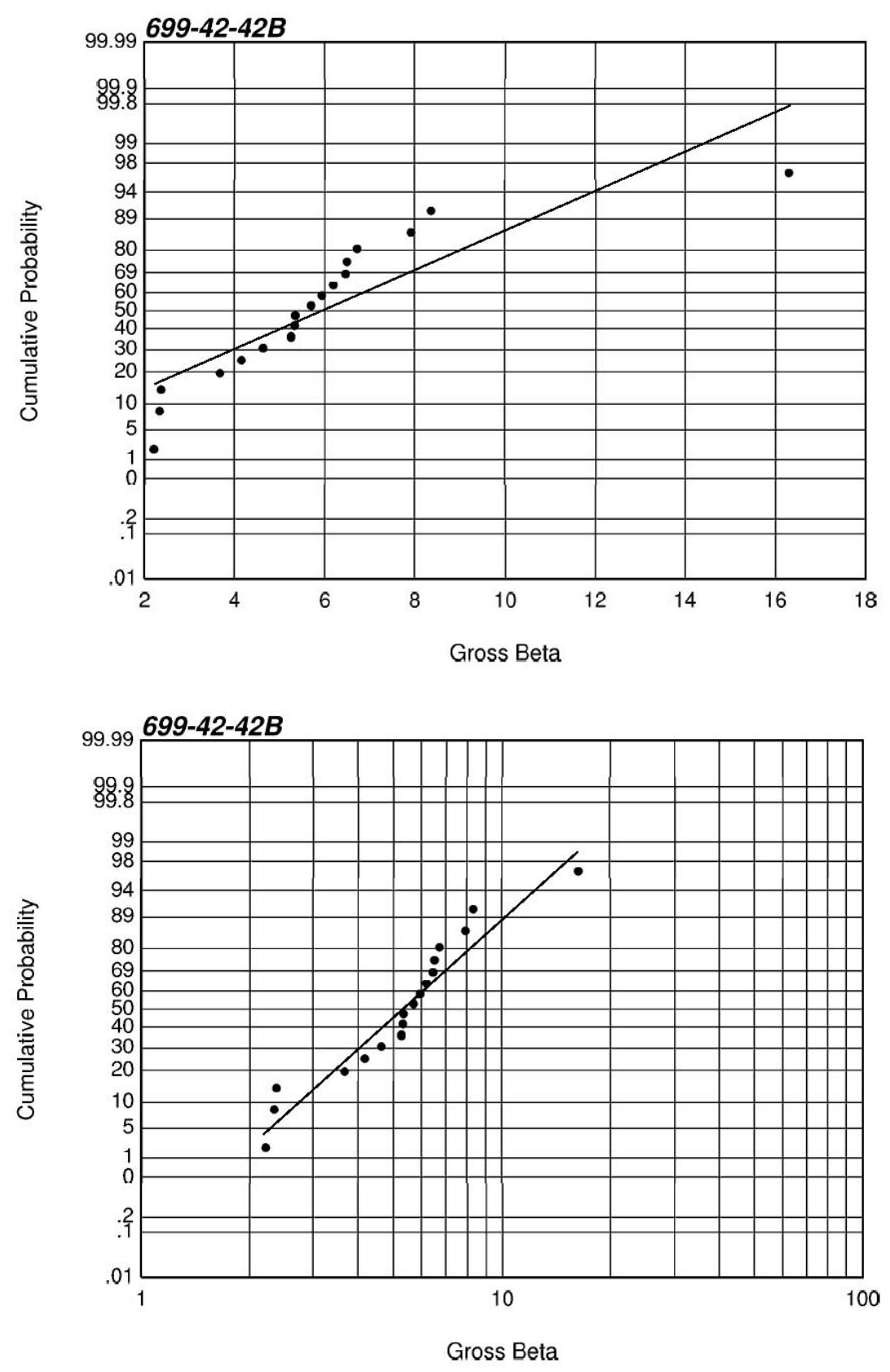

C. 5 

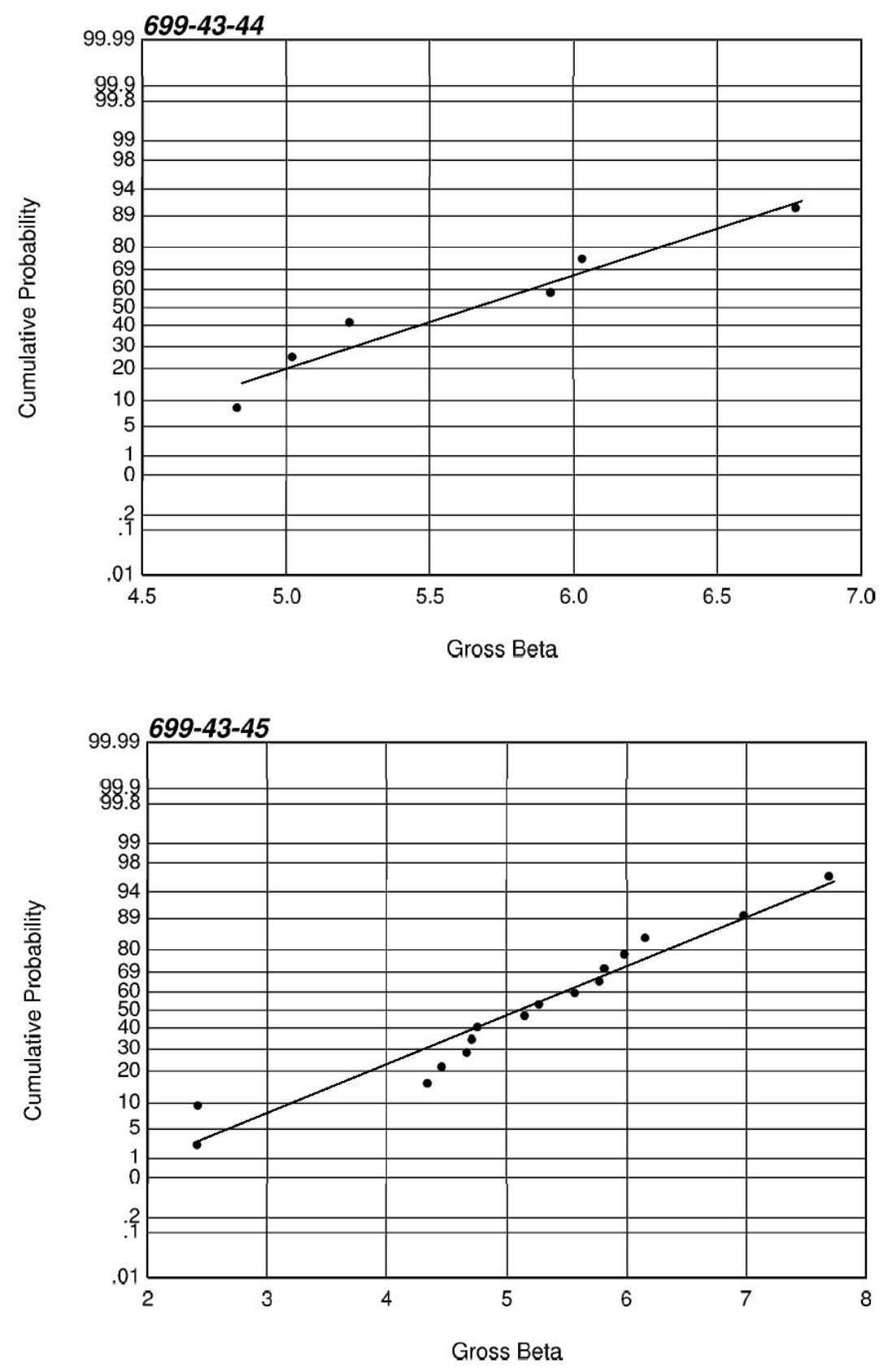

C. 6 


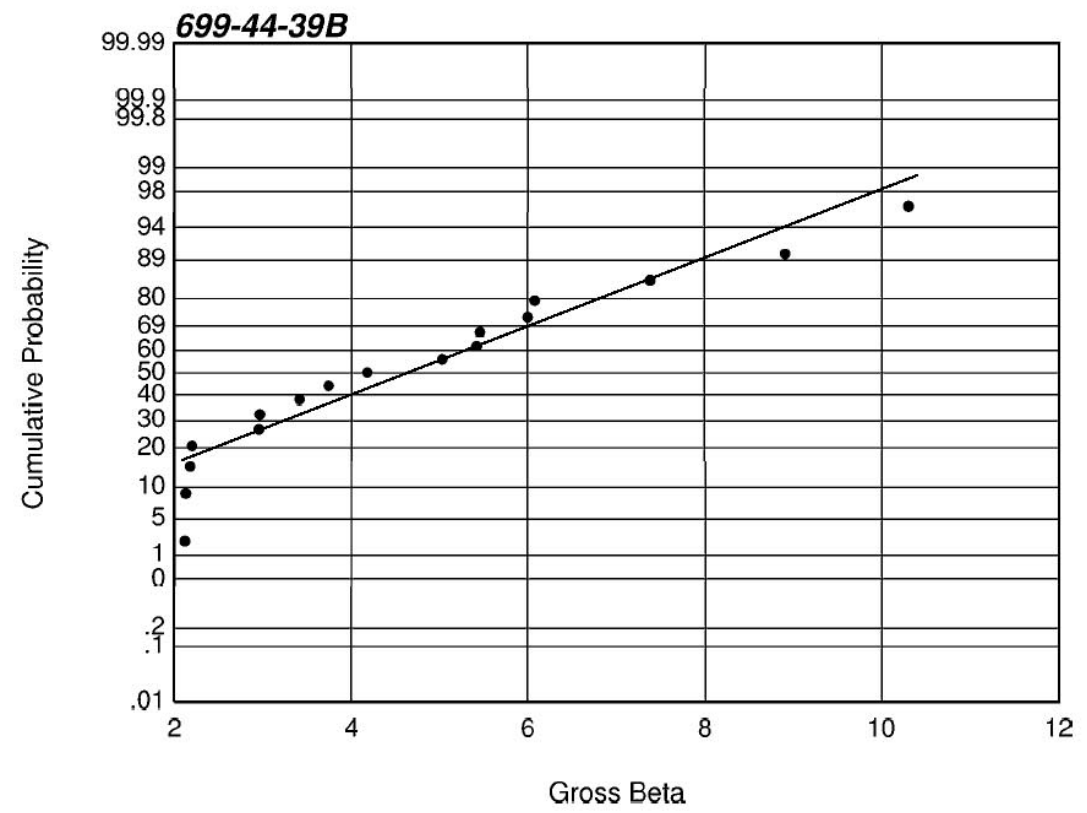

C. 7 


\section{Distribution}

No. of

Copies

OFFSITE

T. Stoops

Oregon Department of Energy

625 Marion Street, N.E., Suite 1

Salem, OR 97301-3742

\section{ONSITE}

7 DOE, Richland Operations Office

J. G. Morse

A6-38

K. M. Thompson

A. C. Tortoso

Public Reading Room (2)

Administrative Record (2)

Environmental Protection Agency

M. L. Goldstein

B5-01

5 Washington State Department of Ecology

J. Caggiano

$\mathrm{H} 0-57$

D. Goswani

H0-57

A. D. Huckaby

H0-57

J. Price

$\mathrm{H} 0-57$

D. G. Singleton

J. Vanni

$\mathrm{H} 0-57$

H0-57
No. of

Copies

7 Fluor Hanford, Inc.

J. V. Borghese

E6-35

V. G. Johnson E6-35

A. Miskho H8-40

M. E. Todd E6-35

J. A. Winterhalder (3) E6-35

18 Pacific Northwest National Laboratory

D. B. Barnett K6-81

C. J. Chou (5) K6-81

P. E. Dresel K6-96

J. S. Fruchter K6-96

M. J. Hartman K6-96

D. G. Horton K6-81

J. W. Lindberg K6-81

S. P. Luttrell K6-96

R. F. O'Brien K5-12

R. E. Peterson K6-96

H. T. Tilden II K3-75

D. Vela (Project File) K6-96

Hanford Technical Library (2) P8-55 